\title{
The role of public capital on economic development
}

Citation for published version (APA):

Getachew, Y. (2009). The role of public capital on economic development. [Doctoral Thesis, Maastricht University]. Universitaire Pers Maastricht. https://doi.org/10.26481/dis.20091015yg

Document status and date:

Published: 01/01/2009

DOI:

10.26481/dis.20091015yg

Document Version:

Publisher's PDF, also known as Version of record

\section{Please check the document version of this publication:}

- A submitted manuscript is the version of the article upon submission and before peer-review. There can be important differences between the submitted version and the official published version of record.

People interested in the research are advised to contact the author for the final version of the publication, or visit the DOI to the publisher's website.

- The final author version and the galley proof are versions of the publication after peer review.

- The final published version features the final layout of the paper including the volume, issue and page numbers.

Link to publication

\footnotetext{
General rights rights.

- You may freely distribute the URL identifying the publication in the public portal. please follow below link for the End User Agreement:

www.umlib.nl/taverne-license

Take down policy

If you believe that this document breaches copyright please contact us at:

repository@maastrichtuniversity.nl

providing details and we will investigate your claim.
}

Copyright and moral rights for the publications made accessible in the public portal are retained by the authors and/or other copyright owners and it is a condition of accessing publications that users recognise and abide by the legal requirements associated with these

- Users may download and print one copy of any publication from the public portal for the purpose of private study or research.

- You may not further distribute the material or use it for any profit-making activity or commercial gain

If the publication is distributed under the terms of Article $25 \mathrm{fa}$ of the Dutch Copyright Act, indicated by the "Taverne" license above, 
The Role of Public Capital on EConomic Development 
(C) 2009 Y. Y. Getachew

All rights reserved.

Cover artwork by Y.Y. Getachew

Prepared with SWP

Published by Universitaire Pers Maastricht ISBN 9789052788722

Printed in the Netherlands by Datawyse Maastric 


\title{
The Role of Public Capital on Economic Development
}

\author{
PROEFSCHRIFT
}

ter verkrijging van de graad van doctor aan de Universiteit Maastricht, op gezag van de Rector Magnificus, Prof. Mr. G.P.M.F. Mols, volgens het besluit van het College van Decanen, in het openbaar te verdedigen op donderdag 15 oktober 2009 om 14.00 uur

door

Yoseph Yilma Getachew

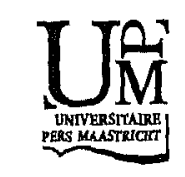


Promotor:

Prof. Dr. L.L.G. Soete

Co-promotor:

Dr. T.H.W. Ziesemer

Beoordelingscommissie:

Prof. Dr. B. Verspagen, voorzitter

Prof. Dr. C. de Neubourg, Maastricht G

Prof. Dr. A.K. Fosu, UNU-WIDER

Dr. A. van Zon 


\section{Acknowledgement}

First and foremost I offer my sincerest gratitude to my supervisor, Thomas Ziesemer, who has supported me throughout my thesis with his patience and knowledge while allowing me the space and time to work in my own way. Thomas sees problems as opportunities to learn new things. I learn to learn from him. I could not wish for a better or more supportive, kind and friendly supervisor.

Secondly, I am grateful to UNU-MERIT and to its director and my promoter Luc Soete for providing me the opportunities to carry out the research. Luc has helped me to solve some of the problems that have risen during my study.

I want to thank UNU-WIDER for providing me the internship that helps me to finalize my research. I am grateful to its deputy director Augustin Fosu for his valuable advises, comments, and ideas. I am also grateful to Bruck Tadesse and Adam Swallow for administrative and editing assistance respectively. I thank Alemu Gonsamo for assisting getting me a house in Helsinki. I thank Hugo Hollanders for giving me the opportunity to involve in WKR project. I wish to thank Rose Kiggundu for providing me a working facilities while I have been working in Addis.

I am grateful to Abbi Kedir, Adriaan Von Zon, and Mulu Gebreeyesus for their willingness to read and to comment on my works. I thank Bart Verspagen for commenting on the proposal and chairing the reading committee at the beginning and end of my research respectively. I also thank Francisco Toro for editing and commenting. I am grateful to the $\mathrm{PhD}$ secretory Eveline de Break for her excellent assistance that makes my life quite easy in UNU-MERIT. I also thank Evelin (and Rifka Weehuizin) for the dutch translation of the summary of the dissertation. I am also grateful to the Librarian Ad Notten and the Webmaster Herman Pijpers for their consistent supports.

$\mathrm{PhD}$ is a long journey. It is impossible to exaggerate the importance of good friends and families whose existence helps in different dimensions of life to reach the end of this journey. There are a number of people whom I owe in this respect. I would like to express my gratitude to Mary Rose Sarausad for taking care of our son. She is great as a mother, and great as a person. I have enjoyed the friendship of Abraham Garcia. We had good time whether we laughed at the silliest things on earth or frowned upon the hardest problem in the models. I am grateful for the love, care, and patience of my girlfriend Eleni Abraham. Semih Akçomak always has had important information and advises. Fernando Santiago-Rodriguez and Nantawan Noi Kwanjai have been great office mates. I am also grateful to other many UNU-MERIT students and researchers for various reasons: Ekin Keskin, Marion Motari, Kirsten Halaand, Victoria Kravtsova, Bulat Sanditove, Asel Doranova, Ivan Kulis, Alexis Habiyaremye, Donatus Kosi Ayitey, Ionara Da Costa, and Theo Dunnewijk. Outside UNU-MERIT, I thank Martien Schrooten, Roberto Anonietti, Susana Ravassa, Jose Galaico, Abiot Mindaye, Biniam Bedasso, Helen Aklilu, Ayalu Reda, Tesfaye Tewabe, Kassahun Begashaw (and his families). I have also blessed with the lifetime friendship of many people outside Maastricht. I am grateful to Letay Sebhatu, Minwuyelet Nigatu, Yusuf Kedir, Girma Moges, Tewodros Mesfin, Daniel Shibru, Befikadu Alemayehu, Menelik Solomon and Yohannes Regassa. 
I gratefully acknowledge the supports I have received from my families: my grandparents (Wordofa Geletu and Felekech Zamanel), my sisters and their families (Bizunesh Wordofa, Mohammed Jemal, Rebka Yilma, Ephrem Mehari, Lewi Ephrem, Beza Mohamod, Bersi Ephrem and Yonatan Mohammed), my brothers (Samuel Seifu and Nahom Wordofa), my father Yilma Getachew, and my uncle Solomon Getachew and his families. And finally, the special ones, my son Alek Yoseph and my mother Tirunesh Wordofa. I dedicate the thesis to them! 
To Alek and Tirunesh 


\section{Contents}

Contents

List of Tables $\quad$ iii

List of Figures $\quad$ iv

1 Introduction 1

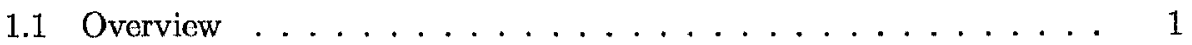

1.2 Thesis Outline ..................... 5

2 Background 7

2.1 Public Capital and Growth ... . . . . . . . . . . . 8

2.2 Public Capital, Income Inequality, and Growth . . . . . . . . . . 16

2.3 Public Capital in Multiple-Equilibria Models . . . . . . . . . . . 19

2.4 Summary ....................... 22

3 Public Capital, Income Distribution, and Growth 23

3.1 Introduction . . . . . . . . . . . . . . . 23

3.2 The Model . . . . . . . . . . . . . . . . . . 26

3.3 Income Distribution and Public Capital . . . . . . . . . . . . 30

3.4 Growth, Inequality and Public Factors . . . . . . . . . . . . 32

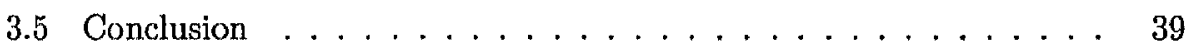

$\begin{array}{ll}\text { Appendix } 3 & 41\end{array}$

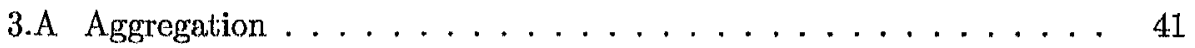

3.B The Growth Rate . . . . . . . . . . . . . . . . . . 42

4 Distribution, Public Capital, \& Elasticity of Substitution $\quad 45$

4.1 Introduction . . . . . . . . . . . . . . . 45

4.2 The Model . . . . . . . . . . . . . . . . . . . 49

4.3 Public Capital and Income Distribution . . . . . . . . . . . . 53

4.4 Aggregate Capital, Growth, and Inequality . . . . . . . . . . . . . 54

4.5 Conclusion ..................... 55 
Appendix $4 \quad \mathbf{5 7}$

4.A Production Function . . . . . . . . . . . . . . . . 57

4.B Aggregation . . . . . . . . . . . . . . . . . . . . 57

$4 . C$ Capital Dynamics. . . . . . . . . . . . . . 59

5 Public Capital and Economic Growth: Empirics 61

5.1 Introduction . . . . . . . . . . . . . . . 61

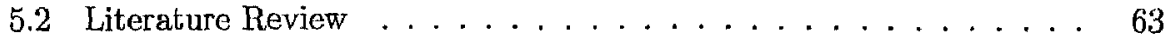

5.3 Theoretical Description . . . . . . . . . . . . 66

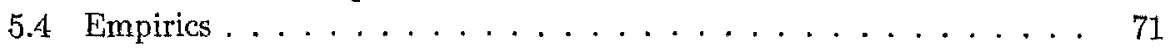

5.5 Conclusion ........................ 82

Appendix 5

5. A Growth Rate . . . . . . . . . . . . . . . . . 85

5.B Other Regressions and Tables . . . . . . . . . . 86

6 Poverty Trap and Public Capital $\quad 89$

6.1 Introduction . . . . . . . . . . . . . . . . . 89

6.2 The Model ... . . . . . . . . . . . . . . . . . 93

6.3 Dynamics, Multiple Equilibria, and Poverty Traps . . . . . . . . . 98

6.4 Public Investment and Threshold Externality . . . . . . . . . . 100

6.5 Conclusion ......................... 102

Appendix $6 \quad \mathbf{1 0 5}$

6.A Individual Human Capital Dynamics . . . . . . . . . . . . . 105

6.B Aggregate Human Capital Dynamics . . . . . . . . . . . . . . 105

$\begin{array}{lll}7 \text { Conclusions } & 107\end{array}$

$\begin{array}{ll}\text { Bibliography } & 111\end{array}$

$\begin{array}{ll}\text { Samenvatting } & \mathbf{1 2 5}\end{array}$

$\begin{array}{ll}\text { Curriculum Vitae } & 127\end{array}$ 


\section{List of Tables}

5.1 Summary statistics for SSA countries over the period 1960-2004 _. 72

5.2 Growth and public spending GMM estimators, estimates of (18") . . . 76

5.3 Growth and public spending GMM estimators, sensitivity analysis, estimates of $\left(18^{\prime \prime}\right) \ldots \ldots \ldots \ldots \ldots \ldots \ldots \ldots$

5.4 Growth and public spending, nonlinear SUR, WNLS and NLS with FE, estimates of $(21) \ldots \ldots \ldots \ldots \ldots$. . . . . . . . . . . . 81

5.5 Growth and public spending, FE and OLS, 5 years average . . . . 86

5.6 Countries used in the study . . . . . . . . . . . . 87 


\section{List of Figures}

2.1 Electricity consumption per capita . . . . . . . . . . . 10

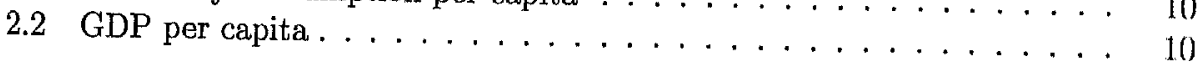

3.1 Phase diagram for a case $\theta>\xi$ or $0<\frac{0-\xi}{\theta}<1$. Together with the eigenvalues the steady state is globally stable. . . . . . . .

3.2 Phase diagram for a case $\theta<\xi$ or $\frac{\theta-\xi}{\theta}<0$. The result is the same with that of Fig. 3.1 except here the phase line for equation (3.34) is

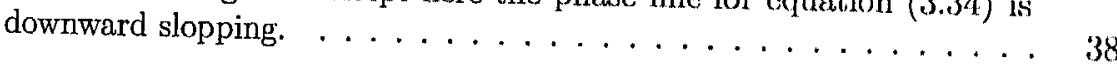

5.1 Average public investment (years 1965-2003) $\ldots \ldots \ldots \ldots \ldots$

5.2 Public investment $($ year 2000$) \ldots \ldots \ldots \ldots \ldots \ldots \ldots \ldots \ldots$

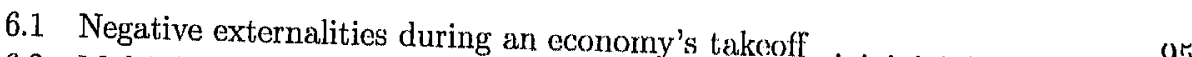

6.2 Multiple equilibria and poverty trap $\ldots \ldots \ldots$. 95

6.3 A shock that may abolish a poverty $\ldots \ldots \ldots \ldots \ldots$. . . . . . . 100 miracle . . . . .

6.4 A policy shock that does not n............... . . 101 
CHAPTER 1

Introduction

\subsection{Overview}

The end of the Second World War marked the beginning of the rise of economic development as a major discipline. After the end of the colonial system, in the late 1940s and $1950 \mathrm{~s}$, different strands of economic development thought stiarted to emerge that concerned the social and economic development of the Third World. Economic growth and modernization were placed at the top of economic agendas of the newly independent developing states (Thorbecke 2007). ${ }^{1}$ Neoclassical growth theory was a main strand of such thought. Since then, it has become the standard economic growth theory due to its analytical rigor, particularly in relation to long-run growth dynamics. However, it has important shortfalls when it comes to development economics studies.

In traditional neoclassical growth models (e.g., the Solow model), exogenous technical progress is the source of long-run growth. This lcaves no room for public policy decisions to have long-term effects on the economy. A policy shock will have a transitory effect, influencing only the level of (long-run) output. An econorny's institutions and infrastructure development, and initial income distribution, will have no lasting effect on its growth. Neither initial distribution nor redistribution of incorne determine the long-run dynamics of per-capita output and capital. Neoclassical growth models and theories on governmont expenditure and income redistribution mainly focused on the cost of taxation (see, e.g., Atkinson and Stiglitz 1980). Because they neglected the intrinsic characteristics of economies that result in growth over long periods, these models and theories chiefly viewed important economic variables from a one-sided perspective.

\footnotetext{
1.This was at a timo whon advancing economic growth was viowed as the equivalont of advancing economic devolopment. There was consonsus among seholars that; through oconomic growth and modernization, development; problems such as income and social incequalitios could be tiken care of (Thorbecke 2007).
} 
The poor performance of neoclassical theory, particularly in antalyzing the source of long-run growth and the role of public policy, led to goneral disstalisfaction with it and hence the emergence of the "new" growth theory. Also known as endogenous growth theory, this brings to light the source of long-run growth in terms of innovation and technology. It allows for the study of economic devel opment by analyzing the roles of public policy, technology, human capit,al, and infrastructure development in long-run economic growth and income distribution, It also acknowledges the important relationship between initial income distrilsution and long-run economic growth while retaining the analytical rigor of its predecessor - traditional neoclassical theory.

In endogenous growth theories and models, policies may have a lasting impacet. on growth rates and income distribution dynamics. Productive government ('xpenditure on infrastructure and human capital development plays an important role in promoting long-run growth and improving income inequality, while incoms: distribution determines the long-run dynamics of aggregate variables. Absent the representative agent assumption, the dynamics of macroeconomic variables are determined jointly with those of income distribution (Benabou 2002).

This thesis analyzes the role of public capital on economic devolopment using endogenous growth models. It investigates important problems and questions surrounding economic development that are rarely addressed in endogenous grow $\mathrm{h}_{\mathrm{h}}$ literature. These relate to public capital, income inequality, economic growth, and poverty trap: Does public capital affect economic growth and incomo incouulity simultaneously? Can the public good - non-excludable by definition generule disproportionate growth that benefits the poor? What level of public investment. maximizes growth in poor developing countries? What role does pulblic: capital play in poverty trap? Does public capital lead poor societies to evade priverty trap, particularly if they are already in one?

The thesis consists of both a theoretical and an empirical part. The theoretical section develops a number of endogenous growth models that analyze the role of public capital in income inequality, economic growth, and poverty trep. Although these models are usually built in complex dynamic heterogenous-agent coconorny or non-ergodic/multiple-equilibria dynamic environments, they remain analytically tractable. The empirical section, on the other hand, comprises an andysis of a panel data from a large set of Sub-Saharan African countries to identify the nonlinear relationship between public capital and economic growth, and determine? the level of public investment that maximizes growth in those countries.

A major contribution of this thesis is its analysis of the relationship betwecen public investment and income inequality. ${ }^{2}$ It presents models and theories thet. analyze the link between public investment and income/wealth distribution, in the context of capital markets imperfection. Other contributions include its analysis of the possible role of public policy in an economy with poverty trap, and empirical determination of the level of public capital that maximizes long-run conomic: growth in developing countries.

The thesis extends the theories of imperfect capital markets in inequality and growth to inequality, public capital and growth. Inequality is bad to grow th whon

\footnotetext{
${ }^{2}$ The terms 'income distribution' and 'wealth distribution' are intorchangenbly uHod in the text reforring to the distribution of (human) capital among the individual housoholda.
} 
imperfection in capital markets prevents the poor from undertaking the efficient amount of investment (Loury 1981; Benabou 1996). The new theories suggest that certain public investment may relax some of their resource constraints through factor substitution and thus improve the distribution of income and hence economic growth (through an indirect channel).

A common feature in the literature of growth and public capital is the (implicit) assumption that infrastructure benefits the individual households proportionally. The use and efficiency of public capital, however, may vary among different households. Depending on the type of the public good, infrastructure may benefit the poor (the rich) more than proportionally due to their lack of (greater) access to its private substitutes (complements). For instance, a construction of a new dam may benefit more those who have access to fertilizer and high-yielding variety of seeds (Songco 2002 and Estache 2002). Whereas, a provision of certain public services (such as public education, clean water, sanitation, and public transport) may benefit those who lack these basic inputs (World Bank 1994).

This disproportionate impact of public capital, - once it is explicitly acknowledged, - could be important for income distribution dynamics, and, hence, the evolution of macroeconomic aggregates, through its effect on relative factor shares. When the credit market is imperfect and there are diminishing returns to private factors, income inequality is negatively related to economic growth (see, e.g., Benabou 1996). As we will see later on, income distribution dynamics is determined by relative factor shares. Therefore, if provisions of public capital affect the relative income shares of inputs, they will also affect income distribution dynamics. Furthermore, they affect long-run growth through an indirect effect on income distribution.

Another important contribution of the thesis is built upon John Hicks's (1932) classical concept of the "elasticity of substitution" - the major factor that determines changes in relative factor shares - to depict the impact of public capital on income distribution. Using the Newman and Read (1961) production function - a generalized Cobb-Douglas variable elasticity of substitution production function -, the thesis shows that the distributional effect of public investment depends on its elasticity of substitution to private capital, in a model that gives a complete analytical solution. The elasticity of substitution between private and public capital determines the relative private factor income shares, which, in turn, determines income distribution dynamics. If the elasticity of substitution of a given type of public input is greater (lesser) than unity, it will have a positive (negative) impact on income distribution.

Studying how publicly provided inputs could affect income distribution dynamics in a formal and an analytically tractable manner appears to require the use of a tractable production function that allows some flexibility in its parameters. However, the popular production functions rarely posses both properties at the same time. The analytical tractability of the standard Cobb-Douglas production function, for instance, comes with the cost of stringent restrictions on factor shares, which makes it unsuited for income distribution analysis. Fortunately, applying the Newman-Read production function - a variable elasticity of substitution production function - to Hicks's notion of elasticity of substitution as the determinant of factor shares overcomes the technical difficulties, and the complex 
dynamics remain analytically tractable.

This thesis also consists of a growth model of multiple equilibria that analyzes the role of public investment in poverty trap. Most of the analytical literature in growth and public investment studies public capital within traditional growth models that generate a unique high-income equilibrium outcome. The thesis takes a different track from this literature by studying public investment in an environment with multiple equilibria/poverty trap. The sources of the poverty trap are negative externalities, which prevail during an initial stage of economic development (e.g. skilled "migration humps") along with a positive learning-by-doing externality that of similar to Arrow's (1962), Frankel's (1962) and Romer's (1986). The study finds that a change in public policy towards the growth-maximizing level of public investment is crucial but indeterminate with respect to poverty trap. Depending on some initial conditions, however, such policy change could create a threshold externality that could lead economies to evade poverty trap.

Policy and history matter much more in environments with poverty trap than they do in those without, such as in traditional ergodic growth models (Azariadis 2006). In an economy with a poverty trap, even a temporary policy shock may bring a permanent growth miracle (depending in particular on the economy's initial condition) and, if the shock is not too weak or followed by a negative offsetting/counterbalancing one, push the economy above the critical value required to escape the poverty trap. On the other hand, a temporary shock like war, disease, short-term capital flight, or bad policy may permanently change the course of development of an economy by reducing it from slightly above to slightly below the threshold value, and consequently leading it into a poverty trap.

The empirical side of the study addresses the important question raised by Romp and de Haan (2005): not whether public capital is productive, but what level of public capital maximizes economic growth. Few studies have attempted to ascertain the growth-maximizing level of public capital and to compare it with the existing public investment, particularly in developing countries. This study estimates the growth maximizing level of public investment for a set of developing countries using more robust techniques than those used in previous studies. It also determines empirically the nonlinear relationship between public capital and growth.

Economists have long believed a positive relationship exists between public capital and economic growth; however, many argue the relationship is far from linear (see, e.g., Barro 1990). Public capital could have a negative as well as a positive effect on the economy. Though an adequate and efficient supply of public capital promotes output and growth, the distortions resulting from such financing may also have an adverse effect, such as crowding out private capital. For instance, an enhanced transportation system (e.g., roads and highways) improves the efficiency of trucks. But if the public capital is financed by overly burdensome taxes on private return, the accumulation of these trucks will be negatively affected. If no large private factors take advantage of the infrastructure development, there would be no change in output, as roads do not produce by themselves (Aschauer 1998).

Therefore, the relationship between public investment and long-run growth is nonlinear, forming an inverted U-shape, whereas the growth-maximizing level of 
public investment becomes equal to the output elasticity of public capital in the production function (Barro 1990).

\subsection{Thesis Outline}

This thesis is organized as follows. Chapter 2, in providing the background for the rest of the thesis, reviews the theoretical and empirical literature on various issues of public capital and growth, income inequality, and poverty trap. Chapter 3 presents a joint theory of income inequality, public capital, and economic growth, in the context of capital markets imperfection. The chapter develops a two-sector overlapping generation model in which initial wealth differs among individuals, access to credit is limited, and the government provides productive public goods used in both final goods production and human capital accumulation. Based on the theories of capital markets imperfection, where inequality is bad for growth because it implies that more productive investment opportunities (which offer relatively higher return due to the existence of diminishing returns to factors) are forgone by the poor, the model shows that certain public investment could be important for income distribution through factor substitution (or complementarity). If a provision of public capital has a disproportionate impact on households, - if it benefits the poor more than proportionally, for instance, due to their lack of access to its private substitutes -, then it will have an offect on the relative factor shares of private inputs that in turn affects the dynamics of income distribution. Therefore, there could be an indirect channel through which public capital may affect growth (in addition to standard productivity effects).

The study analytically captures the relationship between public capital and income inequality (with explicit dynamies of the distribution) using a simple production function such as Cobb-Douglas, but not, of course, without a constraint. The analytical tractability of the Cobb-Douglas function cornes with the cost of a stringent restriction on relative factor shares and elasticity of substitution between factors, which makes the production function unsuitable for distribution analysis. The next chapter, therefore, employs a more flexible production function to characterize the effect of public capital on income inequality dynamics.

In Chapter 4, we thus use the Newman and Read (1961) production function - a generalized Cobb-Douglas and variable elasticity of substitution production function - to study the distributional effect of public investment in a model that gives a complete analytical solution. The model shows a change in the supply of public capital could affect income distribution dynamics, although (this timo) no additional specifications are imposed to vary the benefit that accrues from using the public capital among different households.

The chapter finds that the distributional effect of public investment depends on its elasticity of substitution to private capital. The elasticity of substitution between private and public capital determines the relative private factor income shares, which, in turn, determines income distribution dynamics. If the elasticity of substitution of a given type of productive public good is greater than unity, thon a provision of the public good may have a disproportionately positive impact on the income of the poor because it lowers the relative factor shares of the private 
inputs that ultimately benefit the poor, who hold less of these resources, more than proportionally.

Chapter 5: How much does public capital matter to economic growth? How big should it be? This chapter makes an empirical investigation to address these policy-oriented problems, taking the case of Sub-Saharan African countries. A model is presented as the basis for the empirical analysis. Economists have long believed there is a positive relationship between public capital and economic growth; however, many argue the relationship is far from linear. The model and the empirical analysis presented capture this nonlinear relationship between public capital and economic growth. In addition, the level of public investment that maximizes growth is determined and compared to the actually existing levels of public capital in those countries.

Chapter 6 departs from conventional ergodic dynamic models to study the role of public capital in poverty trap. It develops a model that shows analytically how poverty trap could rise due to negative externalities that prevail during a country's economic take-off. The chapter then analyzes the role of growth-maximizing public policy in the poverty trap model. Though policy may not necessarily enable a country to evade a poverty trap, its role in non-ergodic economies has been found to be important. In the model, the policy shock changes the threshold value of the poverty trap. But whether the change enables the economy to evade the trap depends on other exogenous factors such as the history and technology of the country at stake.

Chapter 7 concludes the study. 
CHAPTER 2

Background

Ahead of the African Union Summit of Heads of States and Government in Addis Ababa, Ethiopia (scheduled for February 1 to 3, 2009, with the theme of "Infrastructure Development in Africa"), the World Bank announced that Africa risks a lost decade of underdevelopment if it neglects infrastructure development. ${ }^{1}$ That was based on the World Bank's (2004) own research, which estimated that the lack of investment in Latin American infrastructure in the 1990s had reduced growth in the region by 1 to 3 percentage points. The same study noted that if Africa's stock of telecommunication and power generation capabilities had been equal to those in East Asia, the continent's annual growth rate could have risen by one percentage point over the last two decades.

The important role of public capital in economic growth is well acknowledged among leaders, scholars, and practitioners. Public investment in infrastructure, institutions, technology, and human capital development plays an important role in promoting output and long-run growth. Public capital, and in particular infrastructure, could generate a sustained increase in economic growth by promoting the accumulation and enhancing the total productivity of private inputs by reducing production and transaction costs (Aschauer 1997).

The World Bank (1994) once called infrastructure the "wheels" of an economy, central to the economic activity of households and firms (Romp and de Haan 2005). An adequate supply of public capital helps generate a sustained increase in economic growth. Public capital investment is particularly important in developing countries, where the public capital stock is often insufficient and inadequate. Due to the law of diminishing returns, where the initial public capital stock is low and basic infrastructure services (e.g., electricity, telecommunications, education, health, clean water, and sanitation) are lacking, an increase in stock should have a larger effect than in countries starting from relatively higher levels of public capital.

\footnotetext{
${ }^{1}$ Reuters (2009), www.alertnet.org/thonews/newsdesk/LS284128.htm, January 28.
} 
Public capital is important not only for economic growth but also for cconomic development. The Organization for Economic Cooperation and Development (OECD) (2006) reports that public capital, especially infrastructure, promotes growth and reduces poverty at the same time. Its report sets out three main functions of public capital with regard to economic development: (1) it enhances economic activity and thus economic growth, (2) it creates distributional effects on growth and poverty reduction, and (3) it removes societal bottlenecks that are detrimental to the poor by impeding asset accumulation and creating market failures. These are also the areas on which this thesis focuses. The thesis can be broadly classified and related to the major roles of public capital in promoting economic growth, improving income distribution and evading poverty
traps.

The present chapter lays the background for the rest of the thesis. It is divided into three sections: public capital and growth; public capital, inequality, and growth; and public capital and poverty trap. The first section deals with various issues and clarifies the main concepts surrounding public capital and economic growth. For instance, it discusses the particular relevance of public capital to developing countries, lists different channels by which public capital may relate to growth, and addresses other issues to do with public capital and growth (e.g., congestion costs, financing, distortion, linearity and nonlinearity, etc.). The second section discusses income inequality, growth, and public capital. It surveys the theoretical and empirical literature on the relationships between public capital and income inequality, and income inequality and growth. Finally, the third section presents a theoretical and empirical literature review of multiple-equilibria povertytrap models and their implications for public policy.

\subsection{Public Capital and Growth}

\section{A Bit of History}

Economists have long known that public capital is an important input in the production function of firms and households (see, e.g., Arrow and Kurz 1970). ${ }^{2}$ However, earlier studies mainly focused on the cost of taxation: whether taxation encourages or discourages growth assuming the tax is redistributed back to households (e.g., Atkinson and Stiglitz 1980). Of course, during that time - the late 1970 s and early 80 s - orthodox economics (i.e., neoclassical growth theory) was only capable of analyzing the effect of taxation policy on the level of per-capita capital and income. Thus, many models developed at that time studied the shortrun impact of taxation on growth. At the end of 1980s, however, when endogenous growth models were introduced, a number of models appeared that studied the role of taxation on long-run growth (e.g., Jones and Manuelli 1990; Lucas 1990; King and Rebelo 1990; Rebelo 1991).

\footnotetext{
${ }^{2}$ Other than providing public capital, the government plays an indisputably important role in nations' processes of economic development. Some functions attributable to governments that are important to economic growth include protecting property rights, enforcing contracts, and
redistribution.
} 
On the other hand, Barro (1990) developed an endogenous growth model with public capital that captured not only the negative effect of distortionary taxation but also the positive spillover stemming from public service in individual household productivity. In doing so, he incorporated the productive public expenditure into the production function of individual firms and showed that government expenditure on infrastructure plays an important role in promoting long-run growth, and that taxation for public capital may have a positive net effect on economic growth. A series of theoretical and empirical studies following on from Barro then further clarified the role of public capital in economic growth.

In the empirical literature, Aschauer (1989) claimed in an influential work that public capital has a large impact on output. Using annual data for the United States, he estimated the public capital elasticity of output at 0.39 . These findings were met with disbelief (Glomm and Ravikumar 1997). Although economists knew that public capital was an important input in production, they did not expect its impact to be higher than that of private capital's, which is about 0.3 . Subsequently, a series of studies following up on Aschauer's proposed a wide range of estimates. Kocherlakota and Yi (1996), for instance, estimated the marginal product of public capital to be higher than private capital, while Mumnell (1990) and Holtz-Eakin (1994) respectively estimated it as approximately equal to and below that of private capital.

Some researchers have argued that the wicle range of estimates renders earlier studies virtually useless from a policy perspective (Sturm et al. 1998, and Romp and de Haan 2005; 2007). Moreover, these earlier studies faced criticism on other grounds. Aschauer's (1989) methodology, for example, was criticized on its endogeneity of public capital and spurious correlation clue to the nonstationarity of the data. $^{3}$ However, a number of recent studies using modern econometric techniques agree on the significance of the output and growth contribution of public capital, especially infrastructure (e.g., Canning 1999; Calderon and Serven 2004; Kamps 2005). ${ }^{4}$

\section{Public Capital and Developing Economies}

Infrastructure development is believed to be insufficient, and inadequate in most of the developing world. Countries that have low GDP per capita have often also low infrastructure (see, e.g., Figure 2.1 and 2.2). However, though the literature on public capital's impact on economic growth is voluminous, studies that address developing countries, particularly in Sub-Saharan Africa, are few. Estache eta al. (2005) point out that only a handful of papers study public capital and economic growth quantitatively with regard to SSA countries. Most merely mention it, in passing, as an important variable. This is somewhat paradoxical, considering that the role of public capital in poor nations' economic growth is expected to be decisive.

Public investment is particularly important in developing countries, where infrastructure is often under-invested. Agénor and Moreno-Dodson (2006) argue that, due to the law of diminishing returns, it may have a particularly large effect

\footnotetext{
${ }^{3}$ See Gramlich (1994) for a detailed survey of earlier literature.

${ }^{4}$ See Romp and de Han $(2005 ; 2007)$ for a detailed survey of this literature.
} 
Figure 2.1: Electricity consumption per capita

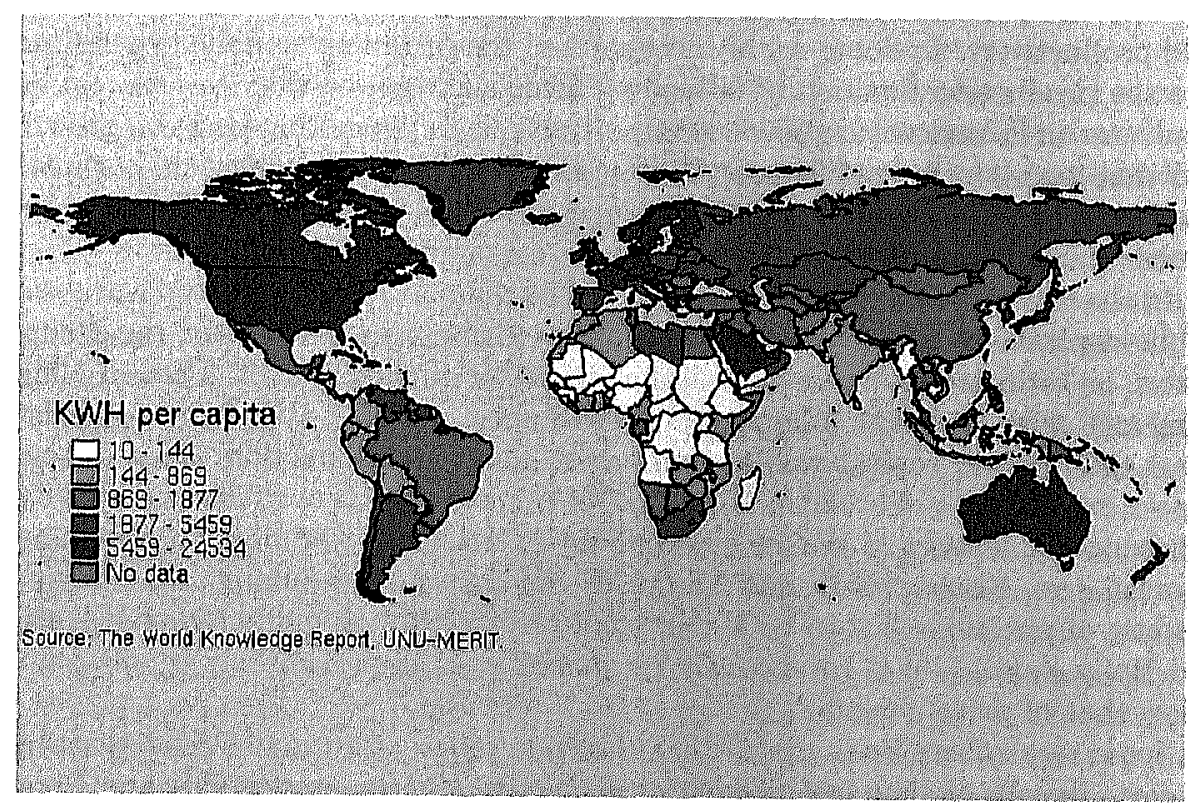

Figure 2.2: GDP per capita

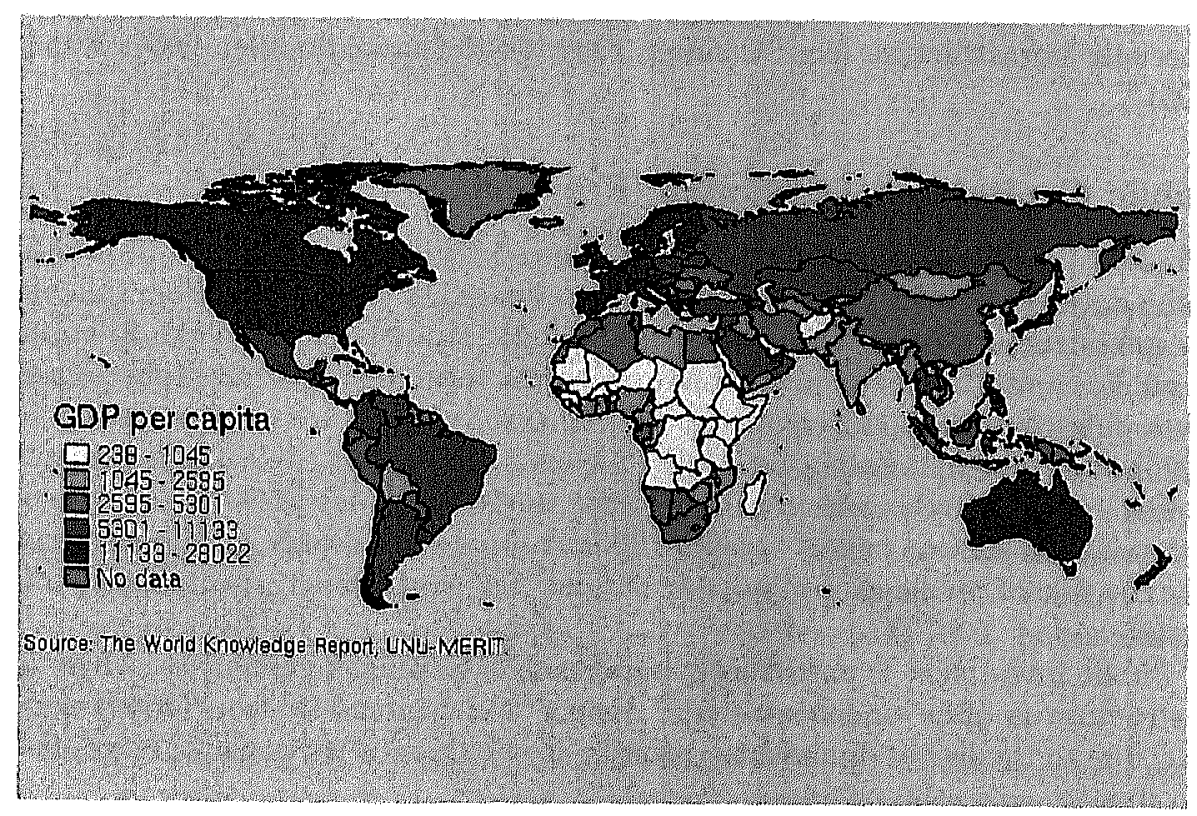


in countries where the initial infrastructure stock is low. An increase in public capital stock should affect countries with low public capital stock more than those starting from relatively higher level of public capital. Demetriades and Mamuneas (2000), for instance, found that countries with small public capital stocks have the highest marginal productivity return on public capital.

A different but important perspective on the relative importance of public capital (notably infrastructure and institutions) in developing countries can be seen in its intrinsic properties - such as less mobility, in particular - compared to human capital (Fosu 2004). Given today's high international human capital mobility, human capital accumulation in developing countries faces at least two serious challenges: the possibility of losing the upgraded capital through brain drain, and the negative externality effect of brain drain. On the contrary, the upgrading immobile of factors (e.g., physical and institutional infrastructure) is unlikely to encounter similar problems. Developing countries should be aware of this when investing in various types of capital (human capital versus physical and institutional infrastructure).

Standard growth theories promote human capital as a source of long-run growth. Their relationship is primarily established through either an intergenerational spillover effect (Lucas 1988) or research and development, technical change and new ideas (e.g., Romer 1986; 1990; Aghion and Howitt 1992). Physical capital, on the other hand, is chiefly seen as having transitional growth effects (Solow 1956). ${ }^{5}$ However, when human capital is highly mobile (as witnessed in today's exodus of highly skilled labor from developing to developed countries) ${ }^{6}{ }^{6}$ and its drainage consists of negative externality on the emigrants' country (as documented in the brain drain literature) ${ }^{7}$ immobile factors such as physical capitial and institutions play major roles in the economic growth of developing countries. ${ }^{8}$

The last premise rests upon the following observations: (1) unlike human capital, immobile capital - once it has been accumulated - can more easily be retained and thus made available for final goods production in the home country; and (2) more importantly, immobile factors (e.g., physical and institutional infrast;ucture) can be used to reduce the mobile (human) capital's flight through a complementarity effect of enhancing its productivity, which, in turn, mitigates the negative externality that could arise from brain drain.

While the flight of highly skilled individuals from developing countries is usually caused by their relatively lower wages for skilled labour, the lower productivity of

\footnotetext{
${ }^{5}$ Tndeed, in the $A K$ model, physical and human capitial ofton complement each other to form a nondininishing aggregnte production function that sustinius long-run growth.

${ }^{B}$ E.g., Collior ot al. $(2004)$ noted that brain drain has rapidly increased in Africa over the last decade.

${ }^{7}$ See, e.g., Bhagwati and Hamada (197d). The negative impacti of brain drain on tho source country has also been emphasized in recent endogenous growth litorature (Miyagiwa L991; Haque and Kim 1995; Galor and Tsiddon 1997; Wong and Yip 1999; Boine et al. 2001).

${ }^{8}$ Recently, somo studies have turned the issue of brain drain to brain gain, by looking for some compensatory effect of brain drain. The main rationale is that when oducation is privatoly and endogenously determined, the possibility of migrating to th highor wage country incroasos the average rate of retimn in the home country, which, in turn, increases domestic individual investment on human capital accumulation (Mountford 1997; Slark et al. 1998; Beine ol al 2001). However, the fact that much of the educational investment in dovoloping countries is undertaken by the state (Fosu 2007) could undermine lihis compensatory offect.
} 
human capital in turn is caused mainly by the existence of lower (i.e., inadequate) complementarity inputs, such as physical and institutional infrastructure. Fosu et al. (2004), for instance, state that the low return in education could be caused by the low levels of complementary physical capital. In his quest to examine the lack of capital flight from rich to poor countries, Lucas (1990) stresses the important role of complementarity among production factors. ${ }^{9}$

\section{Flow Versus Stock?}

Does the flow or the stock of public capital matter for economic growth? Studies focusing on the relationship between public capital and economic growth treat public capital as either a flow or a stock variable. The distinction between the two is subtle but could be important. The public capital stock can be defined as an accumulated public investment in the form of stock variables such as roads, railways, airports, etc., whereas its flow is periodical, productive government expenditure on public administration, policing, maintenance of law and order, and also maintenance of the public capital stock. Both analytical and empirical studies have been conducted using the flow and/or stock of public capital.

For instance, from the analytical side, Barro (1990), Turnovsky and Fisher (1995), Turnovsky (2000), and Agénor (2008) model public capital as a flow of public investment. In contrast, Futagami et al. (1993), Cassou and Lansing (1998), Rioja (1999), Turnovsky (1997; 2004), and Ziesemer (1990;1995), among others, treat public capital as a stock. Ghosh and Roy (2004), however, model public capital as both a stock and a flow variable simultaneously. From the empirical side, Aschauer (1989) studied the effect of public capital stock on output, while Easterly and Rebelo (1993) examined the effect of public capital flow on growth. Aschauer (2000a) later considered both the stock and the flow of public capital simultaneously. This thesis predominantly treats public capital as a flow variable.

\section{The Channels: How Does Public Capital Affect Growth?}

What are the functions of public capital? What makes public capital matter for economic growth? The literature mentions various potential channels through which public capital affects growth. The most important functions of public capital are enhancing the productivity and complementing the accumulation of private inputs. In increasing the productivity of private inputs, public capital affects both costs and transaction the growth rate. In particular, it reduces private production finding that it reduces Kuroda 2005). Further, public capital could b., Cohen and Paul 2004; Teruel and private capital formation. For instance, the existenconic growth by stimulating (e.g., water and road systems, telecommunications, and developed infrastructure

\footnotetext{
${ }^{9}$ Lucas (1990) argues the rate of return of financial and other capital in rich countries is still as high as that poor countries, though they have higher capital per worker (in the presence of diminishing return) due to a higher complementary effect of other inputs - in this case, human
capital. His findings have greater supports instance, argue that the marginal product of capital is similar across countries Feyrer (2007), for
} 
private and foreign investment. This in turn could enhance competition, technical progress, and growth.

Public capital affects the economy through many channels. Agénor and MorenoDodson (2006) list indirect channels through which public capital could affect economic growth, such as reducing adjustment costs (those associated with increased private capital formation), increasing private capital's durability, and aiding education, nutrition, and health. Moreover, public capital could also function as a substitutable factor. It provides opportunities and resources to individuals that they could not otherwise afford. In fact, it is usually modeled in the economic growth literature as a factor that enhances productivity and complements the accumulation of private inputs. There is no doubt, however, that public capital could also function as a substitutable factor to relax households' resource constraints, particularly poor households, in the context of imperfect credit markets. ${ }^{10}$

This is particularly important from the perspective of income inequality dynamics. As we will discuss in detail later on, the link between public capital and income distribution can be made through elasticity of substitution between factors. Income distribution evolves according to factor shares, in the context of capital markets imperfection. Whereas, the elasticity of substitution of factors is the major determinant of changes in relative factor income shares (Hicks 1932). Therefore, whether public capital affects income distribution dynamics depends on the magnitude of its elasticity of substitution to private capital.

\section{Public Capital in Endogenous Growth Models}

In the literature of public capital and growth, government spending on infrastructure often enters into a production function as an input which augments private factors. In this case, its effect is identical to the effects that learning-by-doing and knowledge spillovers have on the $A K$ model (Barro and Sala-i-Martin 2004, p. 221).

For instance, following Barro and Sala-i-Martin (2004), consider the following production function,

$$
y_{t}=B\left(k_{t}\right)^{\alpha}\left(G_{t}\right)^{1-\alpha}\left(L_{t}\right)^{1-\alpha}
$$

where $k_{t}$ and $y_{t}$ are the individual firm's private capital and output, respectively; $G_{t}$ is public capital. ${ }^{11}$ One may standardize the labor force to a unit (i.e., assume that each individual in the economy is endowed with a unit of labor which she supplies to firms inelasitically), $L_{t}=1,{ }^{12}$ and then rewrite (2.1) as $y_{t}=B\left(k_{t}\right)^{\alpha}\left(G_{t}\right)^{1-\alpha}$. If all firms are assumed to be identical, then $k_{t}=K_{t}$ in equilibrium.

The production function of the representative agent is thus given by

$$
Y_{t}=B\left(K_{t}\right)^{\alpha}\left(G_{t}\right)^{1-\alpha}
$$

\footnotetext{
${ }^{10}$ See, e.g., World Bank (1994) and R.omp and cle Hann (2005; 2007).

${ }^{11}$ Let individual and aggregate variables denote small and capital lotiors, respectivoly. For instance, $k_{t}$ and $K_{t}$ are the individual firm's and the economy's aggregate capital, respectively.

${ }^{12}$ This is not, however, without; a consequence. The presence of population growth in the $A K$ model will create a scalo effect.
} 
This implies

$$
G_{t}=\left(\frac{G_{t}}{Y_{t}}\right)^{1 / \alpha} B^{1 / \alpha} K_{t}
$$

The zero-profit condition in a competitive economy implies that factors are rewarded their marginal returns. Thus,

$$
R_{t}=\alpha B\left(\frac{G_{t}}{K_{t}}\right)^{1-\alpha}
$$

where $R_{t}$ is the rental price of capital. Assume the government chooses a constant ratio of its investment to aggregate output, $\frac{G_{t}}{Y_{L}}$, which will be financed by a nondistorting tax. Using (2.3) and (2.4), we get

$$
R_{t}=\alpha B^{1 / \alpha}\left(\frac{G_{t}}{Y_{t}}\right)^{(1-\alpha) / \alpha}
$$

Therefore, if $\frac{G_{t}}{Y_{t}}$ is constant, the marginal product of capital remains constant over time. Barro and Sala-i-Martin (2004) show that $R$ in equation (2.5) plays the same role in the growth process as $A$ plays in the $A K$ model. Therefore, the model will have no transitional dynamics where the economy converges to a balanced growth path in the long run.

In most of the models of this thesis, public investment is also modelled as a productive input which augments private factors. In chapter 3 , for instance, we use similar $A K$ type production functions to the one described above but within an environment characterized by heterogenous agents, multiple sectors, and capital holds disproportionately the model, public capital in particular benefits houseomy. Whereas, income distribution of income on the econvariables in the dynamics of macroeconomic variables in the economy. Therefore, public capital affects growth through not only the standard productivity effect but also an indirect channel of its effect on income distribution. The model also shows a lengthy transition period (unlike standard $A K$ model) due to the presence of income distribution.

\section{Short Run or Long Run? Output or Growth Effect?}

Is public capital's effect on economic growth temporary or permanent? Does a given policy shock affect the long-run growth rate or only the economy's level of per-capita output? From a theoretical perspective, whether public capital is found to have a long-run growth effect will very much depend on the type of the source of long-run neoclassical growth models, exogenous technical progress is growth. Therefore, in these will only have a transitory effect on a shock to public capital stock, for instance, level of long-run output). public capital may have a lasting imper in endogenous growth models, a shock to 


\section{Linear or Nonlinear?}

What is the relationship between public capital and economic growth: is it linear or nonlinear? Researchers' presumptions in this regard are important for at least two reasons. First, it influences the empirical strategy adopted (i.e., the choice between linear or nonlinear econometric models during estimation). Second, the various relationships have different implications for the role of public capital in economic growth. A nonlinear relationship implies that public capital can have a negative as well as a positive effect, whereas a linear relationship implies that only one of the two can exist. Consequently, empirical studies that implicitly or explicitly assume a linear relationship between public capital and growth may not be able to estimate the growth-maximizing level of public capital (Aschauer 1998).

In general, analytical studies predict a nonlinear relationship between public capital and economic growth (e.g., Barro 1990; Glomm and Ravikumar 1997; Aschauer 2000a). All models developed in this thesis also demonstrate a nonlinear relationship between public capital and economic growth.

\section{Other Related Issues}

Many factors directly or indirectly related to public capital may affect economic growth. In particular, the magnitude of the productivity increase attributable to public capital depends on a variety of factors, such as efficiency, maintenance, financing, and congestion costs associated with public capital.

\section{Efficiency, Maintenance, and Financing}

The quality of a given public capital stock appears to be important to output, and growth. Predictably, in most of the developing world, much public capital stock is not in good condition. Rioja (2003a; 2003b) asserts that this has major repercussions, most particularly the loss of steady state income. Policymakers usually prefer to build new infrastructure rather than pay to maintain existing stock. However, empirical and analytical findings show that optimal spending on maintenance is necessary to improve the efficiency of public capital and hence its impact on long-run output and growth. Hulten (1996) prosents empirical evidence that suggests the efficiency of public capital is even more important than the size of the stock. Rioja (2003b), too, using a sample of Latin American countries, shows that reallocating funds from building new infrastructure to maintaining existing infrastructure may have a positive grow th effect.

Analytical studies on the growth effect of maintenance spending mainly focus on the allocation (and reallocation) of funds between new infrastructure investments and existing infrastructure maintenance (Rioja 2003b; Kalaitzidakis and Kalyvitis 2004; Agénor 2005). Rioja (2003b), for instance, developed a dynamic general equilibrium model that shows that the size of externally financed new investments as a share of existing infrastructure negatively relates to optimal maintenance expenditure.

Not only the quality and quantity of public capital but also its financing matters for economic growth. There are at least two primary modes of financing 
Chapter 2. Background

public capital: tax financing and seigniorage. We mentioned earlier that financing public capital through distortional taxation may adversely affect the economy. Some authors suggest that seigniorage may in fact be more detrimental to growth than income taxation, particularly in developing countries where poorly developed financial markets prevail (e.g. de Gregorio 1993; Bose ct al. 2005). Others recommend a mix of both financing methods (e.g. Pecorino 1997).

\section{Congestion Costs}

Congestion costs related to public goods also feature in the growth literature. Congestion may be modeled as factors that influence utility-enhancing public services, and affect infrastructure services in goods production and/or human capital accumulation sectors (e.g. Turnovsky 1996; 1997; Glomm and Ravikumar 1999; Agénor 2005). The congestion costs related to infrastructure are usually found to be important for economic growth; some theoretical works relate congestion costs to optimal and growth-maximizing taxes (e.g., Agénor 2005).

\subsection{Public Capital, Income Inequality, and Growth}

Does public capital affect economic growth and income inequality simultaneously? Could public capital disproportionately increase economic growth? Under what conditions, provisions of infrastructure benefit the poor/the rich more than proportionally? Or, what determines the distributional effect of public capital? In an attempt to answer these questions, chapters 3 and 4 provide a joint theory of income inequality, public capital, and economic growth. In short, the theory shows that public capital plays an important role in long-run growth by enhancing productivity and complementing the accumulation of private capital. Moreover, under certain conditions, public capital could have important implications for income distribution dynamics. Particularly, when the use and efficiency of public capital vary among households, it becomes important for the dynamics of income distribution. On the other hand, when the credit market is imperfect and there are diminishing returns to private input, income inequality is negatively related to economic growth. In this case, public capital once more becomes an important determinant of long-run growth through its indirect effect on income distribution.

In this section, we explore existing theoretical and empirical findings on the relationship between public capital, income inequality, and economic growth. In the previous section, we introduced a number of empirical and theoretical studies on the relationship between public capital and economic growth. Numerous other studies address the relationship between income distribution and economic growth. In addition, empirical researchers in particular have recently shown growing interest in the relationship between public capital and income inequality. This section surveys these types of literature.

\section{Public Capital and Income Inequality}

There is increasing interest in assessing the impact of infrastructure on income inequality. Many empirical studies have reported that public capital in general has 
a positive effect on income distribution dynamics. Calderón and Servén (2004), Calderon and Chong (2004), Lopez (2003), the World Bank (2003), the OECD (2006), and Estache (2003) have all indicated that infrastructure has a disproportionately positive impact on growth. In fact, however, certain infrastructure provisions may have a limited distributional impact in particular if access to the services is limited for the poor. For instance, Khandker and Koolwal (2007) find that commercial bank expansion and paved road access have limited distributional impact in rural Bangladesh.

Infrastructure development improves income distribution and/or reduce poverty when it provides opportunities and resources not otherwise affordable by individuals. The provision of public capital (e.g., public education, public health and clean water) could serve as substitutable inputs for those who may not be able to afford them privately. ${ }^{13}$ The provision of piped water, for instance, substitutes unsafe drinking water for the poor; this consequently improves children's and adults' health and thus enhances their productivity. Jalan and Ravallion (2003) found that in rural India the prevalence and duration of diarrhea (the major cause of infant mortality in developing countries) were significantly lower on families with piped water than those without. Lavy et al. (1996), too, stated that public investment plays a key role in reducing rural urban disparities in health status and improves the health status and mortality rates of rural children in particular. ${ }^{14}$

However, much of the literature discussed above studied the relationship between public capital and income distribution relying on informal analysis or structural theoretical frameworks. Few attempts have been made to investigate the relationship formally. ${ }^{15}$ Therefore, a number of questions relating to public capital and income inequality that are relevant from both a policy and an academic perspective remain unanswered. How precisely is public capital linked to income distribution dynamics? How is the income of two individuals affectied differently by using a public good in their production function? What are the determinants of the relationship between public capital and income inequality? Chapter 3 and 4 address these questions.

Chapter 3 attempts to analytically capture the relationship between public capital and income inequality using a simple production function such as CobbDouglas. However, as mentioned earlier, the analytical tractability of CobbDouglas comes with the cost of stringent restrictions on relative factor shares, which makes the production function unsuitable for distribution analysis. In CobbDouglas, relative factor income shares are fixed (i.e., constant) due to the constancy of elasticity of substitution, which is indeed equal to unity. Thus, Chapter $4 \mathrm{em}-$

\footnotetext{
${ }^{13}$ Hicks (1932, p.120) notod that ono thing upon which olasticity of substitution dopends is "...the mere extiension of the use of instruments and methods of production from firms where thoy were previously employed to firms which could not proviously afford thom."

${ }^{14}$ Sec Brenneman and Kerf (2002) and Leipzigor at al $(2003)$ for at dotailed discussion on how public investmont plays a key role in the lives of the poor, such as improving health, aducation, and thus productivity.

${ }^{15}$ To our knowledgo, only Ferreira (1995), Gurcín-Peñalosen and Turnovsky (2007) and Chatiterjee (2008) have explicitly studied the relationship between infrastruction and income inequaliliy analytically. Ferreira (1995) studied the rolationship botween public capital and incequaliy in a model with quite a complex sotup while Garcin-Poñalosa and Thrnovaky (2007) and Chatiterjoo (2008) analytically studied the distributional impacti of public capibal focussing on its financing aspect. Wo discuss this literature in details in Chapter 1 , Section 1.
} 
ploys a more flexible but tractable production function - specifically, a generalized Cobb-Douglas production function from Newman and Read (1961) - to formally characterize the effect of public capital on income inequality.

\section{Income Inequality and Economic Growth}

Is income inequality bad for economic growth? The most popular theories give an affirmative answer. At the risk of oversimplification, these theories fall into one of three categories: the imperfect credit market, the political economy, and the social discontent theory. With regard to the first, Galor and Zeira (1993) and Benabou (1996) (among others) show that, in the face of capital market imperfection, inequality has a definite negative effect on growth. The essence of this theory is that when credit markets are imperfect, relatively more highreturn investment opportunities would be forgone by resource-poor households in inegalitarian societies than in egalitarian ones. From a political economy context, Alesina and Rodrik (1994) and Persson and Tabellini (1994) argue that inequality harms growth because it demands a higher transfer of income from the rich to the poor that distorts savings, resulting in lower capital investments and hence lower growth. The theory works within a typical political economy mechanism, the majority rule. In democracies, when the median income is lower than the mean, a higher distortionary tax is chosen at equilibrium, which favors the poor but hurts growth. The social discontent approach, promoted by Alesina and Perotti (1996) and Benhabib and Rustichini (1996), states that income inequality discourages growth by increasing sociopolitical instability which in turn decreases investment.

Earlier literature in particular was rife with the opposite perspective of these views. Kaldor (1957) and Bourguignon (1981) argued that higher inequality tends to boost economic growth through its positive effect on savings and investments. They believed that saving rates rise in line with income level, which therefore makes inequality a suitable growth environment by channeling resources to those who have higher propensity to save, which in turn increases aggregate savings and capital accumulation. Galor and Moav (2004) attempt to reconcile the two theories by unifying two different approaches (credit market imperfection and the classical approach) to describe the process of economic development with respect to inequality. They argue that during the Industrial Revolution, income inequality motivated growth by promoting physical capital accumulation, but later on - when physical capital was replaced by human capital as a primary source of growth - equality came to enhance growth by alleviating the adverse effects of credit constraints.

The empirical literature is more controversial. Perotti (1996), using crosscountry data, found a negative relationship between income inequality and economic growth. However, Forbes (2000) and Li and Zou (1998), using panel data, claimed that inequality does not harm economic growth. Barro (2000) indicated that inequality tends to retard growth in poor countries while encouraging it in rich places. Likewise, Deininger and Squire (1997) found that income inequality only reduces economic growth in poor countries. Panizza (2002), also using crosscountry panel data, stated that a negative relationship exists between inequality 
and growth, but the relationship is not robust. ${ }^{16}$

\subsection{Public Capital in Multiple-Equilibria Models}

Almost all the analytical literature mentioned in the previous sections studies public capital within traditional growth models that generate a unique high-income equilibrium outcome. In conventional growth models, efficient practices predict efficient outcomes (see, e.g., Solow, 1956; Romer, 1986; and Lucas, 1988). In a perfectly competitive economy and a perfect market, a rational representative agent makes productive efforts and savings that unanimously lead to a unique highincome steady state equilibrium or balanced growth path. However, a snapshot of the real world provides a different perspective: that both efficient and inefficient outcomes - multiple equilibria - coexist.

It is therefore important to investigate the role of public capital in non-ergodic economies with multiple equilibria and poverty trap. Chapter 6 develops such a model, in which the presence of certain negative externalities (such as skilled "migration humps" or temporary increases in brain drain) during an economy's takeoff causes a poverty trap. The chapter then analyses the role of public investment in helping economies to evade poverty trap.

In this section, we provide a background for the study. We explore existing theoretical and empirical findings with regard to multiple equilibria, poverty trap, and public capital. First, we briefly discuss the convergence debate and the relevance of poverty trap models in explaining economies and their implications for public policy. We also touche upon the famous 1990s debate of absolute, conditional, or club convergence and divergence. Then, we discuss poverty trap models, causes of poverty trap, and what it takes to get out of a poverty trap.

\section{The Convergence Debate and Its Implications for Public Policy}

An important challenge for economic growth theories is whether they satisfactorily explain what has happened in the history of world economies. In the last decade of the 20 th century intense debate raged over whether the world's economies would ultimately converge. There has also been major theoretical and empirical controversy about whether economies indeed absolutely (or conditionally) converge, or form club convergences. The convergence debate is based on the convergence hypothesis initiated by Gerschenkron (1962), who first formulated a hypothesis of "relative backwardness" - that is, that laggard countries could grow faster than the early leaders by taking advantage of the backlog of un-exploited technology. This notion prompted much empirical and theoretical literature on whether the per-capita income of the world (or a set of countries) would ultimately converge.

Many of the empirical contributions claim convergence in the per-capita income of a set of developed countries but divergence as a whole. In the productivity race that began in the last quarter of 19 th century, the laggards, over time, grew sufficiently fast to catch up to those at the front (Baumol 1986; Dowrick and Nguyen 1989; Abramovitz 1986; Gruen 1986; Kormendi and Meguire 1985; Barro

\footnotetext{
${ }^{16}$ Frequently mentioned reasons for these differences are low-quality data and methodological differences.
} 
and Sala-i-Martin 1992; Mankiw, Romer, and Weil 1992). However, for the world in its entirety, the last 150 years have seen "divergence, big time" (Pritchett 1997). It has been observed while the developing countries as a whole were falling further behind, a subgroup within them was in fact growing faster than the developed countries.

A great challenge in the theoretical literature is to reflect these empirical findings consistently. There may be consensus that endogenous growth theories in general do not predict any kind of convergence. In these models, economies largely determine their own fate, which leaves room for policy and technological variations among nations, which in turn creates divergence. On the other hand, neoclassical growth theories (e.g., the Solow model), arguably, predict convergence. Barro (1989) and Lucas (1988) argue that in the Solow model of neoclassical economics, countries' per-capita growth rates tend to be inversely related to their starting level of per-capita income, meaning that in the absence of a shock, poor and rich countries would coverage in terms of per-capita income. This is called unconditional convergence, and is inconsistent with cross-country evidence. However, Mankiw, Romer, and Weil (1992) argue that the Solow model does not predict unconditional convergence in per-capita world income, but rather that per-capita income in a given country converges to that country's steady-state value: conditional convergence. They argue that in neoclassical (Solow) models, convergence is conditional on the steady state-determined variables.

According to Mankiw, Romer, and Weil (1992), convergence might be analyzed with respect to how two economies are differently structured in terms of these variables: capital per worker, savings, and population growth rate. Quah (1996), however, indicates that at issue is not whether a single economy tends towards its own steady state, but what happens to the distribution of economies in general. Ho argues that convergence is only one possible outcome among many. Alternatively, the poorest countries are falling behind while the intermediates are converging towards the richest, forming "Twin Peaks," or club convergence.

Theoretical models used to explain club convergence have multiple equilibria - steady state outcomes with at least two equilibrium points such that one is low, the other is high (see Durlauf 1993; 1996 and Galor 1996).

\section{Poverty Trap and Public Policy}

\section{Definition}

What is a poverty trap? The low equilibrium in multiple-equilibria models is usually referred as a poverty (underdevelopment) trap (Azariadis and Drazen 1990). Many multiple-equilibria models are characterized by three steady state levels of output and capital: a low-stable, an unstable, and a high-stable steady state. A poverty trap may be defined as the stable steady state with low levels of percapita output and capital, whereas the unstable and stable steady states represent a threshold and high-income equilibrium points respectively. If an economy's percapita capital stock is slightly below the threshold point, the economy is in poverty trap. Whenever this economy attempts to break out of the trap, it tends to return to the low equilibrium point. 


\section{What Causes Poverty Trap?}

In growth models, some deviations from the neoclassical benchmark could generate multiple equilibria with poverty trap. As mentioned earlier, these models are characterized by multiple equilibria: high and low equilibrium points. Becker et al. (1990) show that multiple equilibria are likely to rise when fertility is endogenous. Azariadis and Drazen (1990) developed a poverty trap model when technologies are non-convex, while Galor and Zeira (1993) and Galor and Tsiddon (1997) show multiple equilibria when income inequality prevails and/or the capital market is imperfect. ${ }^{17}$

\section{How Do Economies Evade Poverty Trap? Is There Any Role for Public Capital?}

Some economists argue that poor societies need to remove any "barriers" that stand in the path of growth or that prevent the flow of positive technological spillover from leading economies. They stress the existence of a world stock of knowledge (technology) which could be exploited by poor countries at no (or moderate) cost, but are not due to the complex economic, social, political, and other institutional factors that exist in such countries (Abramovitz 1986; Abrannovitz ct al. 1996; Parente and Prescott 1997; Verspagen 1995). Lucas (2000) and Tamura (1996) present a model that shows, in the very long run, how poor countries climb onto the modern economic growth escalator at different points in time. This occurs, the argument goes, when the world stock of knowledge atlains its critical level such that an economy currently at stagnant equilibrium begins to grow.

Analytical models showing the role of public policy and technology in poverty trap include those of Galor and Zeira (1993), Galor and Tsiddon (1997), and Hung and Makdissi (2004). As briefly discussed earlier, the role of public policy in economic development could be crucial in an environment with poverty trap. A temporary decline in public investment in human and physical capital in a developing country, for instance, may permanently change the course of the economy's development by reducing the capital stock from slightly above to slightly bolow the threshold value, and consequently leading the economy into a poverty trap. By the same token, if the economy is on a bad-growth path leading to a povorty trap, enlarging public investment to its growth-maximizing level could return it to the high-growth path by increasing the capital stock from slightly below to slightly above the threshold value. ${ }^{18}$

\footnotetext{
${ }^{17}$ Moreover, Galor (1996), Azariadis (1996), and A zariadis et al (2006) show the rise of multiple oquilibria with subsistence consumption, impatient government, incompletic inarket, monopolistic: competition in product or factor market, augmentod human capital, externalition and incomo distribution.

${ }^{18}$ The need for an external temporary shock - the Bigh-Push - (c.g., nid to developing countries) to got them out of poverty trap has been dobated since the 1950s. Seo Easterly (2006) and Sachs (2005) for contrasting modern views on using a Big-Push to get, ont of a poverty trap.
} 


\subsection{Summary}

We divided this chapter into three sections that provide a background for the rest of the thesis. In the first section, we surveyed both the theoretical and the empirical literature, and discussed and clarified various concepts of public capital and economic growth. In the second, we discussed the relationship between public capital, income inequality, and economic growth from both theoretical and empirical perspectives. We pointed out the gap in the literature, and showed that few attempts have made so far to study analytically the relationship between public capital and income inequality. Chapters 3 and 4 attempt to fill these gaps, while Chapter 5 empirically investigates the nonlinear relationship between public investment and economic growth. There, we attempt to identify the growth-maximizing level of public capital, taking the case of Sub-Saharan African countries and presenting a model as the basis for the empirical analysis. In the third section of the present chapter, we discussed the pros and cons of multiple equilibria, poverty trap models, and related concepts. In Chapter 6, we continue this study in greater depth by presenting a growth model of multiple equilibria with poverty trap and analyzing the role of public capital in these types of economies. 


\section{CHAPTER 3}

\subsection{Introduction}

The role of public: capital and income distribution in economic growth is well stiudied both analytically and empirically. However, the distributional effect of public capital is usually ignored in the theoretical literature despite evidence and intuition to its disproportionate impact on houschold income (see, e.g., Jacoby 2000, and Calderón and Chong 2004). Provision of public services (such as public: education, public health and clean water) may benofit poor houscholds more than proportionally due to their lack of access to their private substitutes. On the other hand, infrastructure services (such as telecommunications and electricity) may tend to favor richer groups due to their greater access to their private complements. This disproportionate impact of public capital, once it is explicitily acknowledged, could be important for the dynamics of income and hence the cvolution of macroeconomic aggregates.

This chapter chiefly develops a joint theory of public capital, income distribution, and economic growth. Using a two-sector growth model, which yields analytical solutions, the chapter studies the role of public capital on growth and inecquality. It particularly extends the imperfect capital markets theorics in inequality and growth to public capital, inequality and growth. According to these theories, when the credit market is imperfect and the rate of return to private factors is diminishing, inequality is bad for growth (see, e.g., Benabou 1996). The chapter shows that infrastructure services in both human and goods production sectors could affect inequality dynamics and hence growth (through an indirect channel), by altering relative factior shares, due to their disproportionate impact on the individual houschold. The basic idea and intuition bohind the theory is described below.

Public capital plays an important role in long run growth through enhancing productivity and complementing the accumulation of private inputs. Undor cortain conditions, it could also have important implications for income distribution 
dynamics. In an economy with heterogeneous agents and imperfect credit markets, the dynamics of aggregate variables such as public and private capital and the economic growth rate are determined jointly with those of income distribution. When the credit market is imperfect and there are diminishing returns to private factors, income inequality is negatively related to economic growth. Income distribution dynamics are determined by the relative private factor income shares, wherever initial endowment differs among individuals, and, when the credit market is imperfect. Therefore, if provisions of public capital affect private factor income shares (in the presence of credit market imperfection), then they will also affect income distribution dynamics. In this case, public capital once more becomes an important determinant of long-run growth through its indirect effect on income distribution.

The following example could help set the above theory in perspective. Consider an economy with heterogeneous agents in terms of their initial wealth but similar otherwise. If there is no trade in factor inputs (or, in other words, if access to credit is limited), investment opportunities depend on individuals' initial level of wealth. If the individual production function faces diminishing returns to factor inputs, relatively poor individuals, who have relatively lower investment opportunities, would have high marginal productivity in production. This implies initial wealth distribution determines aggregate output that would be produced in this economy. Therefore, ceteris paribus, the more egalitarian (initial) wealth distribution is, the higher the aggregate production would be.

What determines income distribution dynamics? When the credit market is imperfect, income distribution evolves according to relative private factor income shares. When there are differences in initial endowment among households who are otherwise similar, and, when households are not allowed to borrow and lend from each other, the dynamics of income distribution depends on the degree to which households are able to exploit their relative initial advantage. In this type of economy, the presence of any other (public good-type) inputs (e.g. infrastructure) in production has no effect on income distribution dynamics unless it alters the relative private factor income shares. ${ }^{1}$ If the provision of public capital as an additional input in production, however, could affect private factor income shares, then public capital becomes important for income inequality dynamics. This happens rather than by considering public capital as an input where its service accrues homogeneously among individual households, but as input where its importance varies among households. In the latter case, public capital becomes important for income inequality dynamics and hence to growth (through an indirect channel).

The next section presents the model. In the model, we suppose an economy, populated by heterogeneous agents, consists of two production sectors: the human capital accumulation and final goods production sectors. In the former, human

\footnotetext{
${ }^{1}$ This is simple to demonstrate. Suppose that the individual production function $y t=$ $A\left(k_{t}\right)^{\alpha}\left(X_{t}\right)^{0}$ is taken place with two complementary inputs, $k_{t}$ and $X_{t}$, private and public capital respectively, in an economy with imperfect credit market. Assume further that private capital, which initially differs among individuals, is distributed lognormally, i.e., $\ln k_{0} \sim N\left(\mu_{0}, \sigma_{0}^{2}\right)$. Then, an individual's saving at $t+1$ is $k_{t+1}=s y_{t}=s A\left(k_{t}\right)^{\alpha}\left(X_{t}\right)^{\theta}$, where $s$ is an cxogcnous suving rate. Income distribution at $t+1$ is given by, a long story cut short, $\operatorname{var}\left(\ln k_{t-1+1}\right)=\sigma_{t+1}^{2}=\alpha^{2} \alpha_{l}^{2}$. Therefore, in this economy, what matters for income distribution dynamics is neither $X_{t}$ nor its output elasticity $\theta$ but the private capital income share $\alpha$.
} 
capital is generated using inputs from public and private resources while production technology is characterized by inter-generational spillover. Production in the goods sector takes place also using private and public inputs. The benefit accrues from using the public inputs is different among households. That is, depending on the type of the public good, infrastructure development may benefit the poor (rich) more than proportionally due to their lesser (greater) access to their private substitutes (complements).

Within such setup, we show that a provision of public capital not only affects growth but also inequality. That is, the dynamics of income inequality not only depends on the magnitude of the elasticity of private capital but also public capital. The greater the output elasticity of public capital, the larger is its effect on inequality. Whereas income inequality is negatively related to economic growth, under appropriate condition, public capital could help to mitigate this effect. That is, certain infrastructure development in both the human and final goods production sectors could improve income inequality dynamics, and hence could promote economic growth, once more, through an indirect effect of mitigating the negative influence of income inequality on economic growth.

With respect to growth and public capital nexus, infrastructure development in both sectors have a net positive effect on long run growth while the magnitudes of optimal taxes (growth maximizing taxes) on both sectors depend on whether there is inter-generational spillover in the human capital accumulation sector (in contrast to Barro-type findings). For instance, the optimal tax for the public good in the goods sector decreases at the elasticity of human capital (the spillover parameter) in the human eapital accumulation sector.

The study rolates to three main strands of literature, which we oxtend along various dimensions. It relates to the large volume of literature dedicated to studying the relationship between public capital and economic growth (e.g., Barro (1990), Futagami of al. (1993), Turnovsky and Fisher (1995), Turnovsky (2000), Agonor (2008), Ziosemer $(1990 ; 1995)$ among many). This literature studies the relationship between public capital (stock or flow) and economic growth analytically in a ropresentative agent framework. Barring a fow exception, the literature has restricted public capital to a single section (either in the goods production or the human capital accumulation sector) ${ }^{2}$ In reality, the two public inputs coexist, and interact in their technological parameters, affecting each other's macroeconomic porformance. For instance, public expenditure on primary schooling, basic research and health, which are important for accumulation of individuals' human capital, cssentially coexists with othor infrastructure services such as roads, airports and onorgy, which are primarily crucial for the production of firms. Inter-generational spillover in the human capital accumulation sector may affect the optimal tax in the goods production sector. Morcover, factor elasticities of oulput in the sectors may intoract in determining inequality dynamics.

The chapter is also related to literature that studies the relationship between public capital and income inequality. Recently, a growing number of empirical studies try to assess the impact of infrastructure on income inequality, For instance, Calderón and Chong (2004), and Lopez (2003) show that infrastiructure

\footnotetext{
${ }^{2}$ Itiojn (2005) studios two public: capitals, in educntion and goods sectors, will respoet to growth, in a representative agont, framework. But, he does not provide an analytical solution.
} 
reduces income inequality and enhances economic growth at the same time. Jacoby (2000) argues that some infrastructure services could result in substantial benefits on average, much of it going to the poor. On the other hand, Garcfa-Peñalosa and Turnovsky $(2007 ; 2008)$ and Chatterjee (2008) analytically studied the distributional impact of different ways of financing public good. They argue that growth-enhancing fiscal policies are mostly related to greater pre-tax inequality although this might also depends on the type of financing the public good (Chatterjee 2008). In contrast, the present chapter focuses on the type of public service (rather than the type of financing it) in determining the distribution dynamics. ${ }^{3}$

The third strand of literature related to the present study deals with the dy namics of income inequality and long-run growth within an imperfect credit market scenario (e.g., Loury (1981), Galor and Zeira (1993), Banerjee and Newman (1993), Piketty (1997), Aghion and Bolton (1997), Aghion and Howitt (1998), Aghion, Caroli, and García-Peñalosa (1999), and Benabou (1996;2000;2002)). ${ }^{4}$ Our study complements their findings. For instance, Benabou $(2000 ; 2002)$ showed, in his way of studying the effect of redistributive tax on income inequality and growth, that private factor income shares and family wealth determine income distribution dynamics and growth. We show here that public capital could also be an important determinant of income inequality dynamics.

The remainder of the chapter is organized as follows. Section 3.2 provides the model. Section 3.3 is all about income distribution and public capital. Various macroeconomic aggregates that rise in the model and their dynamic behaviors are studied in section 3.4. Section 3.5 concludes.

\subsection{The Model}

\section{Households and firms}

There is a continuum of heterogeneous households, $i \in[0,1]$. Each household $i$ consists of an adult of generation $t$ and a child of generation $t+1$. At the beginning, each adult of the initial generation is endowed with human capital $h_{0}$ and a public infrastructure $G_{0}$ which is shared among others. The distribution of wealth (human capital) is assumed to take, initially, a known probability distribution of $\Gamma_{0}($.$) . Thus, the initial distribution is given and evolves over time at equilibrium. { }^{5}$

Agents care about their consumption level and the human capital stock of their children. When young, they accumulate human capital using both private and public input. When adult, they use their human capital for final goods production. Government tax income with two fixed flat rate taxes, $\psi$ and $\tau$, in order to finance the public inputs, denoted by $G_{t}$ and $M_{t}$, in the goods production and human capital accumulation sectors, respectively. Individuals allocate after tax

\footnotetext{
${ }^{3}$ The chapter may also be related to literature in public education, redistribution and inequality (Sec, for instince, Glomm and Ravikumar 1992, and Saint-Paul, G, and T. Verdier 1993 among many). This literature focuses on the education sector, with a particular cmphasis of the distributional impact of public education rather than the general infrastructure services.

"In contrast to the first and the second strand of literatures, this literature does not focus on public capital.

${ }^{5}$ In all the text, small and capital letiters represent individual and aggregate (average) variables, respectively.
} 
income between current consumption $c_{t}$ and children education $e_{t}$, while the latter represents private investment for human capital accumulation of the offspring. Preferences are logarithmic. Production functions are Cobb-Douglas.

A utility of an individual is thus defined as

$$
\ln c_{t}+\beta \ln h_{t+1}
$$

subject to

$$
c_{t}+e_{t}=(1-\tau-\psi) y_{t}
$$

where $y_{t}$ is income of an individual.

Human capital accumulation function for the offspring $h_{t+1}$ is a function of parental human capital $h_{t}$, private educational investment $e_{t}$, and public input on the sector $m_{t}$,

$$
h_{t+1}=B\left(h_{t}\right)^{\varepsilon}\left(m_{t}\right)^{v}\left(e_{t}\right)^{\eta}
$$

The public input $m_{t}$ is adjusted to the individual's value of infrastructure service in the sector,

$$
m_{t}=\frac{M_{t}}{\left(h_{\iota}\right)^{\zeta}} ;-1<\zeta<1
$$

where $M_{t}$ and $h_{t}$ denote the total public expenditure in the sector, and the individual's initial wealth (human capital) respectively.

The use and efficiency of public capital thus vary among households. Depending on the type of the public good, infrastructure may benefit the poor (rich) more than proportionally due to their lack of (greater) access to its private substitutes (complements). The direction and magnitude of $\zeta$ in (3.4) respectively convey the type and the degree of the disproportionate impact of infrastructure service on the individual human capital accumulation. $0<\zeta<1(-1<\zeta<0)$ corresponds to infrastructure that benefits the poor (rich) moro than proportionally. When $\zeta=0$, which is usually (implicitly) assumed in the literature, infrastructure benefitis the poor proportionally.

A number of practical instances can be mentioned in both cases. Construction of a new dam (or improved irrigation) may benefit more those who have access to fertilizer and high-yielding varicty of seeds. The same goes for rural roads and internet use where they benefit more those with bicycles and motorbikes, and computers and better education, respectively (Songco 2002 and Estache 2003). On the other hand, the provision of public services such as public education, clean water, sanitation and public transport may benefit the poor more than proportionally. To a great extent, the poor are poor because thoy lack these basic inputs (such as clean water, sanitary surroundings, and mobility) (World Bank 1994).

While aggregating equation (3.4), intieresting enough, the model captures congestion cost. In this case, $\zeta$ (where $0<\zeta<1$ ) denotes congestion factor. ${ }^{6}$ How-

\footnotetext{
${ }^{6}$ Traditionally, congestion is modoled in the litematiure as $M_{t}^{c}=\frac{M_{h}}{\left(\Pi_{b}\right)^{\zeta}}$, whore $\zeta$ ropresentis the degres of congestion; $H_{L}$ and $M_{t}$ are aggrognte private capital and public oxpenditure, respectively; and henee $M_{t}^{c}$ represents public expenditure with congestion cost. Seo also Glomm and Ravikumar (1994).
} 
ever, neither the distributional effect of public capital nor equation (3.4) shall be confused with congestion. At the individual level, equation (3.4) and its distributional parameter $\zeta$ do not reflect congestion but distribution.?

Combining (3.3) and (3.4), the human capital accumulation function becomes

$$
h_{t+1}=B\left(h_{t}\right)^{\xi}\left(M_{t}\right)^{v}\left(e_{t}\right)^{\eta}
$$

where $B>1,0<\varepsilon, \eta, v,<1,0 \leq \xi \equiv(\varepsilon-v \zeta)<1$, and $-1<\zeta<1$.

\section{Firms}

We assume each household owns a firm. ${ }^{8}$ Aggregate output is thus the surn of the individuals' production functions. We also assume individuals differ only in their initial human capital (wealth), which is lognormally distributed across agents: $\ln h_{0}{ }^{\sim} N\left(\mu_{0}, \sigma_{0}^{2}\right)$.

Thus, the income of an agent of generation $t$ is

$$
y_{t}=A\left(h_{t}\right)^{\alpha}\left(g_{t}\right)^{\theta}
$$

Once more we define the public service $g_{t}$, which is adjusted to the individual's value of infrastructure service in the goods production sector, similar to (3.4)

$$
g_{t}=\frac{G_{t}}{\left(h_{t}\right)^{\kappa}} ;-1<\kappa<1
$$

Thus, $g_{t}$ and $\kappa$, in the goods production sector, are counterparts of $m_{t}$ and $\zeta$, in the human capital accumulation sector, respectively; whereas, (3.7) is a counterpart equation of (3.4), in the human capital accumulation sector. Therefore, $g_{t}$ represents infrastructure service that is passed to the individual household, and depends on the infrastructure stock $G_{t}$ in the goods production sector and the private wealth (human capital) of the agent.

Combining (3.6) and (3.7), the individual production function for the final goods production becomes

$$
y_{t}=A\left(h_{t}\right)^{\omega}\left(G_{t}\right)^{\theta}
$$

where $A>1,0<\alpha, \theta, \omega<1,-1<\kappa<1$, and $\omega \equiv(\alpha-\theta \kappa){ }^{9}$

While aggregate, production $Y_{l}$ is

$$
Y_{t}=A\left(H_{t}\right)^{\omega}\left(G_{t}\right)^{\theta} \exp \left(\frac{\sigma_{t}^{2}}{2}(\omega(\omega-1))\right)
$$

\footnotetext{
${ }^{7}$ First, congestion is an aggrogate phonomenon. Congestion cost from an individual perspective (in light of equation (3.4)) is thus negligible. Moreover, if we had modeled (3.4) to refloct congestion (as $\frac{M_{t}}{\left(I_{l}\right)^{\zeta}}$ ), then public capital would not have had any effect on the individual private factor income shares, and hence, on income distribution dynamics.

${ }^{8}$ This assumption shuts off the input market, or it is another way of assuming that credit market is imperfecil (see, e.g., Benabou 2000; 2002, for a similar specification).

${ }^{9}$ The case $\alpha=\theta \kappa$ is not included, in contrast to the human capital accumulation sector where a case of $\varepsilon=v \zeta$ is considered, because it is unlikely that goods would be produced using only infrastructure services. In fact, roads do not produce by themselves.
} 
since $\int_{0}^{1}\left(h_{t}\right)^{\omega} d \Gamma_{t}(h)=\left(H_{t}\right)^{\omega} \exp \frac{\sigma_{t}^{2}}{2} \omega(\omega-1)$ where $H_{t}$ is the aggregate (average) human capital (see Appendix 3.A).

According to (3.9), aggregate income is smaller in heterogeneous economies than representative ones $\sigma_{t}^{2}=0$.

\section{Government}

We assume that government budget is at all times balanced:

$$
\begin{aligned}
I_{t}^{g} & \equiv \int_{0}^{1} y_{t} \psi d \Gamma_{\iota}(h)=Y_{\iota} \psi \\
M_{t} & \equiv \int_{0}^{1} y_{\iota} \tau d \Gamma_{t}(h)=Y_{t} \tau
\end{aligned}
$$

Thus, government collects proportional taxes $\tau$ and $\psi$ on output $Y_{t}$, to finance public expenditure $I_{t}^{g}$ and $M_{t}$ in the final goods production and the human capital accumulation sectors, respectively. The accumulation of public capital in the goods production sector follows the rule

$$
G_{t+1}=I_{i}^{g}+G_{t}\left(1-\cdots-\delta^{g}\right)
$$

where $G_{l}$ and $\delta^{g}$ denote the public capilal stock and the depreciation rate in tho goods sector, respectively.

\section{Competitive Equilibrium}

According to the above descriptions, an individual of generation $t$ solves the following problem, which is derived by substituting (3.2) and (3.5) into (3.1),

$$
\operatorname{Max}_{e_{t}} \ln \left((1-\tau-\psi) y-e_{t}\right)+\beta \ln B\left(h_{t}\right)^{\xi}\left(M_{t}\right)^{v}\left(e_{t}\right)^{\eta}
$$

taking as given $\tau, \psi, M_{t}, I_{t}^{g}$ and $G_{l}$.

The first order condition gives

$$
e_{t}=a(1-\tau-\psi) y_{\iota}
$$

where $a=\frac{\beta \eta}{1+\beta \eta} ;(3.14)$ shows the agent's optimal saving as the function of her income. Notice that the saving rate is identical among individuals, due to logarithmic preferences, although the rate of return on investment is different. ${ }^{10}$

To derive the individual human capital accumulation equation, which is associated to her optimal behavior, first substitute (3.14) and (3.11) into (3.5), then use (3.8) and (3.9), to got:

\footnotetext{
${ }^{10}$ In a logaribhmic utility function, the intor-tomporal elasticity of substitiution is onc, and consequently the income effect exactly compensates the tubstitution offect (Soe Do La Croix and Michol 2002, p. 13-14). In this case, tho individunl saving rate is indepenelent of the ralo of rotiurn.
} 


$$
\begin{aligned}
h_{t+1}= & B A^{v+\eta} \tau^{v}(a(1-\tau-\psi))^{\eta}\left(h_{t}\right)^{\xi+\omega \eta}\left(G_{t}\right)^{\theta(v+\eta)}\left(H_{t}\right)^{v \omega} \\
& \exp \left(\frac{\sigma_{t}^{2}}{2}(v \omega(\omega-1))\right)
\end{aligned}
$$

From (3.15), the individual's optimal human capital accumulation function is determined by the human capital of her parents $h_{t}$, the initial income distribution $\sigma_{t}^{2}$, and aggregate public and private capital ( $H_{t}$ and $G_{t}$, respectively), in the economy. The negative effect of income inequality in the individual human capital accumulation could not be a surprise. In the model, the individual human capital accumulation is a function of the provision of public capital $M_{t}$, which, in turn, depends on the level of aggregate income $Y_{t}$. But $Y_{t}$ has a negative relationship with income inequality due to the presence of credit market imperfection, and, the existence of diminishing returns to private factors.

Therefore, from (3.15), the following proposition can be established:

Proposition 1 Income inequality bears additional cost to the individual household's optimal human capital accumulation.

\subsection{Income Distribution and Public Capital}

From (3.15), we derive the following two difference equations, which characterize the evolution of capital accumulation and income distribution in the economy

$$
\begin{aligned}
\mu_{t+1} \equiv & E\left[\ln h_{t+1}\right]=(\xi+\omega(\eta+v)) \mu_{t}+(v+\eta) \ln A \\
& +\ln B+\theta(v+\eta) \ln G_{t}+v \ln \tau+\eta \ln a(1-\tau-\psi) \\
& +\frac{\sigma_{t}^{2}}{2}\left(v \omega^{2}\right) \\
\sigma_{t+1}^{2} \equiv & \operatorname{var}\left[\ln h_{t+1}\right]=(\xi+\omega \eta)^{2} \sigma_{t}^{2} \\
\equiv & (\varepsilon-v \zeta+(\alpha-\theta \kappa) \eta)^{2} \sigma_{t}^{2}
\end{aligned}
$$

11

Equation $\left(3.16^{\prime}\right)$ has a solution, $\sigma_{t}^{2}=(\xi+\eta \omega)^{2 t} \sigma_{0}^{2}$, where $\sigma_{0}^{2}$ is a known initial distribution of income. Thus, the steady state income distribution, $\sigma^{2}$, may take a value of $\sigma_{0}^{2}, 0$ or $\infty$, depending on some conditions,

$$
\begin{aligned}
& \sigma^{2}=0 \text { if } \xi+\eta \omega<1 \\
& \sigma^{2}=\sigma_{0}^{2} \text { if } \xi+\eta \omega=1 \\
& \sigma^{2}=\infty \text { if } \xi+\eta \omega>1
\end{aligned}
$$

\footnotetext{
${ }^{11}$ We use the fact that $E\left[\ln h_{t}\right]=\ln H_{t}-\frac{\sigma_{t}^{2}}{2} \equiv \mu_{t}$ in deriving (3.16) (see Appendix 3.A, and recall that $\left.\ln h_{t} \sim N\left(\mu_{t}, \sigma_{t}^{2}\right)\right)$.
} 
where $0 \leq \xi \equiv(\varepsilon-v \zeta)<1,0<\varepsilon, \eta, v, \alpha, \theta, \omega<1, \omega \equiv(\alpha-\theta \kappa)$, and $-1<\zeta, \kappa<1$

Therefore, income inequality will decline through time and ultimately vanish for certain values on the parameters, $\xi+\omega \eta<1 .{ }^{12}$ However, this should not be confused with a stylized fact. The reason for the vanishing is that the heterogeneity, in this model, is only on the individuals' initial wealth; agents are similar otherwise, in their ability, technology, etc. Thus, a diminishing return on net private accumulative factors, $\xi+\omega \eta<1$, implies resource poor households are more productive than rich ones; consequently, it is inevitable for the poor to catch up with the rich in the long run. ${ }^{13}$

The model thus captures the possible role of public capital and other important variables such as family wealth on income inequality dynamics in the short run. Particularly, (3.16) and (3.16') capture the intuition that differences in family wealth and the existence of public capital as an input for the production of goods and/or the accumulation of human capital play important role in the persistence of income inequality. Depending on the values of the distributional parameters, whether $0<\zeta, \kappa<1(-1<\zeta, \kappa<0)$, public capital would have a positive (negative) impact on inequality. ${ }^{14}$

Family wealth, however, similar to what is found by Benabou (2000; 2002), determinately exasperates income inequality. More important is the parent's wealth, i.c., the larger is $\varepsilon$, for the accumulation of the offspring's human capital, the more income inequality persists. But, more important are the public services for the accumulation of human capital and the production of goods, that is, the greater are $\theta$ and $v$, also the larger their disproportionate impact on the individual houschold, i.e., the greater are $\zeta$ and $\kappa$, the faster (the slower) income inequality declines for $0<\zeta, \kappa<1(-1<\zeta, \kappa<0)$. In regard to the effect of infrastructure service on the economy, we thus have the following proposition:

Proposition 2 Infrastructure services in the human capital and the goods production sectors speed up (slow down) income distribution convergence, in the short run, when $0<\zeta, \kappa<1 \quad(-1<\zeta, \kappa<0)$.

To sum up, we have shown hore, as we argued in the introductory section, in the presence of imperfect credit market, the dynamics of income distribution is governed by the relative private factor income shares (such as $\varepsilon, \eta$, and $\alpha$ ). However, under the appropriate conditions, a provision of public capital in the goods production and the human capital accumulation sectors would have a positive role in income distribution dynamies, by altering rolative private factor income shares. The impact of public capital on income inequality dynamics depends on the the degree of its importance to private production, which is reflected on the magnitude of $\theta$ and $v$. Moreover, whether an infrastructure service is pro-poor or not as reflected on the magnitude and the direction of the parameters $\zeta$ and $\kappa$ is important; to income distribution dynamics.

\footnotetext{
${ }^{12}$ This result, is comparable with that of Glomm and Ravikumar (1992). In a privatic sducation economy, they state that income inceguality may decline, increase, or remain constant depending on the sum of parmeters in the sector.

${ }^{13}$ Seo also Saint-Panl and Vordior (1993) for a model whore inequanlity dynamics is speceded up through public: (education) intervention.

${ }^{14}$ Rocall from (3.4) and (3.7) that, $0<\zeta, \kappa<1(-1<\zeta, \kappa<0)$ implics pro-poor (pro-rich) infrastructure service provision.
} 


\subsection{Growth, Inequality and Public Factors}

\section{Aggregate Capitals}

To determine the remaining macro-variables, first, aggregate (3.15) in order to obtain the equation that characterizes the evolution of aggregate human capital,

$$
H_{t+1}=B A^{v+\eta} \tau^{v}\left(G_{t}\right)^{\theta(v+\eta)}\left(H_{t}\right)^{\xi+(\eta+v) \omega}(a \cdot(1-\tau-\psi))^{\eta} \Omega_{t}
$$

where $^{15}$

$$
\Omega_{t}=\exp \left(\frac{\sigma_{t}^{2}}{2}((\xi+\omega \eta)(\xi+\omega \eta-1)+v \omega(\omega-1))\right)
$$

By assuming constant returns to scale with respect to accumulative factors, in both the human capital accumulation and the goods production sectors, i.e., $\eta+v=1$ and $\omega+\theta=1$, respectively, we can rewrite the above equation as

$$
H_{t+1}=B A \tau^{v}\left(G_{t}\right)^{\theta}\left(H_{t}\right)^{\xi+\omega}(a(1-\tau-\psi))^{\eta} \Omega_{t}
$$

Then, we easily derive the difference equation for public capital in the goods production sector by substituting the last term of (3.10) into (3.12), using (3.9), and assuming a complete depreciation $\left(\delta^{g}=1\right)$,

$$
G_{t+1}=\psi A\left(H_{t}\right)^{\omega}\left(G_{t}\right)^{\theta} \digamma_{t}
$$

where

$$
F_{t}=\exp \left(\frac{\sigma_{t}^{2}}{2}(\omega(\omega-1))\right)
$$

Equations (3.16), (3.20), and (3.21) describe the dynamics of the economy. The growth rate of the economy is thus determined by these equations.

The negative effect of income inequality on the economy is shown in the relationship between income inequality and the economy's capital accumulation functions, in (3.20) and (3.21). Equations (3.20) and (3.21) state income inequality is detrimental for the accumulation of aggregate public and private capital. In (3.20) and (3.21), $\Omega_{t}, F_{t} \leq 1$. The maximum values $F_{t}, \Omega_{t}=1$ are reached when $\sigma_{t}^{2}=0$. Therefore, in this case, the highest capital accumulation is realized when the society is perfectly egalitarian $\sigma_{t}^{2}=0$.

\section{Dynamics and Steady State}

The value that $\xi(\equiv \varepsilon-v \zeta)$ assumes is important in determining the long run behavior of the system. First of all, when $0<\zeta<1$, recall that $\varepsilon$ (the effect of family wealth on the human capital accumulation of the offspring) and $v \zeta$ (the disproportionate effect of public capital on the individual income) have opposite

\footnotetext{
${ }^{15}$ We use the fact that $\int_{0}^{1}\left(h_{t}\right)^{\xi+\omega \eta} d \Gamma_{t}(h)=\left(H_{t}\right)^{\xi+-\omega \eta} \exp \left(\frac{\sigma_{t}^{2}}{2}(\xi+\omega \eta)(\xi+\omega \eta-1)\right)$ (see Appendix 3.A).
} 
roles on income distribution dynamics. The former (the greater) makes income inequality persistent whereas the later (the greater) reduces it through time. ${ }^{16}$

When $\xi=0$, the system behaves in the long run similar to the standard one sector $A K$ model. However, unlike the $A K$ model, it has a lengthy transition period due to the presence of income inequality. From (3.20) and (3.21), the short run capital ratio is given by,

$$
\frac{H_{t+1}}{G_{t+1}}=B a^{\eta} \tau^{v} \psi^{-1}(1-\tau-\psi)^{\eta} \exp \left(\frac{\sigma_{l}^{2}}{2} \omega^{2} \eta(\omega-1)\right)
$$

In steady state, $\sigma^{2}=0$, the capital ratio $\frac{H}{G}$ is constant, ${ }^{17}$

$$
\frac{H}{G}=B a^{\eta} \tau^{v} \psi^{-1}(1-\tau-\psi)^{\eta}
$$

Therefore, at equilibrium $\left(\sigma^{2}=0\right)$, the system is characterized by a continuum of steady state equilibria while each can be reached only if the system starts at equilibrium. Moreover, aggregate variables will be in a balanced growth path, where $H, G$ and $Y$ grow at the same rate. And, the growth rate of the economy can be analytically determined at any point in time. However, in the short run, it exhibits transitional dynamics, unlike the textbook $A K$ model, which arises from the existence of income inequality dynamics $\sigma_{0}^{2} \neq 0$ in the model.

When $\xi>0$, there exists a stable and a unique global steady stato where $H, G$ and $Y$ converge, where the steady state is saddle point stable. However, aggregate variables exhibit imbalance growth. While human capital grows faster than output, public capital grows at the same rate with the latter.

Propositions 3 and 4 below are related to the two different cases, $\xi=0$ and $\xi>0$, respectively. ${ }^{18}$ But, first, in order to characterize the dynamics, we need to log-linearize the system, $(3.20)$ and $(3.21)$, near a local steady state point $(H, G)$. That is,

$$
\begin{aligned}
\left(\ln H_{t+1}-\ln H\right)= & (\xi+\omega)\left(\ln H_{l}-\ln H\right)+\theta\left(\ln G_{l}-\ln G\right) \\
& +\left(\ln \sigma_{l}^{2}-\ln \sigma^{2}\right) \ln \Omega \\
\left(\ln G_{t+1}-\ln G\right)= & \omega\left(\ln H_{t}-\ln H\right)+\theta\left(\ln G_{l}-\ln G\right) \\
& +\left(\ln \sigma_{t}^{2}-\ln \sigma^{2}\right) \ln F
\end{aligned}
$$

If we consider only equilibrium values of distribution which only exist, $\sigma^{2}=\sigma_{0}^{2}$ or $\sigma^{2}=0(\sec (3.17)-(3.19))$, then we will have $\left(\ln \sigma_{t}^{2}-\ln \sigma^{2}\right) \sigma^{2}=0$. Thus, $(3.22)$ and (3.23) will be simplified to

$$
\begin{aligned}
\left(\ln H_{t+1}-\ln H\right) & =(\xi+\omega)\left(\ln H_{t}-\ln H\right)+\theta\left(\ln G_{t}-\ln G\right) \\
\left(\ln G_{t+1}-\ln G\right) & =\omega\left(\ln H_{t}-\ln H\right)+\theta\left(\ln G_{t}-\ln G\right)
\end{aligned}
$$

\footnotetext{
${ }^{16}$ Sec (3.16) and $\left(3.16^{\prime}\right)$ and the subseguent discussion in Section 3.3 .

${ }_{17}$ Variables withoul tirne subseript (o.g., $I I, G, Y$ and $\left.\sigma^{2}\right)$ denoto slondy stato values.

${ }^{18}$ Wo exclude the cuse $\xi<0$ because of its unlikeliness.
} 
In matrix form, (3.24) and (3.25) become

$$
\begin{aligned}
{\left[\begin{array}{c}
\ln H_{t+1}-\ln H \\
\ln G_{t+1}-\ln G
\end{array}\right] } & =\left[\begin{array}{cc}
(\xi+\omega) & \theta \\
\omega & \theta
\end{array}\right]\left[\begin{array}{l}
\ln H_{t}-\ln H \\
\ln G_{t}-\ln G
\end{array}\right] \\
A & =\left[\begin{array}{cc}
(\xi+\omega) & \theta \\
\omega & \theta
\end{array}\right]
\end{aligned}
$$

where $A$ is the Jacobian matrix.

In regard to the dynamic behavior of the economy, for the case $\xi=0$, we make the following proposition:

Proposition 3 For $\xi=0$ (or $\varepsilon=v \zeta$ ), the system is non-hyperbolic, i.e., one of the characteristic roots is a unit.

Proof. The characteristic polynomial $P(\lambda)$ for the linear system, which is given by $(3.24)$ and $(3.25)$, is (recall $\omega+\theta=1$ )

$$
\begin{aligned}
P(\lambda) & =\lambda^{2}-\operatorname{Tr}(A) \lambda+\operatorname{Det}(A) \\
& =\lambda^{2}-(\xi+1) \lambda+\xi \theta
\end{aligned}
$$

Since $\xi=0$, then $\lambda^{2}-\lambda=0$ and hence $\lambda_{1}=1$.

In this case, we can analytically derive the ( $A K$ type) growth rate $\gamma_{t}$ at any point in time (see Appendix 3.B for details on the derivation),

$$
\gamma_{t+1}=\omega \ln \chi+\omega \eta \ln (1-\tau-\psi)+\omega v \ln \tau+\theta \ln \psi+\Delta_{t}
$$

where

$$
\begin{gathered}
\Delta_{t}=\omega^{3} \frac{\sigma_{t}^{2}}{2} \eta(\omega \eta-1)<0 \\
\chi=B a^{\eta} A^{\frac{1}{\omega}}
\end{gathered}
$$

According to $(3.29)$, both taxes $\tau$ and $\psi$ and income distribution variable $\sigma_{t}^{2}$ are important for the economy's growth rate $\gamma_{t}$. The term $\Delta_{t}$ captures the extent to which income inequality hampers economic growth during transition, in a heterogeneous economy with a production function that exhibits diminishing returns to factors, and, where there exists imperfect credit market. Whereas, infrastructure is shown here mitigating (exasperating) this effect, under the condition $0<\kappa<1$ $(-1<\kappa<0)$.

Notice, if $\Delta_{t}=0$, i.e., $\sigma_{t}^{2}=0$, then the growth rate of output $\gamma>0$. But, for greater $\Delta_{t}$ (due to greater $\sigma_{t}^{2}$ ), the growth rate of output could be zero and even negative.

The relationship between the taxes used to finance public capital and long run growth is non-linear, in line with the literature. The growth maximizing taxes $\left(\psi_{g \max }\right.$ and $\left.\tau_{g \max }\right)$, for the case $\xi=0$, are derived by 


$$
\begin{aligned}
\frac{\partial \gamma}{\partial \psi} & =\frac{\theta}{\psi}-\frac{\eta(1-\theta)}{1-\tau-\psi}=0 \\
& \Rightarrow \psi=\frac{\theta(1-\tau)}{\theta+\eta(1-\theta)} \\
\frac{\partial \gamma}{\partial \tau} & =\frac{v(1-\theta)}{\tau}-\frac{\eta(1-\theta)}{1-\tau-\psi}=0 \\
& \Rightarrow \tau=(1-\psi) v
\end{aligned}
$$

(Recall the assumption on constant returns to scale on accumulative factors $\eta+v=$ 1 and $\omega+\theta=1$ ) Combining the above two, we obtain

$$
\begin{aligned}
& \psi_{g \max }=\theta \\
& \tau_{g \max }=v \omega(\equiv v(\alpha-\theta \kappa))
\end{aligned}
$$

The optimal tax (growth maximizing) for public capital in the goods production sector $\psi_{g \max }$ is equal to the share of public capital in the sector, similar to that found by Barro (1990) and others, whereas the growth maximizing tax for public capital in the human capital accumulation sector $\tau_{g \text { max }}$ is equal to the share of public capital $v$ in that sector times the net output elasticity of human capital $\omega(\equiv \alpha-\theta \kappa)$. The reason that technological parameters from the goods production sector (such as $\alpha, \theta$ and $\kappa$ ) are related to $\tau_{g \text { max }}$ is becauso the tax used to finance the public factor in the human capital accumulation sector $\tau$ affects growth via its positive role in the accumulation of human capital, which in turn will be used for the final goods production.

With regard to the dynamic behavior of the economy for the case $\xi>0$, the following proposition is established:

Proposition 4 For $\xi>0$, the characteristic polynomial of the log-linearized system admits two positive roots, where only one root is stable. Given $G_{0}$ and $H_{0}$, there exists a unique solution to (3.24) and (3.25), which converges to (H, G). The path is monotonic and the steady state is saddle point stable.

Proof. The characteristic polynomial for the Jacobian matrix of tho lincar system is given by (3.28)

$$
P(\lambda)=\lambda^{2}-(\xi+1) \lambda+\xi \theta
$$

Generally, when $|1+\operatorname{Det}(A)|<|\operatorname{Tr}(A)|$, the steady state equilibrium is a saddle; there is one and only one real root which belongs to $(-1,1) .^{19}$ But, we have $|1+\xi \theta|<|1+\xi|$. Moreover, since the product of the roots, which is equal to the determinant of the Jacobian matrix $\left(\lambda_{1} \lambda_{2}=\xi \theta\right)$, is positive, both roots have the same sign and hence positive. Therefore, the characteristic roots are positive, real and only one root is within a unit circle, $\left(0<\lambda_{1}<1\right)$. Thus, given $G_{0}$ and $H_{0}$ (since both $G_{l}$ and $H_{t}$ are predetermined variables), the trajectory of the dynamic

\footnotetext{
${ }^{19}$ See De la Croix and Michel (2002), A.3.4.
} 
system is uniquely, locally, determined. The global analysis is established below using phase diagrams (Figures $3.1 \& 3.2$ ).

The graphical analysis can be done near the set of points where $\sigma_{t}^{2}=0$, for $\xi \neq 0$. Thus, from (3.20) and (3.21) we have

$$
\begin{aligned}
& H_{t+1}=B A\left(H_{t}\right)^{\xi+\omega}\left(G_{t}\right)^{\theta}(a(1-\tau-\psi))^{\eta} \tau^{v} \\
& G_{t+1}=\psi A\left(H_{t}\right)^{\omega}\left(G_{t}\right)^{\theta}
\end{aligned}
$$

To build the phase diagram, first we need to characterize the set of points where there is no change on the variables, for (3.32) and (3.33). That is, for (3.32) we solve $H_{t+1}=H_{t}$ for $G_{t}$ and for (3.33) we solve $G_{t+1}=G_{t}$ for $H_{t}$, to get

$$
\begin{aligned}
& G_{t}=\left(B A(a(1-\tau-\psi))^{\eta} \tau^{v}\right)^{\frac{1}{\omega}}\left(H_{t}\right)^{\frac{a \cdots \xi}{\theta}} \\
& H_{t}=(\psi A)^{\frac{-1}{\omega}}\left(G_{t}\right)^{\frac{1-\theta}{\omega}}=(\psi A)^{\frac{-1}{\omega}} G_{l}
\end{aligned}
$$

The slope of the phase line (3.34) depends on the relative values of $\theta$ and $\xi$. If $\theta>\xi$, then $0<\frac{\theta-\xi}{\theta}<1$ and hence $G_{t}$ is increasing at a decreasing rate in $H_{t}$, in space $\left(H_{t}, G_{t}\right)$ (Figure 3.1). If $\theta<\xi$, then $\frac{0-\xi}{\theta}<0$, and $G_{t}$ is decreasing at an increasing rate in $H_{t}$ (Figure 3.2). The curve (3.35) is easy to characterize. The phase line is a diagonal line, with slope $(\psi A)^{-\frac{1}{\omega}}$.

By combining (3.34) into (3.35), we obtain the equilibrium values where the two phase lines meet:

$$
\begin{aligned}
& G=\left(B A(a(1-\tau-\psi))^{\eta} \tau^{v}\right)^{\frac{1}{\xi}}(\psi A)^{\frac{\frac{\xi-0}{\omega \xi}}{\omega \xi}} \\
& H=\left(B A(a(1-\tau-\psi))^{\eta} \tau^{v}\right)^{\frac{1}{\xi}}(\psi A)^{\frac{-0}{\omega \xi}}
\end{aligned}
$$

Figures 3.1 and 3.2 capture the qualitative feature of the model. Notice that although the slopes of the phase lines for $H_{t}$ are different for the two cases, $\theta<\xi$ and $\theta>\xi)$, the steady state equilibrium loci $Z$ remains the same. Moreover, the saddle path has a negative slope.

Once again by using the log-linearized system, we can characterize the growth maximizing tax rates $\left(\psi_{g \max }^{*}\right.$ and $\tau_{g \text { max }}^{*}$ ), for the case $\xi>0$, near the steady state. The economy's growth rate near the steady state is defined, $\gamma=\ln Y_{t}-\ln Y$,

$$
\gamma=\omega\left(\ln H_{t}-\ln H\right)+\theta\left(\ln G_{t}-\ln G\right)
$$

Combining (3.25) and (3.38), we obtain

$$
\gamma=\ln G_{t+1}-\ln G
$$

Alternatively, from (3.24) and (3.38), we can get

$$
\ln H_{t+1}-\ln H=\xi\left(\ln H_{t}-\ln H\right)+\gamma
$$

From (3.38') and (3.38'), we see that there is an imbalance in the growth rate of macro-variables when $\xi>0$. While output $Y_{t}$ grows at the same rate with public 


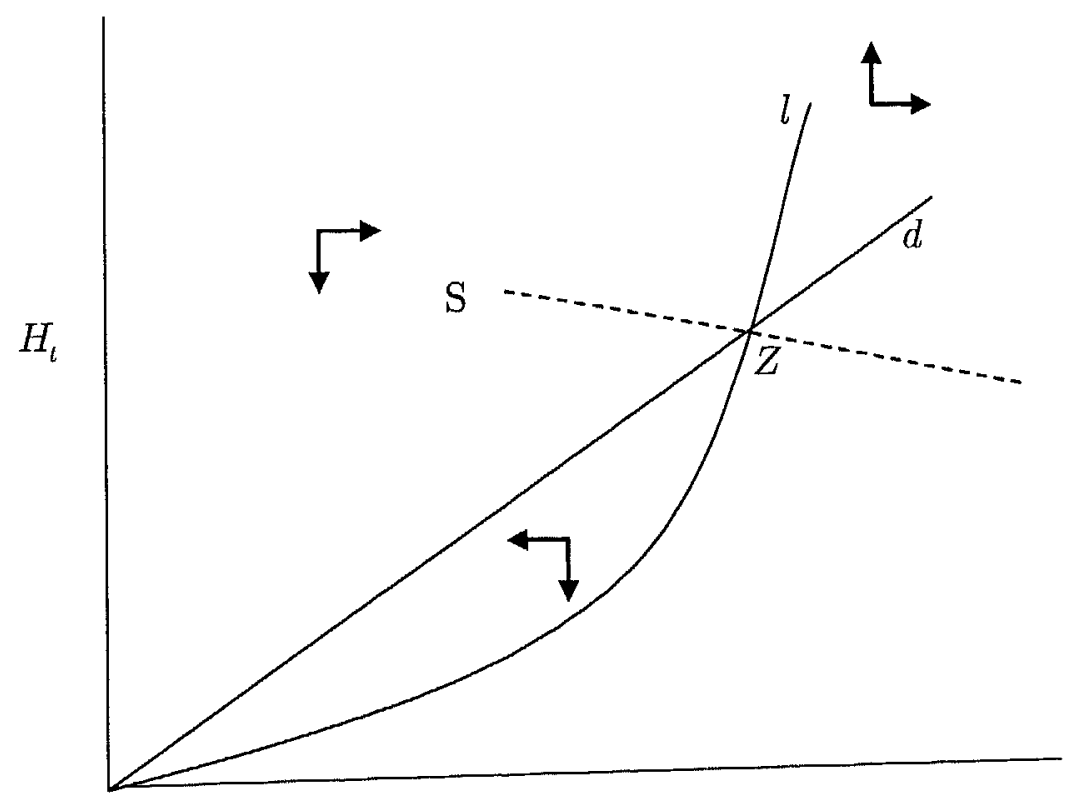

Figure 3.1: Phase diagram for a case $\theta>\xi$ or $0<\frac{0-\xi}{\theta}<1$. Together with the eigenvalues the steady state is globally stable.

capital $G_{t}$, human capital $H_{t}$ grows faster. To derive the growth maximizing taxes, we substitute (3.33) and (3.36) in (3.38'), to obtain,

$$
\gamma=\ln \psi A\left(H_{t}\right)^{\omega}\left(G_{t}\right)^{\theta}-\ln \left(B A(a(1-\tau-\psi))^{\eta} \tau^{v}\right)^{\frac{1}{\xi}}(\psi A)^{\frac{\xi-\theta}{\omega \xi}}
$$

By leaving out the superfluous variables and parameters, we can rewrite the last equation in an equivalent form

$$
\max _{\psi, \tau} \gamma=\frac{\theta(1-\xi)}{\omega \xi} \ln \psi-\frac{\eta}{\xi} \ln (1-\tau-\psi)-\frac{v}{\xi} \ln \tau
$$

Thus, the FOC is

$$
\frac{\partial \gamma}{\partial \psi}=\frac{\theta(1-\xi)}{\omega \xi} \frac{1}{\psi}+\frac{\eta}{(1-\tau-\psi) \xi}=0
$$

Then, solving for $\psi$, we get

$$
\psi=\frac{(1-\tau) \theta(1-\xi)}{\eta \omega+\theta(1-\xi)}
$$

We do the same for the growth maximizing tax in the human capital accumulation sector 


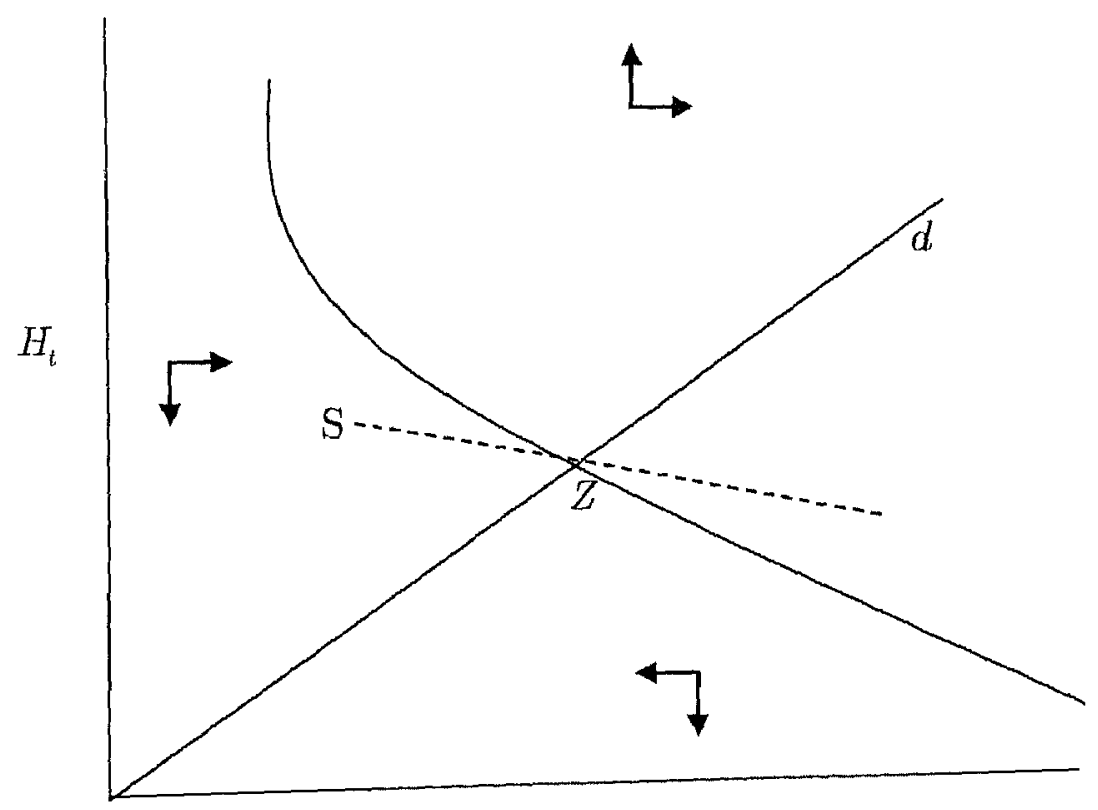

Figure 3.2: Phase diagram for a case $\theta<\xi$ or $\frac{\theta-\xi}{\theta}<0$. The result is the same with that of Fig. 3.1 except here the phase line for equation (3.34) is downward slopping.

$$
\begin{aligned}
\frac{\partial \gamma}{\partial \tau} & =\frac{\eta}{(1-\tau-\psi) \xi}-\frac{v}{\xi \tau}=0 \\
\tau & =(1-\psi) v
\end{aligned}
$$

Solving (3.39) and (3.40) simultaneously, we obtain the growth maximizing tax rate for public capital in the goods production sector, for the case $\xi>0$,

$$
\psi_{g \max }^{*}=\frac{\theta(1-\xi)}{1-\theta \xi)}
$$

and human capital accumulation sector

$$
\tau_{g \max }^{*}=\frac{\omega v}{1-\xi(1-\omega)}
$$

Note that when $\xi=0$, equations (3.41) and (3.42) are equivalent to equation (3.30) and (3.31).

The technological parameter from the goods production sector, $\omega$, is important for $\tau_{g \max }^{*}$, in the case of $\xi>0$. Moreover, when $\xi>0, \tau_{g \text { max }}^{*}$ is increasing at the net inter-generational spillover $\xi$ whereas $\psi_{g \max }^{*}$ is decreasing at it. 
The existence of (net) inter-generational spillover in the human capital accumulation sector, $\xi>0$, increases the role of human capital in the economy, which is reflected by a positive relation between $\tau_{g \max }^{*}$ and $\xi$. On the other hand $\psi_{g \text { max }}^{*}$ and $\xi$ are inversely related because both have a similar role in the economy a spillover effect. According to Barro and Sala-i-Martin (1992), the tax rate $\psi^{*}$ raises growth since the private rate of return on investment falls behind the social return, which, in turn, invites some forms of stimulus (such as public investment) to investment.

\subsection{Conclusion}

We studied public spending, in a two-sector economy populated with hetcrogeneous agents, as a factor that both onhances productivity and promotes accumulation of human capital. We showed that public investment in both the human capital accumulation and the goods production sectors have a net positive effect on long run growth while the magnitudes of optimal taxes (in terms of growth maximizing) on both sectors depend on whether there is inter-generational spillover in the human capital accumulation sector. We disclosed the effect of incomo inequality on the individual and aggregate production and accumulation of capital. That is, we captured the negative effect of income incquality on economic growth, when the credit market is imperfect and there aro diminishing roturns to private factors.

More importantly, we showed that certain infrastructure development in both sectors could improve income incequality dynamics, and hence could promote economic growth, once more, through an indirect effect of mitigating the negative influence of income inequality on economic growth. Therefore, wo conclude that under the appropriate conditions, in line with recent empirical findings (o.g., Jacoby 2000 and Calderón and Chong 2004), infrastructure could promoto pro-poor growth (i.e., loosely dofined as an increase in growth and reduction in income inequality simultancously). In particular, with public investment; (especially infrastructure service) which is pro-poor, not only would the economic pie grow but also a larger slice would pass to the poor. That makos a wise investment on productive public good an area that belongs to the win-win type of policies. 


\section{A Aggregation}

The logarithm of a variable with lognormal distribution will have a normal distribution (and vice versa). A normal distribution preserves under linear transformation (Greene 2003, appendix B). We use these facts and other important relations betwcen lognormal and normal distribution to study the evolution of income distribution in our model.

Since we assume a lognormal distribution for the individual initial human capital, $\ln h_{\iota} \sim N\left(\mu_{t}, \sigma_{\iota}^{2}\right)$, we have the following relation

$$
\begin{aligned}
\ln E\left[h_{t}\right] & =E\left[\ln h_{t}\right]+\frac{\sigma_{t}^{2}}{2} \\
& \Longleftrightarrow \quad\left[\ln h_{t}\right]=\ln E\left[h_{t}\right]-\frac{\sigma_{t}^{2}}{2} \equiv \ln H_{t}-\frac{\sigma_{t}^{2}}{2}
\end{aligned}
$$

where $H_{l} \equiv E\left(h_{t}\right)=\int_{0}^{1} h_{l} \Gamma_{l}(h) ; \Gamma_{l}(h)$ is the probability distribution of $h_{t}$.

We derive $E\left[\left(h_{l}\right)^{\omega}\right]=\left(H_{l}\right)^{\omega} \exp \left(\frac{\sigma_{l}^{2}}{2} \omega(\omega-1)\right)$, for instance, in equation (3.9), using the above facts. If $h_{t}$ is a lognormal distribution then $\left(h_{t}\right)^{\omega}$ is also a lognormal distribution, thus, according to (3.A.1),

$$
\begin{aligned}
\ln E\left[\left(h_{t}\right)^{\omega}\right] & =E\left[\ln \left(h_{t}\right)^{\omega}\right]+\frac{1}{2} \operatorname{var}\left[\ln \left(h_{t}\right)^{\omega}\right] \\
& =E\left[\omega \ln h_{t}\right]+\frac{1}{2} \operatorname{var}\left[\omega \ln h_{t}\right] \\
& =\omega\left(\ln H_{t}-\frac{\sigma_{t}^{2}}{2}\right)+\omega^{2} \frac{\sigma_{t}^{2}}{2} \\
& =\omega \ln H_{t}+\omega(\omega-1) \frac{\sigma_{t}^{2}}{2}
\end{aligned}
$$




$$
E\left[\left(h_{t}\right)^{\omega}\right]=\left(H_{t}\right)^{\omega} \exp \left(\frac{\sigma_{t}^{2}}{2} \omega(\omega-1)\right)
$$

To derive $E\left[\left(h_{t}\right)^{\xi+\omega \eta}\right]=\left(H_{l}\right)^{\xi+\omega \eta} \exp \left(\frac{\sigma_{t}^{2}}{2}(\xi+\omega \eta)(\xi+\omega \eta-1)\right)$ for equation (3.20) follow similar steps as above.

\section{B The Growth Rate}

For the case $\xi=0$, growth rate $\gamma_{t+1}$ can be derived as follows. Since

$$
\gamma_{t+1}=\ln Y_{t+1}-\ln Y_{t}
$$

From (3.9) and (3.B.1), we have

$$
\begin{aligned}
\gamma_{t+1}= & \omega\left(\ln H_{t+1}-\ln H_{t}\right)+\theta\left(\ln G_{t+1}-\ln G_{t}\right) \\
& +\frac{\left(\sigma_{t+1}^{2}-\sigma_{t}^{2}\right)}{2}(\omega(\omega-1))
\end{aligned}
$$

By substituting (3.20) and (3.21), and using (3.16'), in (3.B.2), we obtain

$$
\begin{aligned}
\gamma_{t+1}= & \omega\left(\begin{array}{c}
\ln B A \tau^{v}\left(H_{t}\right)^{\omega}\left(G_{t}\right)^{0}(a(1-\tau-\psi))^{\eta} \\
\exp \left(\frac{\sigma_{t}^{2}}{2} \omega \eta(\omega \eta-1)+v \omega(\omega-1)\right)-\ln H_{t}
\end{array}\right) \\
& +\theta\left(\ln \psi A\left(H_{t}\right)^{\omega}\left(G_{t}\right)^{\theta} \exp \left(\frac{\sigma_{t}^{2}}{2}(\omega(\omega-1))\right)-\ln G_{t}\right) \\
& +\frac{\sigma_{t}^{2}}{2}(\omega(\omega-1))\left((\omega \eta)^{2}-1\right)
\end{aligned}
$$

Alternatively,

$$
\begin{aligned}
\gamma_{t+1}= & \omega \ln B A \tau^{v}\left(H_{t}\right)^{\omega-1}\left(G_{t}\right)^{0}(a(1-\tau-\psi))^{\eta} \\
& +\theta \ln \psi A\left(H_{t}\right)^{\omega}\left(G_{t}\right)^{\theta-1}+\omega \frac{\sigma_{t}^{2}}{2}(\omega \eta(\omega \eta-1)+v \omega(\omega-1)) \\
& +\theta \frac{\sigma_{t}^{2}}{2}(\omega(\omega-1))+\frac{\sigma_{t}^{2}}{2}(\omega(\omega-1))\left((\omega \eta)^{2}-1\right)
\end{aligned}
$$
Then, simplifying (3.B.3), while applying $\omega+\theta=1$ and $v+\eta=1$ repeatedly, we
get equation (3.29)

$$
\gamma_{t+\mathbf{1}}=\omega \ln B a^{\eta} A^{\frac{1}{\omega}}+\omega \eta \ln (1-\tau-\psi)+\omega v \ln \tau+\theta \ln \psi+\Delta_{t}
$$

where 


$$
\begin{aligned}
\Delta_{\iota} & =\frac{\sigma_{t}^{2}}{2} \omega\left(\begin{array}{c}
\omega \eta(\omega \eta-1)+v \omega(\omega-1) \\
+\theta(\omega-1)+(\omega-1)\left((\omega \eta)^{2}-1\right)
\end{array}\right) \\
& =\frac{\sigma_{l}^{2}}{2} \omega\left(\begin{array}{c}
\omega \eta(\omega \eta-1)+\omega v(\omega-1) \\
\left.+(\omega-1)\left((\omega \eta)^{2}-\omega\right)\right)
\end{array}\right) \\
& =\frac{\sigma_{t}^{2}}{2} \omega\left(\begin{array}{c}
\omega \eta(\omega \eta-1)+ \\
\left.(\omega-1)\left((\omega \eta)^{2}+\omega v-\omega\right)\right)
\end{array}\right) \\
& =\frac{\sigma_{t}^{2}}{2} \omega\left(\begin{array}{c}
\omega \eta(\omega \eta-1)+ \\
(\omega-1) \omega \eta(\omega \eta-1))
\end{array}\right) \\
& =\frac{\sigma_{t}^{2}}{2} \omega((\omega \eta-1)(\omega \eta+(\omega-1) \omega \eta))
\end{aligned}
$$

or,

$$
\Delta_{\iota}=\frac{\sigma_{t}^{2}}{2} \omega^{3} \eta(\omega \eta-1)
$$


CHAPTER 4

Income Distribution and Elasticity of Substitution Between Public and

Private Capital

\subsection{Introduction}

Does public capital have effect in income distribution? Many argue informally that under certain conditions, in particular if it is targeted at lower income social groups, public capital may reduce inequality. ${ }^{1}$ On the other hand, it may aggravate it if only the rich fow have access to it. The question remains: how precisely is public capital linked to income distribution dynamics, especially, when it is provided on a non-discriminatory basis? Put differently, how does the income of two individuals who are heterogenous in terms of their initial wealth but similar othorwise, - one is rich and the other is poor - , be affected differently from using a public good in their production functions? In this chapter, we propose theoretical answers to these questions.

We begin with the general question of what determines income distribution dynamics, especially, when both private and public inputs are involved in production. As mentioned in Chapter 3, in the presence of imperfect credit market, income distribution cvolvos according to the individual private factor income shares. When there are differences in initial wealth among households who are otherwise similar, the evolution of income depends on the degree to which the individual households are able to exploit their relative initial advantage. The presence of public capital in production have no effecti on income distribution dynamics unless it alters the individual private factor shares. ${ }^{2}$

Hicks (1932) argues that the elasticity of substitution between productive factors is the only determinant factor for changes in relative factor shares. ${ }^{3}$ If the

\footnotetext{
'See, for instanco, The World Bank (1994), Songeo (2002) and Brenneman and Kerf (2002).

2'This is demonstrated by an example below. Refor, also, Chaptor 3.

${ }^{3}$ In the beginning of $1930 \mathrm{~s}$, Sir Jolnn Hicks (1932) marked an important advance on identifying the detorminant of the distribution of income. In his book, "On The Thoory of Wages, "Hicks dedientiod a clapter, (wili an appondix), in analyzing the resultant configuration of relative
} 
elasticity of substitution of a factor is greater than unity, then an increase in the supply of that factor more rapid than that of the others will increase its relative income share. Of course, if the elasticity of substitution of the factor is less than unity, then the relative share of the factor decreases. If it is equal to unity (the case of Cobb-Douglas), changes in supplies of factors do not have an effect on relative factors shares.

Hicks's argument provides useful hints for those seeking (informal) solutions to the above problems. Whether public capital has an effect on income distribution dynamics depends on its elasticity of substitution with regard to private capital. If the elasticity of substitution of public capital to private capital, in a production function, is greater than unity, an investment in public capital increases its relative income share, and decreases the private capital income share. Consequently, public capital would have a positive impact on income distribution dynamics as the change in the relative factor shares favors the poor. However, if its elasticity of substitution is less than unity, then the increase in public capital incrcases the private capital income share, and hence, it would aggravate income inequality. Of course, if the elasticity of substitution is unity, infrastructure investment is neutral to the distribution of income.

We formalize these ideas using a variable elasticity of substitution (VES) production function, which is analytically tractable, and, at the same time, allows some flexibility in the parameters. Note that for a change in factor supply in a production function to change the structure of income distribution, first of all, the elasticity of substitution must be different from unity. However, the standard Cobb-Douglas production function has no such property. In the Cobb-Douglas function, the elasticity of substitution is equal to unity and hence the factor shares are fixed. The analytical tractability of this popular production function comes with the cost of stringent restrictions on factor shares, which makes the production function unsuited for income distribution analysis. ${ }^{4}$

Analyzed within the framework of a Cobb-Douglas production function, in the presence of imperfect credit market, income distribution dynamics are wholly independent of the level or change of infrastructure inputs used in the production function. ${ }^{5}$ For example, suppose that the individual production function is the standard Cobb-Douglas function $y_{t}=A\left(k_{t}\right)^{\alpha}\left(X_{t}\right)^{0}$ where $k_{i}$ is privato capital and $X_{t}$ is public capital. Assume further that private capital, which initially differs among the individual households, is distributed lognormally, i.e., $\ln k_{t} \sim N\left(\mu_{l}, \sigma_{l}^{2}\right)$. Then, the individual saving at $t+1$ is $k_{t+1}=s y_{t}=s A\left(k_{t}\right)^{\alpha}\left(X_{t}\right)^{0}$, where $s$ is the exogenous saving rate. Income distribution at $t+1$ is given by, a long story cut short, $\operatorname{var}\left(\ln k_{t+1}\right)=\sigma_{t+1}^{2}=\alpha^{2} \sigma_{t}^{2}$. Therefore, in this economy, what matters

factor shares. He developed a very important concept, which is usoful till this time, what he called it "elasticity of substitutions."

${ }^{4}$ Although Solow (1957) argues a Cobb-Douglas production function may do fairly well in tracking observed changes in production, he states in a condition, "as long ts no doep distributive meaning is read into the rosults" Solow (1960).

${ }^{5}$ An exception to this case has been presented in Chapter 3. In the chapter, wo have modeled public capital, in a Gobb-Douglas function, as input whore its importince varies arnong liho individual households. In that case, in the absence of a perfect credit market, certain infrastinctiure development could relax resource constraints of the poor, and hence could bring a disproportional positive impact on the income of the poor. 
for income distribution dynamics is neither $X_{t}$ nor its output elasticity $\theta$ but the predetermined private capital incomo share $\alpha$.

Therefore, the production function that is used for the study is the less common generalized Cobb-Douglas production function, which is developed by Newman and Read (1961). The Newman-Road production function is a VES production function, bul for a certain value of its parameter it contains the standard CobbDouglas function. As is discussed above, the standard Cobb-Douglas production function $y_{l}=A\left(h_{t}\right)^{x x}\left(C_{t}\right)^{o}$ imposes strict restrictions on the factor shares and on tho olasticity of substitution. Particularly, the relative factor shares, - denoted by cr and $\theta$, are fixed and the elasticity of substitution is equal to unity. On the other laand, the constanl elasticity of substitution (CES) production function, which is the other standard production function, has a rolatively less stringent restrictions on the paranoter's but may not provide an analytical solution for the problems we pose due to difficulties that may arise during aggregation.

The Nowman-Rond genoralized Cobb-Douglas function is both flexible in the values of the parameters, and, is analytically tractable in regard to income distribution studics. Moreover, the production function reduces to the standard Cobb-Douglas funchion for a cortain value of its parameter. Newman and Road (1961) dovoloped the gencralizal Cobb-Douglas production function specifically to addrests the necod for less stringent restrictions on factor incomo sharos. Thoy consitler a case where the income share of a factor remains invariant to changes in that inpul itself, with the other factor held constant, but varios with changes of the other factor. In this catse, the production function becomes a VES production function where the factor shares vary alongside changes in factors supply.

In like next sextions, we develop an overlapping generation growth model in which initial woalth (as monsured by human capital) difters among the individual householeds. Acoss to coredit is limited and, the government provides productive public: resources used in production and accumulation. Whilo human capital is gemerated using inputs from both public and privato resources, the production technology is the shouclarel (cobb-1)ouglas function. Production of final goods also takes place: using both privale and public: reseurces, but the production function that is used this time is the genernliged Cobb-Douglas function of Nowman and Rond ( $19(j 1)$.

Within this setting, wo show lihat he distributional effecti of public investment depends on its elasticity of substitution to private capital. The olasticity of substitution betwen privale and public capital detormines the private factor share, which, in turn, determines the dynamics of income distribution. Therefore, in the model, a chunge in the supply of public capital affect income distribution dymanics althomgh no additiomal specifications are imposed to vary the benefits that acortwe from using the public input, annong differont housoholds. The effect of public: capital on the dymamies of income distribution could be negative or posilivo doponding on tho clesticity of substitution of public capital to private capital. If the olnsticity of substit,ulion is grouter (kesser) than unity, then public capjital allevintes (agyernvales) income incequality.

In the model, in the long run (in tho context of a growing economy), the olusticity of substitution lends loward unity and, honce, the goneralized Cobb- 
Douglas function reduces to the standard Cobb-Douglas function. ${ }^{6}$ Therefore, the model resembles the standard $A K$ type endogenous growth model in the long term. In a "representative agent" feature of the economy (with constant returns to scale), aggregate capital ratio and income growth converge to their steady state values.

The strand of literature related to the present study deals with the relationship between income inequality and public capital. Recent empirical findings provide evidence for the existence of a relationship between income inequality and infrastructure investment. For instance, Calderón and Servén (2004), Calderón and Chong (2004) and Lopez (2003) find that investment in public infrastructure (such as water, sanitary, electricity, etc.) has contributed towards the alleviation of income inequality, in addition to its role in economic growth. The World Bank (2003) and Estache (2003) argue infrastructure has a positive and disproportionate impact on growth. The OECD (2006) reports that "infrastructure is important for pro-poor growth".

Analytically, Ferreira (1995) studied the relationship between public capital and inequality in a model with quite a complex setup where the accessibility of higher production activity requires minimum lumpy investment and hence, if the credit market is missing, depends solely on initial wealth distribution. A steadystate distribution is derived with three social classes: lower class workers, middleclass and upper-class entrepreneurs. The provision of public investment below some level might make the "government dependable" middle-class disappear, the argument goes, creating less equality of opportunity, as well as lower growth. More recently, Garcra-Peñalosa and Turnovsky (2007) and Chatterjee (2008) studied tho distributional impact of different ways of financing public good. In these papers, leisure (combined with unequal distribution of initial private capital) is the source of the distribution dynamics. There would be a positive relationship between wealth and leisure, i.e., wealthier agents choose to supply less labor (where they have a lower marginal utility of wealth). This relationship provides a link between the individual's initial wealth (which is given) and the equilibrium distribution of income. However, in this chapter, labor is exogenous and the capital market is imperfect. The presence of imperfect credit market (combined with unequal distribution of initial human capital and a VES production function) is the source of income (and wealth) inequality dynamics.

Another strand of literature related to the present study deals with the dynamics of income inequality and growth within an imperfect credit markets (e.g. Loury 1981; Galor and Zeira 1993; Aghion and Bolton 1997; Aghion and Howitt 1998; Aghion, Caroli, and García-Peñalosa 1999; Benabou 2000 and 2002)). This literature, in general, shows that in the face of capital market imperfection, income inequality could have a negative effect on economic growth. However, this literature does not deal with the distributional effect of public capital.

This chapter is organized as follows. In section 4.2, we set up the model, with a brief discussion on the property of the Newman-Read production function.

\footnotetext{
6 This is based on obscrvations that are largely supported by empirical evidence. Empirical studies show that factor shares, particularly that of private inputs (such as labor and capital) show a large movement in the short run whereas they become stable in the long run (e.g., Revankar 1971; Acomoglu 2003).
} 
Section 4.3 deals with the interaction between income incquality dynamies and public capitinl. Section 4.4 discusses the long run (equilibrium) properties of the model, and scetion 4.5 conchludes.

\subsection{The Model}

\section{Fouseholds}

Assume a continumu of hotorogenous houscholds, in overlapping generations, $i \in$ $[0,1]$. Wach houscholel $i$ consists of an adult of gencration $t$ and a child of generation $t-t$. Population size is thus constant and normalized to be one. Let, at the boginning initial period, oach housohold $i$ of the initial generation be endowed with an initial human capital $h_{0}$ and a public infrastructure $G_{0}$ which is shared with others. Assume further that the distribution of initial human capital $\Gamma_{0}(h)$ tazkos a lognormal form, $\ln h_{0}{ }^{-} N\left(\mu_{0}, \sigma_{0}^{2}\right)$.

Agents care about their consumption level and their children education. When young, they necumulate: human capital using both privato and public resourcos. Once they become adults, they use their human capitan for final goods production. Government taxes income: with two fixed llat rate taxes, $\psi$ and $\tau$, in order to fintunce infrastructure and public oducation (denoted by $C_{t}$ and $M_{l}$ respectively). ${ }^{7}$

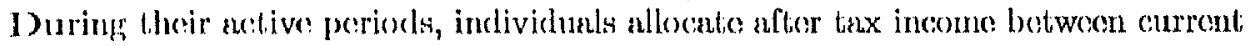
consinmplion ct sund saving e, that will bo used to educate their children. Tho lanterer is incorporaled in the individual utility function as the "joy of giving".

In a logerithmic: preforence, the individual utility function is dofined as

$$
\ln c_{b}+\beta \ln h_{t+1}
$$

subjoxt to

$$
c_{t} \mid c_{t}: \therefore(1-T-\bar{\psi}) y_{t}
$$

whore $\%$ is incomo of an individunl of generation $t$.

T'le: human capital acoumulntion function of the offspring $h_{t+1}$ is a function of public: $M_{1}$ and privale investment a. 'Tho accomulation function takes tho

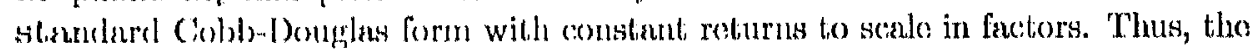
humatu enpital of an individunl of gonoration $t, 1.1$ is givon by

$$
h_{1,1} \cdot B\left(M_{1}\right)^{1 \cdot \eta}\left(a_{1}\right)^{\eta}
$$

\section{Tho Firm}

T'here is an inlinite: number of smull firms. Houscholds own tho firms. The capilal marked is thus imperfect." Production at the firm level occurs using both privato

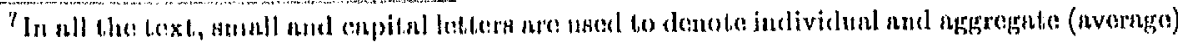
vorinbles, rewpestivaly

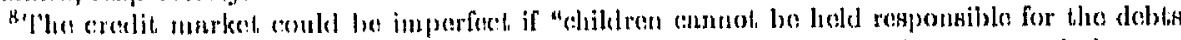

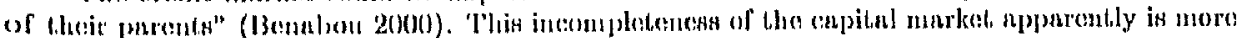

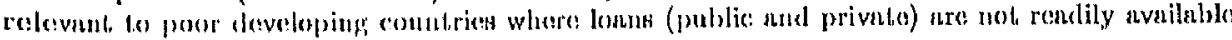

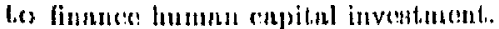


and public capital, in a Newman-Read production function setting. Thus, the incorne of an agent of generation $t$, in the Newman-Read production function, is defined as

$$
\begin{aligned}
y_{t} & =A\left(G_{t}\right)^{0}\left(h_{t}\right)^{\alpha} \exp \left(\lambda\left(H_{t}\right) \ln h_{t} \ln G_{t}\right) \\
& =A\left(G_{t}\right)^{0}\left(h_{t}\right)^{\alpha+\lambda\left(H_{t}\right) \ln G_{t}}
\end{aligned}
$$

where $y_{t}$ is the firm's output. $G_{t}$ is public capital and $H_{t}\left(\equiv \int_{0}^{1} h_{t} \Gamma\left(h_{t}\right)\right)$ is aggregate private capital. The generalized Cobb-Douglas production function imposes less stringent restrictions on factor shares than the usual Cobb-Douglas. The term $\alpha+\lambda\left(H_{t}\right) \ln G_{t}$ shows that the factor shares are endogenous where they vary alongside changes in factors supply.

For a well-behaved production function, we have the following conditions:

\section{Assumptions 4.2}

1. $0<\alpha+\lambda\left(H_{t}\right) \ln G_{t}, \theta+\lambda\left(H_{t}\right) \ln h_{t}<1 ; 0<\eta, \alpha, \theta<1$; and $A, B, h_{l}, G_{t}, H_{l}>$ 1 .

2. $\lim _{H_{t}, G_{t} \rightarrow \infty} \alpha+\lambda\left(H_{t}\right) \ln G_{t}=\alpha$

3. $\lim _{H_{t} \rightarrow \infty} \lambda\left(H_{t}\right)=0,\left|\lambda\left(H_{t}\right)\right|<1$ otherwise

The first assumption specifies sufficient conditions for a neoclassical production function (i.e., positive marginal productivity and concavity) ${ }^{9}$ while the second recovers the standard Cobb-Douglas production function from the VES production function in the long run. The former is more appropriate for analyzing long run trends where factor shares are stable. Whereas, the Newman-Read provides a better framework for analyzing observed fluctuations in factor shares in the short run. The third assumption sets $\left|\lambda\left(H_{t}\right)\right|$ as a decreasing function of the aggregate human capital. ${ }^{10}$ Thus, as $H_{t}$ grows large and $\lambda\left(H_{t}\right)$ tends to zero, in the context of economic development (see Revankar 1971), the elasticity of substitution (between public and private capital) approaches unity and the VES production function converges to Cobb-Douglas as a limit.

The sign of $\lambda\left(H_{t}\right)$ is a major determinant of the elasticity of substitution between public and private capital. The elasticity of substitution $\left(\delta_{t}\right)$ is defined: ${ }^{11}$

$$
\delta_{t}=\frac{\left\{\alpha+\lambda\left(H_{t}\right) \ln G_{t}\right)\left(\theta+\lambda\left(H_{t}\right) \ln h_{t}\right)}{\left(\alpha+\lambda\left(H_{l}\right) \ln G_{t}\right)\left(\theta+\lambda\left(H_{t}\right) \ln h_{t}\right)+\lambda\left(H_{t}\right)}
$$

\footnotetext{
${ }^{9}$ See Appendix 4.A.

${ }^{10} \mathrm{In}$ Newman and Read $(1961), \lambda\left(H_{t}\right)$ is a fixed parameter, i.c., $\lambda\left(H_{t}\right)=\lambda$.

${ }^{11}$ The original formula is presented by Hicks (1932), Appendix (iii),

$$
\delta_{t} \equiv \frac{\frac{\partial y_{t}}{\partial h_{t}} \frac{\partial y_{t}}{\partial G_{t}}}{y_{t} \frac{\partial y_{t}}{\partial G_{t} \partial h_{l}}}
$$
}


Therefore, from (4.5), the sign of $\lambda\left(H_{L}\right)$ determines whether the elasticity of substitution between private and public capital is greator or losser than, or, equal to unity:

$$
\text { If } \lambda\left(H_{l}\right) \lesseqgtr 0, \text { then } \delta_{l} \gtreqless 1
$$

Aggrogate Income The aggregate production function is derived, using (4.4),

$$
\begin{aligned}
Y_{l} & \int_{0}^{1} y_{l} \Gamma\left(h_{l}\right) \\
& \therefore A\left(C_{l}\right)^{0}\left(H_{l}\right)^{\left(\alpha+\lambda+\lambda\left(H_{l}\right) \ln \left(H_{l}\right)\right.} \exp \left(\frac{\sigma_{l}^{2}}{2} \Delta_{l}\right)
\end{aligned}
$$

whore $Y_{l}$ is aggeregnto (averago) income, and

$$
\Delta_{t}:\left(\alpha+\lambda\left(H_{t}\right) \ln C_{t}\right)\left(\alpha+\lambda\left(H_{t}\right) \ln C_{t} \cdots 1\right)
$$

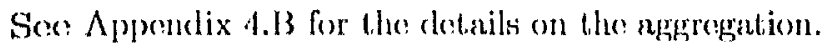

'The rolationship betwon incepuality and aggregate ontput is defined in equation (4.7). In the presenes of imperfect excelit, market, and, when the individunl pro-

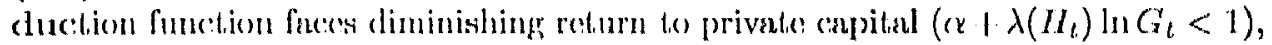
income incepulity is had for output and growth. ${ }^{2}$ ()n the olher hand, the privalos capilal share changing alongside chenges in public capilab, tho latter is an important cleterminant of the ine(puality growth relationship).

\section{Proportios of Nowman-Read}

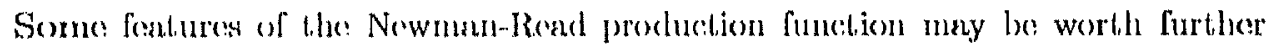

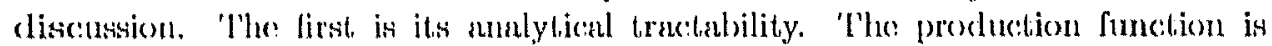
both lloxible in the values of ils partuneters and analy tically lanctable in regard to income distribution studies. 'The factor shoures are ondogenous where thoy vary alongsicke clanges in factors supply whilo changing the distribution of income. This is in sharp (ontrast, to the shandard (b)h-1)ouglus production function which impeses strict, restrictions on the factor shares and on the elasticity of substitution that mokes it ansuitable for distribulion mulysis. In particular, in tho GobbDouglas function, the factor shares are fixed and tho elasticity of substitiotion is oquel to mnity. Wherens, the constant celasticity of substibution production function has a relntively less stringent. restriction on the ponranoters but it has loss analytionl trenc:tubility.

Second, the Newmant- Round producdion funchion provides a bether framework in characterizing factor shares in the short run than the standard Cobb-Douglas

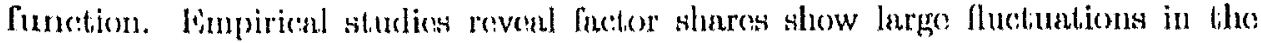

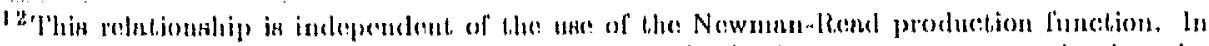

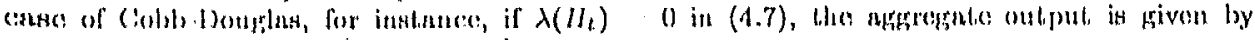

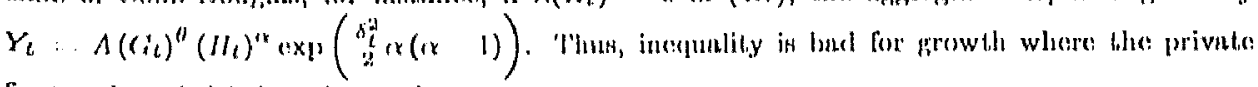

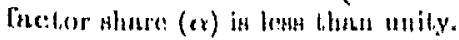


short run whereas they show no trend in the long run. For instance, Acomoglu (2003) demonstrates that the labor shares (for the United States and France) show a large movement in the short run whereas they remain stable in the long run. ${ }^{13}$ The Newman-Read generalized Cobb-Douglas production function contains a framework that provides a satisfactory approximation to this reality whereas the standard Cobb-Douglas function does not. The latter is morc appropriatc for analyzing long run trends.

Third, the Newman-Read production function is a general form of the standard Cobb-Douglas function that could reduce to it when necessary(e.g., when analyzing long run trends). If we set $\lambda\left(H_{t}\right)=0$ in (4.4), for instance, then it turns to be a Cobb-Douglas with the usual fixed factor shares.

Fourth, for certain values of its parameters, the Newman-Read production function satisfies important properties of the neoclassical production function. According to Solow (1957), a particular functional form adopted for a production function is a matter of no great consequence as far as it posses a positive partial derivative and the right curvature. Under Assumptions 4.2, the Newman-Read production function in 4.4 has a positive marginal productivity and a concave curvatures (See Appendix 4.A).

\section{Government}

Government budget is balanced at all times:

$$
\begin{aligned}
I_{t}^{g} & =\int_{0}^{1} y_{t} \psi \Gamma\left(h_{t}\right)=Y_{t} \psi \\
M_{t} & =\int_{0}^{1} y_{t} \tau \Gamma\left(h_{t}\right)=Y_{t} \tau
\end{aligned}
$$

Thus, the government collects fixed proportional taxes $\psi$ and $\tau$ on output $Y_{t}$ to finance public investment, while the accumulation of public capital in the goods production sector follows the rule,

$$
G_{t+1}=I_{t}^{g}+G_{t}\left(1-\varkappa^{g}\right)
$$

where $G_{t}, I_{t}^{g}$ and $\varkappa^{g}$ are the public capital stock, public investment and depreciation, respectively.

\section{Competitive Equilibrium}

According to the above description, an individual of generation $t$ solves the following problem, which is derived by substituting (4.2) and (4.3) into (4.1),

$$
\left.\underset{e_{t}}{\operatorname{Max}} \ln (1-\psi) y_{t}-e_{t}\right)+\beta \ln B\left(M_{t}\right)^{1-\eta}\left(e_{t}\right)^{\eta}
$$

taking as given, $\psi, \tau, I_{t}^{g} M_{t}$ and $G_{t}$.

\footnotetext{
${ }^{13}$ Accmoglu (2003) has plotted the labor share for the United States and Franco (figure 1 and 2) using the data from Piketty (2001) and Piketty and Sacz (2003), respectively.
} 
The first order condition gives

$$
c_{t}=a(1 \cdots \tau \cdot y) y_{\ell}
$$

whore $a \cdots \frac{f i \eta}{1+f \eta} ;(4.12)$ shows the agont's optimal saving as tho function of his income.

\subsection{Public Capital and Income Distribution}

From (1.3), (4.4), (4.7), (4.9) and (4.12), capital accumulation associated to aggents' optimal behevior is derived:

$$
\begin{aligned}
\ln h_{l+1} \ldots & \ln x+\theta \ln G_{l}+\left(\alpha+\lambda\left(H_{l}\right) \ln G_{l}\right)(1-\eta) \ln H_{t} \\
& +\eta\left(\alpha \mid \lambda\left(H_{l}\right) \ln \left(x_{t}\right) \ln h_{l}+\left(\frac{\sigma_{l}^{2}}{2} \Delta_{l}(1 \cdots \eta)\right)\right.
\end{aligned}
$$

whore $\chi \quad B A T^{1 \cdots "}(a(1 \cdots T \cdot \psi))^{\eta} \cdot 14$

From (4.13), the individual human capital aceumulation is detormined by the parent's human copital $h_{t}$, the aggregahe privato conpital $H_{t}$, public capital $G_{t}$, and the initial distribution of incomo $\sigma_{l}^{2}$. Under $\Lambda$ ssumption 4.2 , incomo inecpuality has thus a megative impanet on the individual capital accumulation.

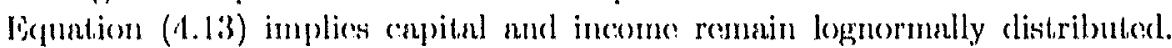
'Thus, if ln $h_{1}, N\left(\mu_{1}, \sigma \sigma_{i}^{2}\right)$, then

$$
\begin{aligned}
& \mu_{t+1} \quad \ln x\left|\theta \ln C_{t}\right|\left(\alpha+\lambda(\phi) \ln C_{n}\right) \mu_{t} \\
& 1 \frac{\sigma_{i}^{2}}{2}\left(\left(\begin{array}{ll}
1 & \eta
\end{array}\right)\left(\alpha+\lambda(\phi) \ln \left(x_{l}\right)^{2}\right)\right.
\end{aligned}
$$

and $^{15}$

$$
\sigma_{i \mid 1}^{2} \quad \eta^{2}\left(\alpha+\lambda(\phi) \ln \left(i_{i}\right)^{2} \sigma_{l}^{2}\right.
$$

where: $\phi \exp \left(\mu,+r_{i}^{2}\right)$.

From (4.14) nnd (4.15), moder Assumptions 4.2 (which implices $0<\alpha+\lambda(\phi)<$

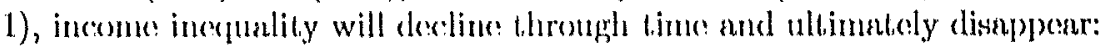

$$
\lim _{t \rightarrow \infty} \sigma^{2} \quad 0
$$

where $\sigma^{2}$ is equilibrium income distribution. ${ }^{16}$ 'The model thus cuptures the distributional impnet of public capital during the ocomony's transition to its long rum equilibrium.

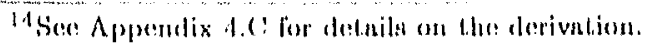

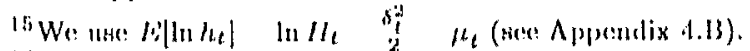

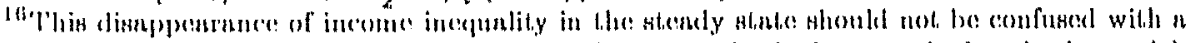

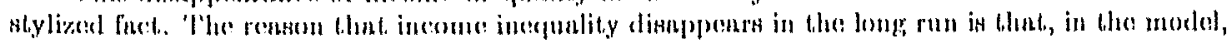

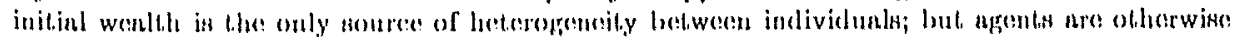

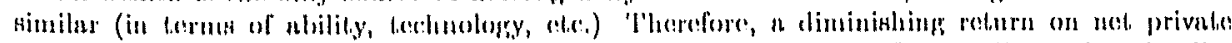

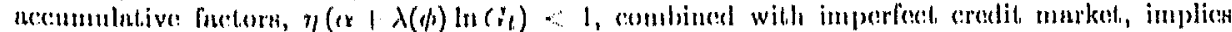

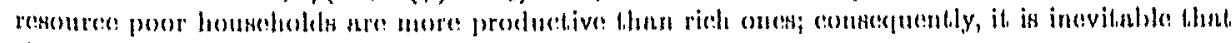
the poor will chleh up wilh the rich in the lonk rum.
} 
In (4.14) and (4.15), the impact of public capital on incomo incquality dynarnics is shown depending on the sign of $\lambda(\phi)$, and, henes, on the value of the dasticity of substitution between public and private capital $\left(\delta_{t}\right)$ (sec opuation $(4.6)$ ). Therofore, public capital could increase (decrease) incquality, if $\delta_{t}<1\left(\delta_{t}>1\right)$. But, if $\lambda(\phi)=0$, then $\delta_{t}=1$, the Cobb-Douglas case , it could be neutral. 'The intuition behind this result is simple. If $\delta_{l}<1$, a positive change in public capital incroasos the factor share of private capital, which ultimately disproportionally bonefit tho rich who hold much of the production resources. On the other hand, if $\delta_{l}>1$, the change in the productive public good supply docroases tho rolative income sharo of private capital. Consequently, income incquality decronses as poor houscholds are able to relax some of their resource constraints through factor substitution.

\subsection{Aggregate Capital, Growth, and Inequality}

The aggregate private capital accumulation function is obtained from aggrogating (4.13),

$$
\begin{aligned}
H_{t+1}= & B A T^{1-\eta}(a(1-\tau-\psi))^{\eta}\left(G_{l}\right)^{\eta}\left(H_{l}\right)^{\left(v_{t} \mid \lambda\left(H_{l}\right) \ln C_{l}\right.} \\
& \exp \left(\frac{\sigma_{l}^{2}}{2}\left(\left(\alpha+\lambda\left(H_{l}\right) \ln G_{l}\right)^{2} \eta(\eta \cdots 1) \cdot \mid \Delta_{l}\right)\right)
\end{aligned}
$$

${ }^{17}$ The difference equation for public capital is dorivod by substituting (4.8) into (4.10), using (4.7), and assuming a complete deprociation $\left(x^{\prime}, 1\right)$ :

$$
G_{t+1}=\psi A\left(G_{l}\right)^{0}\left(H_{l}\right)^{\left(\alpha+\lambda\left(H_{l}\right) \ln \left(a_{l}\right)\right.} \exp \left(\frac{\sigma_{l}^{2}}{2} \Delta_{l}\right)
$$

Rewriting (4.15), the dynamies of income distribution is given by

$$
\sigma_{t+1}^{2}=\eta^{2}\left(\alpha+\lambda\left(H_{l}\right) \ln G_{l}\right)^{2} \sigma_{l}^{2}
$$

Therefore, the three nonlinear difference equations $\left(\left(4.15^{\prime}\right),(4.16)\right.$ and $\left.(4.17)\right)$ determine the evolution of the economy.

The effect of inequality on capital accumulation is clomr from (4.16) and (4.17). In the presence of credit market imperfection, if lhore is diminishing marginal return to private capital $\left(0<\alpha+\lambda\left(H_{t}\right) \ln G_{t}<1\right)$, then incomo incquality is bad for capital accumulation.

The impact of inequality on income growth is shown bolow wilh the constant returns to scale Cobb-Douglas feature of the production function in (4.7). Applying $\alpha+\theta=1$ and Assumption 4.2 to equation (4.7), and thon using (4.15'), (4.16) and (4.17), we get the cconomy's growth rate $\left(\gamma_{\ell}\right)$

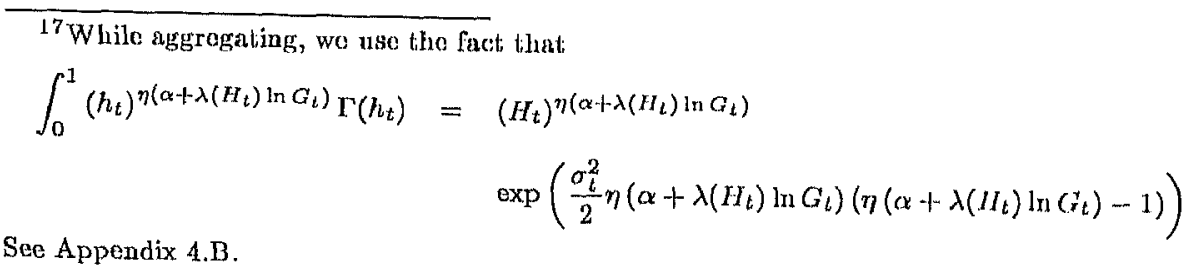




$$
\begin{aligned}
\gamma_{l}= & \ln \frac{Y_{l \mid 1}}{Y_{l}} \\
& \ln \Lambda\left(B a^{\eta}\right)^{\alpha}+\ln (1-\tau-\psi)^{\eta / x} \tau^{(1-\eta) \alpha \alpha} \psi^{1-\alpha} \\
& \left.+\frac{\sigma_{l}^{2}}{2}\left(\alpha^{3} \tau\right) \mid \eta(\alpha-1)\right]
\end{aligned}
$$

Whoroas, aggrogate capilal ralio is given by, (from 4.15 and 4.16 ),

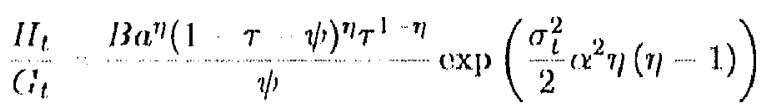

From (1.18), incepality is bad for growth if $\eta \alpha<1$. Noto that larger incequality can have onormous effect, on the coonomy coven offecting a negativo growth.

In a "representative agent" fonture of this ecomomy $\left(\sigma_{l}^{2} \cdots 0\right)$, with constant roluras lo scalc, aggeregale capilat ralio and income grow th converge to their steady stiato valuos:

$$
\gamma_{t} \quad \ln A\left(B a^{\eta}\right)^{\alpha} \mid \ln (1 \quad T \quad \psi)^{\eta / x} \tau^{(1-\eta) \times x} p^{1} \times \alpha
$$

and

$$
\left.\begin{array}{llll}
\| & \operatorname{lin} n^{n}(1 & \tau & \psi
\end{array}\right)^{n} \tau^{1-\eta}
$$

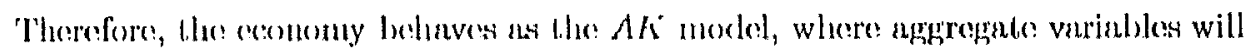
be in a bulanced growilh palli.

As of lihe literntures in public capital and exonomic: growth, both laxes relute posilively but tom-linengly to long torm growth. Irom (18), the grow th maximizing laxes, $y^{*}$ and $\gamma^{*}$, con bo compuled as

$$
\begin{array}{ll}
\psi^{*} & \left(\begin{array}{ll}
1 & \gamma
\end{array}\right) \\
\tau^{*} & \left(\begin{array}{ll}
1 & \eta
\end{array}\right)(x
\end{array}
$$

The: Barro-rule applies to the grow th maximizing tax mate for infrastructure

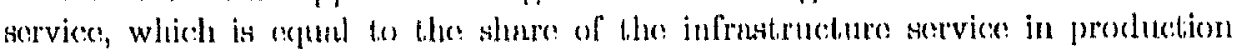

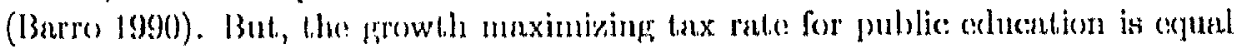

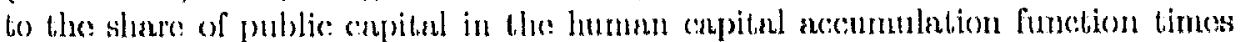
the output clatilicily of human capilal.

\subsection{Conchusion}

It is well understood that public: capital is importunt for economic growth. Bul,

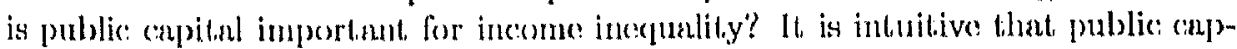
ital may reduce incepulity, particularly if it is bargoted at lower income groups. Nonetheless, public enpital may aggravalo income inecpunlity if only the rich fow have anesess to il. Bul, as we have shown here, evon if it is provided in a nonl-m cliscriminntory busis, publis: onpilab remains important for income distribution dym namics. 
The effect of public capital on income distribution is strongly linked to itss elasticity of substitution to private capital. If the olasticity of substitution of a. given type of public input is grcater than unity, then it might have a positive and disproportionate impact on the income of the poor. Particularly, if the crectit, market is imperfect, the provision of public capital onjoying high clasticity of substitution to private capital, even on a non-discriminatory basis, might halp the poor more by relaxing some of their resource constraints. This, in turn, results in an improvement in the distribution of income of the economy. 


\section{A Production Function}

"The first and the second derivalive of the production function in (4.4) are given by

$$
\begin{array}{ll}
\partial y_{l} & y_{l}\left(\alpha+\lambda\left(H_{l}\right) \ln G_{l}\right) \\
\partial h_{l} & h_{l} \\
\partial y_{l} & \left.\frac{y}{G_{l}}(\theta)+\lambda\left(H_{l}\right) \ln h_{l}\right) \\
\partial C_{r_{l}} & C_{r_{l}}
\end{array}
$$

and,

$$
\begin{aligned}
& \frac{\partial y_{l}}{2 h_{l} i \partial h_{l}} \quad\left(h_{l}\right)^{2}\left(\alpha+\lambda\left(H_{l}\right) \ln C_{l}\right)\left(\alpha+\lambda\left(H_{l}\right) \ln G_{l} \cdots 1\right)
\end{aligned}
$$

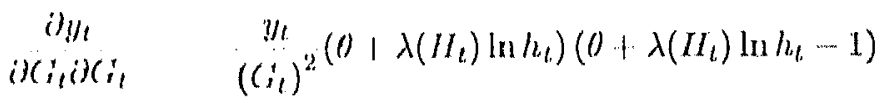

Under Astumplions 4.2, lhe Newman-Rend production function in (4.4) obeys the neoclassical rule in that it has a positive marginal produclivity and a concave curvatures with resipect to both private and public capilaal:

$$
\partial \partial_{l \ell}>0 ; \frac{\partial h_{l}}{\partial h_{r_{l}}}>0 ; \frac{\partial y_{l}}{\partial h_{l} \partial h_{l}}<0 \text { and } \frac{\partial y_{l}}{\partial G_{l} \partial G_{l}}<0
$$

\section{B Aggregation}

We derive cruation (4.7) using the following factiti. Based on the assumption of a leggnormal distribution for initial human capital $h_{0}$, i.c., $\ln h_{0}{ }^{\sim} N\left(\mu_{0}, \sigma_{0}^{2}\right)$, we have the following relations 


$$
\begin{aligned}
\ln E\left[h_{t}\right] & =E\left[\ln h_{t}\right]+\frac{\sigma_{t}^{2}}{2} \\
& \Longleftrightarrow E\left[\ln h_{t}\right]=\ln E\left[h_{t}\right]-\frac{\sigma_{t}^{2}}{2} \equiv \ln H_{t}-\frac{\sigma_{l}^{2}}{2}
\end{aligned}
$$

where $H_{t} \equiv E\left[h_{t}\right]=\int_{0}^{1} h_{t} \Gamma\left(h_{t}\right)$ and $Y_{t} \equiv E\left(y_{t}\right)=\int_{0}^{1}\left(y_{t}\right) \Gamma\left(h_{t}\right) . \quad \Gamma\left(h_{t}\right)$ is the distribution function of $h_{t}$.

Thus, aggregating (4.4) is

$$
\begin{aligned}
Y_{t} & =E\left[A\left(G_{t}\right)^{\theta}\left(h_{t}\right)^{\alpha+\lambda\left(H_{t}\right) \ln G_{t}}\right] \\
& =A\left(G_{t}\right)^{\theta} E\left[\left(h_{t}\right)^{\alpha+\lambda\left(H_{t}\right) \ln G_{t}}\right]
\end{aligned}
$$

If $h_{t}$ has a lognormal distribution, then $\left(h_{t}\right)^{\alpha+\lambda\left(H_{t}\right) \ln G_{t}}$ has also a lognormal distribution since $\left(\alpha+\lambda\left(H_{t}\right) \ln G_{t}\right) \ln h_{t}$ has a normal distribution.

Let $\omega \equiv \alpha+\lambda\left(H_{t}\right) \ln G_{t}$. Then, the expectation value in (4.B.2) is easily computed using (4.B.1)

$$
\begin{aligned}
\ln E\left[\left(h_{t}\right)^{\omega}\right] & =E\left[\ln \left(h_{t}\right)^{\omega}\right]+\frac{1}{2} \operatorname{var}\left[\ln \left(h_{t}\right)^{\omega}\right] \\
& =\omega\left(\ln H_{t}-\frac{\sigma_{t}^{2}}{2}\right)+\frac{\sigma_{t}^{2}}{2} \omega^{2} \\
& =\omega \ln H_{t}+\frac{\sigma_{t}^{2}}{2} \omega(\omega-1) \\
& =\ln \left(H_{t}\right)^{\omega} \exp \left(\frac{\sigma_{t}^{2}}{2} \omega(\omega-1)\right)
\end{aligned}
$$

Back substituting $\omega \equiv \alpha+\lambda\left(H_{t}\right) \ln G_{t}$, we obtain

where

$$
E\left[\left(h_{t}\right)^{\alpha+\lambda\left(H_{t}\right) \ln G_{t}}\right]=\left(H_{t}\right)^{\alpha+\lambda\left(H_{t}\right) \ln G_{\iota}} \exp \left(\frac{\sigma_{t}^{2}}{2} \Delta_{t}\right)
$$

$$
\Delta_{t} \equiv\left(\alpha+\lambda\left(H_{t}\right) \ln G_{t}\right)\left(\alpha+\lambda\left(H_{t}\right) \ln G_{t}-1\right)
$$

Substituting this into (4.B.2), we get equation (4.7)

$$
Y_{t}=A\left(G_{t}\right)^{\theta}\left(H_{t}\right)^{\alpha+\lambda\left(H_{t}\right) \ln G_{l}} \exp \left(\frac{\sigma_{t}^{2}}{2} \Delta_{t}\right)
$$

Follow similar steps for equation (4.16). 


\section{C Capital Dynamics}

To derive the inclividual human capital accumulation equation, substitute (4.9) and (4.12) into (4.3) to get

$$
h_{l, 11}=B\left(\tau Y_{l}\right)^{1-\eta}\left(a(1-\tau-\psi) y_{l}\right)^{\eta}
$$

T'hen, substilute (4.4) and (4.7) into the above equation,

$$
\begin{aligned}
& h_{\ell 11}=B\left(a(1-\tau-\psi) A\left(G_{l}\right)^{D}\right)^{\eta}\left(h_{l}\right)^{\eta\left(\alpha+\lambda\left(I I_{l}\right) \ln G_{l}\right)} \\
& \left(r A\left(G_{l}\right)^{\prime \prime}\left(H_{l}\right)^{\left(\alpha+\lambda\left(H_{l}\right) \ln \left(\theta_{t}\right)\right.} \exp \left(\frac{\sigma_{t}^{2}}{2} \Delta_{l}\right)\right)^{1-\eta} \\
& B\left(G_{t}\right)^{\theta(1 \cdots \eta)) \cdot \theta_{\eta}}\left(\tau A\left(H_{t}\right)^{\left(\alpha x+\lambda\left(H_{t}\right) \ln G_{t}\right)}\right)^{1-\eta \eta} \\
& \left(h_{l}\right)^{\eta\left(\left(x_{1}+\lambda\left(h_{l}\right) \ln \left(i_{l}\right)\right.\right.}\left(a_{l}(1-\tau-\psi) A\right)^{\eta} \exp \left(\frac{\sigma_{l}^{2}}{2} \Delta_{l}(1-\eta)\right)
\end{aligned}
$$

and rearrange it to gret

$$
\begin{aligned}
& h_{1+1} \quad B\left(\left(i_{1}\right)^{\prime \prime}\left(r A\left(H_{1}\right)^{\left(r \times 1 \lambda_{1} \ln \left(i_{1}\right)\right.}\right)^{1 \cdots \eta}\right.
\end{aligned}
$$

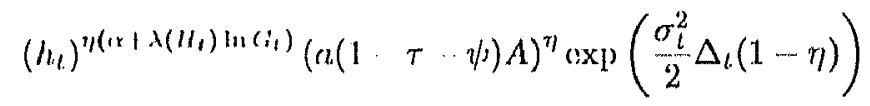

or

$$
\begin{aligned}
& \ln h_{t \mid 1} \quad \ln x+0 \ln G_{l}+\left(\alpha+\lambda\left(H_{l}\right) \ln G_{l}\right)(1-\eta) \ln H_{l} \\
& \eta \eta\left(\alpha x \mid \lambda\left(H_{l}\right) \ln G_{l}\right) \ln h_{t}+\left(\frac{\sigma_{l}^{2}}{2} \Delta_{l}(1-\eta)\right)
\end{aligned}
$$

where $\left.x \quad B A T^{1} "(n(1) \quad r \quad \psi())\right)^{n}$. 
CHAPTER 5

Public Capital and Economic Growth: An Application to Developing

Countries

\subsection{Introduction}

The gap separating the world's rich and poor countries remains startling. Jones (2002) estimates per-capita income in the United States is over forly times higher than in Ethiopia, meaning a typical individual in Ethiopia or Uganda has to work a month and a half to earn what his countorpart in tho US earns in a day. Differences in economic growth rates compounded over long periods of time account for these differences in their entirety. Fortumately, endogenous growth theory suggests there is something we can do about it.

One of the most important contributions of the new growth theory is the new insight it has brought into the role of fiscal policy in long run growth. Over the past decade a substantial number of empirical and theoretical studies have been dedicated to examining the effects of fiscal policy on economic growth, starting with the groundbreaking theoretical and empirical work of Barro (1990) and Aschauer (1989), respectively. The key insight is that public investment in the areas of infrastructure and human capital development plays an important role in promoting output and long run growth. Public capital, and in particular infrastructure, generates a sustained increase in cconomic growth by enhancing the total productivity of inputs and reducing production and transaction costs.

In this chapter, we study the relationship between economic growth and public capital for a set of developing countries. The research comprises of an analysis of a panel data from a large set of Sub-Saharan African (SSA) countries. We use the panel data from SSA countries to determine the elasticity of output with respect to the flow of public capital and, more importantly, the relationship between public investment and growth. We analyze the data extensively using both linear and nonlinear models. We apply dynamic panel data techniques in estimating the linear model. We estimate the nonlinear model using a model, which is developed in this chapter. Our main objectives are, first, to analyze the importance of public 
investment to economic growth and output, taking the case of SSA countries, and second, to measure the gap between the growth-maximizing and the actually existing levels of public capital. We find the latter to be enormously important, particularly from a policy perspective.

The study has a number of advantages. First, though the literature on the impact of public capital on economic growth has grown voluminous in the past few decades, only very few studies have addressed Africa. Estache et al. (2005) argue that only a handful of papers study public capital and economic growth quantitatively. Ayogu (2007) points out a major shortcoming of the literature in Africa is its thinness. It might be also worth mentioning that this literature applies linear models assuming (implicitly) a linear relationship between public capital and economic growth in the region. ${ }^{1}$

However, the relationship between public capital and economic growth might be nonlinear, as has been demonstrated, later in this chapter, and also, in many analytical studies, including Barro (1990), Glomm and Ravikumar (1997) and Aschauer (2000a). Nevertheless, most previous studies implicitly "assume a linear relationship between public capital and output and so are incapable of estimating the growth-maximizing level of public capital spending"(Aschauer 1998, p.8).

Second, there has been little effort (with the exception of Miller and Tsoukis 2001) made to ascertain the growth-maximizing level of public capital and to compare it with the actually existing public investment in developing countries. Miller and Tsoukis (2001) studied the optimality of public capital for set of low and middle income countries. They appealed to a parameterization technique in estimating the growth maximizing public investment. In this study, we employ various nonlinear estimation techniques in determining the growth maximizing public investment for set of developing African countries.

In general, only a few studies estimated the growth maximizing public capital and compared it to the actual level (Sturm et al. 1998, and Romp and de Haan 2007). For instance, Aschauer (2000a) and Kamps (2005) studied the optimality of public capital in the United States and European countries, respectively, based on the nonlinear relationship between public capital and growth. As noted by Romp and de Haan (2005), however, the relevant question for policy is not whether public capital is productive, that is, whether or not a unit increment on public capital stock increases output or growth, but whether public capital is overall growth enhancing. The reason is that public capital has a negative as well as positive effect on the economy. Even though an adequate and efficient supply of public capital promotes output and growth, the distortions resulting from financing it may have an adverse effect as well, such as crowding-out of private capital. ${ }^{2}$

Third, the study applies more robust techniques in determining the nonlinear relationship between public capital and growth, and in estimating the public capital elasticity of output in comparison to previous studies. Studies that estimate the elasticity of output of public capital in nonlinear models usually appeal

\footnotetext{
'We make a brief discussion of the literature in the next section.

${ }^{2}$ For instance, an enhanced transportation system (such as roads and highways) improves the efficioncy of trucks. But, if the public capital is financed by overly burdensome taxes on private return, the accumulation of these trucks will be negatively affected. If there is no largo private factors that take advantage of the infrastructure development, then there would be no change on outptit, as roads do not produce by themselves (Aschaner 1998).
} 
to a parametrization (e.g. Aschauer 2000a and Miller and Tsoukis 2001) or a nonlinear least square (NLS) technique without including fixed effects (FE) (e.g., Kamps 2005). In this study, parameter estimation for the output elasticity of public capital will be done using various nonlinear methods including country-specific effects. We use nonlinear seemingly unrelated regression (SUR), nonlinear least square (NLS), and weighted nonlinear least square (WNLS) methods, in which we include individual countries' $\mathrm{FE} .^{3}$

We organize this chapter as follows. In Section 5.2 , we provide a review of the empirical and theoretical literature on public capital and economic growth. Section 5.3 presents the theoretical model used for the empirical research. Section 5.4 lays out the methodology, and section 5.5 concludes.

\subsection{Literature Review}

Recent years have witnessed a substantial research effort focused on clarifying the relationship between public capital and economic growth, both analytically and empirically. Studies focused on the analytical level treat public capital as either a flow or a stock. Barro (1990), Turnovsky and Fisher (1995), Turnovsky (2000) and Agénor (2008), for instance, model public investment as a flow. By contrast, Futagami et al. (1993), Cassou and Lansing (1998), Rioja (1999), Turnovsky (1997; 2004), Ziesemer $(1990 ; 1995)$ among others treat public capital as a stock.

The distinction between the two is subtle but important. Although many economists argue that it is the stock of public capital (such as roads, railways, airports, etc.) that is important, and most of the empirical rescarch has been conducted accordingly, there are also findings that suggest that the flow of public: investment (c.g., government expenditures for public administration, policing- and maintaining law and order-, and for maintenance of infrastructure) is also productive. For instance, Easterly and Rebolo (1993) find that public expenditure on transport and communication significantly raises growth.

In general, empirical studies on the relationship between public capital and growth revolve around two related questions. First, does an increase in public capital increase output? Second, does additional public investment foster economic growth? Of course, an affirmative answer for the first question is a prerequisite for the later question to be relevant at all. Moreover, tho possibility of finding a longrun impact on growth from public capital cnormously depends on the type of model selected, whether it is a neoclassical exogenous growth model or an endogenous growth model.

In addressing the first question, Aschauer (1989), in an influential work, claims public capital stock has a large impact on output. Using annual data for the United States, he estimates the public capital clasticity of output at 0.39 . This makes the estimate much higher than that of private capital, which is about 0.3 . Aschaver's

\footnotetext{
${ }^{3}$ Estimation of nonlinear dynamic: punel nodols with litis is important considering that NISS

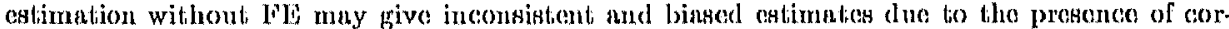
relation botween the lagged depoudent variable and bhe orror term. This correlation does not vanish as the number of individuals or time poriods incrense. ITowever, estimalions with Fe the unbiusod and consistonl; for larga timo dynumic pmol (13ond 2002).
} 
findings were met with disbelief (Glomm and Ravikumar 1997). Economists knew for a long time that public capital is an important input in production (See, for instance, Arrow and Kurz 1970), however, they do not expect its impact to be higher than that of private capital's. A series of studies following up on Aschauer's have came up with a wide range of estimates. For instance, Kocherlakota and Yi (1996) estimated the marginal product of public capital to be higher than private capital. Munnell (1990) estimated the public capital elasticity of output for the United Statesand at about 0.3. Whereas, Holtz-Eakin (1994) estimated the marginal product of public capital as approximately equal to zero. ${ }^{4}$ "The wide range of estimates makes the results of these older studies almost useless from a policy perspective" (Romp and de Haan 2007, p. 8).

However, recently a consensus has arisen among researchers on the proposition that the output and growth contribution of infrastructure is significant." Romp and de Haan (2007) surveyed a large number of recent studies and concluded that there is currently more consensus than in the past, in the positive role of public: capital in economic growth. But, this impact seems to be lower than previously thought. Some of the results have been reported by Canning (1999) using panel data for a large number of countries and Demetriades and Mamuneas (2000) and Kamps (2005) using Organization for Economic Cooperation and Development (OECD) countries. Calderon and Servén (2004) using a Cobb-Douglas production function and a large panel data set obtained results showing a significant and positive contribution to output. Aschauer (2000b), using a data set covering $46 \mathrm{low}$ and middle income countries, estimated a $10 \%$ increase in public capital increases output by $2.9 \%$. Dessus and Herrera (2000), using a sample of 30 developing countries, found growth is positively affected by the stock of infrastructure assets.

Many studies related to African countries also show the importance of public capital to output and economic growth. ${ }^{6}$ For instance, Fedderke et al. (2006) report for South Africa, spanning the years 1875-2001, a significant finding of an infrastructure impact on growth. Ayogu (1999) finds a strong relationship between infrastructure and output using regional panel data from Nigeria. Calderon and Servén (2008), using a large panel data set over 100 countries, find a positive significant relation between infrastructure assets and growth in SSA. Their methodology is that constructing and interacting "synthetic indices" of infrastructure with a dummy for SSA, and adding them to regression in a linear manner. ${ }^{7}$ Estache et al. (2005), applying an augmented Solow model with infrastructure variables on 41 SSA countries, and using pooled ordinary least square (OLS), find all infrastructure variables (except sanitation) are significantly important to output. $^{8}$ Boopen (2006) also reports a positive impact of transport infrastructure on economic growth for SSA countries. He estimated dynamic panel model based on Arellano and Bond (1991) Difference GMM method.

\footnotetext{
${ }^{4}$ See Gramlich (1994) for a survey of earlier literature.

${ }^{5}$ For recent surveys of the literature in public capital and growth, see Romp and do Han (2007), Ayogu (2007) and Straub (2007).

${ }^{6}$ See Ayogu (2007) for a survey of the literature.

${ }^{7}$ See also Calderon (2009) for a similar study.

${ }^{8}$ However, their methodology (pooled OLS), at least, faces a risk of potential endogeneity of the regressors even for stock variables.
} 
However, the Difference GMM estimator would have problems if the time series are persistent. Unfortunately, output is a highly persistent series. In this chapter, we apply both Difference and System GMM techniques in estimating a linear model in the panel data from SSA countries. We also estimate a nonlinear model of public capital and growth, which we develop in the theoretical section of the chapter. As noted earlier, the studies (related to Africa) estimate linear models of public capital and growth implicitly assuming a linear relationship between public capital and growth in the region. Studies conducted in other parts of the world, however, indicate a nonlinear relationship between public capital and growth, and this has, in turn, important policy implication.

The conventional way of studying the relationship between public capital and economic growth is by examining the effect of additional public capital, ceteris paribus. However, a handful of economists study the net effect of extra public capital given that investing in public capital diverts resources from the private sector (Sturm et al. (1998) and Romp and de Haan (2005; 2007)). For instance, Aschauer (2000a) has developed a theoretical model which captures the nonlinear relationship between the public-private capital ratio and economic growth. Using a United States data set, he found the actual levels were below the growth-maximizing level. Kamps (2005) used Aschauer's methodology for European countries, and found that there is no lack of public capital in most "old" European countries. Miller and Tsoukis (2001) studied for middle and low income countries and concluded that the actual level of public capital is suboptimal in these countries. While we study the level of public capital that maximizes growth for countries of SSA, at the same time we complement this literature through employing more robust nonlinear estimation techniques (such as estimating NLS including individual countries' $\mathrm{FE}$ ).

Why does public capital matter for conomic growth? Various potential channels are mentioned in the literature. The most commonly cited channels involve infrastructure's role in onhancing tho productivity and complementing the accumulation of private capital. Public cupital increases the productivity of private inputs and hence affects output and growth. Putting it differently, it reduces private production and transaction costs. By applying a cost-function model to the United States manufacturing data, Cohen and Paul (2004) argue spillover from public infrastructure have cost savings, and thoreby productivity effects on private enterprises. Teruel and Kuroda (2005) find public; infrastructure reduces production cost in agriculture, by applying a translog cost-based model to the Philippine regional agricultural data.

The magnitude of the productivity increase attributable to public capital depends on a variety of factors, such as the initial level of the public capital stock, efficiency and congestion offects. Hulton (1996) presents empirical evidence which suggests the efficioncy of public capital is more important than the size of the stock. Agénor and Moreno-Dodson (2006) argue that infrastructure may have a particularly large effect in countrics where the initial stock of infrastructure is low. Demetriades and Mamuncas (2000) show that countries with small public capital stocks have the highest marginal productivity return on public capital.

Public capital could also boost conomic growth by stimulating private capital formation. The existence of developed infrastructure may attract private and 
foreign investment. Through expansion of infrastructure- building new roads, dams, bridges, power plants and networks- developing countries in particular pave the way for an influx of trade and foreign direct investment that are important channels of knowledge spillovers.

Other indirect channels through which public capital could affect economic growth include reducing adjustment costs, increasing the durability of public capital, and an aiding education and health. ${ }^{9}$

\subsection{Theoretical Description}

Whether or not public capital is found to have a long-run growth effect will very much depend on the type of model employed. In neoclassical growth models, exogenous technical progress is the source of long-run growth, leaving no roorn for policy decisions to have long term effects on economic growth. Therefore, a shock to the infrastructure stock will have a transitory effect on the economy, affecting only the level of (long run) output. By contrast, in endogenous growth models, policies may have a lasting impact on growth rates. Hence, in these models, a shock on public capital may influence both the long-run growth rate and the output level.

In this section, we develop a simple endogenous growth model in an overlapping generation framework where agents live two periods. The model will be used as the basis for the empirical analysis in a later section of the chapter. In the model, the capital stock is treated as long lasting and geometrically depreciating in contrast to the standard linearly depreciating. That is, in both private and public capital, current investment adds to the stock each period but at the same time the stock depreciates at a constant geometric rate. The specification is also used in a study by Cassou and Lansing (1998) who model public capital stock in an infinitoly lived agents economy, in which a benevolent government solves a dynamic vorsion of the Ramsey-type optimal tax problem. In contrast, we model it in a finite two-period-lived household economy. Our model explicitly captures the nonlinear relationship between both the flow and the stock of public capital and economic growth, ${ }^{10}$ which can be readily estimated using standard econometrics methods.

The model is presented in detail in the box and the appendix while here we discuss some of the important results. Theoretically, public capital is believed to have a nonlinear relationship with growth. The reason is that, first, public capital has both positive and negative economic consequences. That is, as well as promoting output and growth by complementing and enhancing the productivity of private inputs, it also discourages private capital accumulation through diversion of resources (distortionary taxation). Second, as of any capital, public capital also faces diminishing marginal returns to output. Therefore, when the initial public capital stock is particularly low, the return is higher. In that case, the positive effect dominates the adverse effect. But if there is too much public capital at tho outset, the positive effect will be overwhelmed by the negative effect.

\footnotetext{
${ }^{9}$ See Agénor and Moreno-Dodson (2006) for a detailed discussion.

${ }^{10} \mathrm{Much}$ of the theoretical literature in growth and public capitnl model public capital cither a flow (e.g., Barro 1990) or stock variable (e.g., a Futagamai et al.1993). Refer tho distussion in Section 5.2 .
} 
In the model presented in the box and Appendix 5.A, equation (5.14) captures the nonlinear relationship between public capital and economic growth. This is shown in the third term, where the public-private capital stock ratio $\frac{G}{k}$ is nonlinearly related to growth. Equation (5.15) shows the growth-maximizing publicprivate capital stock ratio $\frac{G^{*}}{k}$, which is determined by the elasticity of output $\alpha$, and other parameters, such as the depreciation rate $\delta$, the technology parameters $B$, and the discount factor $\beta$. The optimal flow of public investment (the growthmaximizing government expenditure) is given by equation (5.17), which is equal to the public capital elasticity of output $\alpha$. 
Box: A Public Capital and Growth Model

\section{Consumers}

We use an overlapping generation model with a representative agent, of logarithm preferences. When young, during the first period of life, individuals are endowed with a unit labor which they supply to firms inelastically. Their income is equal to the wage income $w_{t}$. Government taxes this income with a fixed flat rate tax $\psi$ in order to finance public capital. The individuals allocate after tax income between current consumption $c_{t}$ and saving $s_{t}^{k}$. When they are old, they consume what they have saved in the previous period plus the after tax return from saving, $c_{t+1}$.

$$
\begin{aligned}
& u\left(c_{t}, c_{t+1}\right)=\ln c_{t}+\beta \ln c_{t+1} \\
c_{t}+s_{t}^{k}= & (1-\psi) w_{t} \\
c_{t+1}= & \left(1+r_{t}(1-\psi)\right) s_{t}^{k}
\end{aligned}
$$

where $r_{t}$ is the interest rate. Private capital is accumulated according to the following equation,

$$
k_{t+1}=B_{0} k_{t}^{1-\delta}\left(s_{t}^{k}\right)^{\delta}
$$

where $k_{t}$ is the private capital stock.

\section{Government}

The government budget is always balanced and given by,

$$
s_{t}^{g}=y_{t} \psi
$$

where $s_{t}^{g}$ and $y_{t}$, are public investment and aggregate income, respectively. We normalize the population size to one $(L=1)$ so that aggregate values are equal to average values. The public capital accumulation equation is

$$
G_{t+1}=B_{1} G_{t}^{\mathrm{I}-\delta}\left(s_{t}^{g}\right)^{\delta}
$$

where, $G_{t}$ and $\delta$ are the stock of public capital and depreciation, respectively. Here, we model public capital as a long lasting. In both private and public capital, current investment adds to the stocks each period. The relationship between the new investment and the next period capital stock is governed by the parameters $\delta \in(0,1]$ and $\left\{B_{0}, B_{1}\right\}>0$. For the case $\delta=1$ and $\left\{B_{0}, B_{1}\right\}=1$, capital depreciates fully as in some models which assume a full and linear depreciation of capital (e.g., $k_{t+1}=(1-\delta) k_{t}+s_{t}^{k}$ ). 


\section{Firms}

The production function is a Cobb-Douglas function, as in Glomm and Ravikumar (1997). Thus, the production function, for the final good $y_{t}$, of individual firm is

$$
y_{t}=A_{t} G_{t}^{\alpha} k_{t}^{1-\alpha}
$$

The firm's problem is a static one. At any point in time, the firm maximizes profit within a competitive economy setting, taking prices and public capital as given:

$$
\underset{k}{\operatorname{Max} \pi}=A_{t} G_{t}^{\alpha x} k_{t}^{1-\alpha}-w_{t}-r_{t} k_{t}
$$

The first order condition for profit maximization is $r_{t}=(1-\alpha) A_{t} G_{t}^{\alpha} k_{t}^{-\alpha}$. In addition, the zero-profit condition in the competitive economy leads to the wage rate,

$$
w_{l}=\alpha A_{l} G_{t}^{\alpha} k_{l}^{1-\alpha}
$$

\section{Competitive Equilibrium}

According to the above descriptions, the representative household of poriod $t$ solves the following problem, obtained by substituting (5.2) and (5.3) into (5.1),

$$
\underset{s_{i}^{k}}{\operatorname{Max}} \ln \left((1-\psi) w_{\iota}-s_{i}^{k}\right)+\beta \ln \left(\left(1+r_{i}\right) s_{t}^{k}\right)
$$

taking prices and public capital variables $\left(\psi, r_{t}, w_{t}\right.$ and $\left.G_{l}\right)$ as given. The optimization yields,

$$
s_{t}^{k}=\frac{(1-\psi)\left(w_{t}\right) \beta}{1+\beta}
$$

Equation (5.11) shows the agent's optimal saving as the function of her wage income. 


\section{Growth}

In the balanced growth path, the public-private capital stock ratio is constant, and is given by (see Appendix 5.A for details on the derivation),

$$
\frac{G}{k}=\left(\frac{B_{1}}{B_{0}}\right)^{\frac{1}{\delta}} \frac{1+\beta}{\beta \alpha} \frac{\psi}{1-\psi}
$$

In other words, the public and private capital stock grow at the same rate, i.e., $\gamma=\ln \frac{G_{t+1}}{G_{t}}=\ln \frac{k_{t+1}}{k_{t}}$. This is also the rate of growth of the economy (see Appendix 5.A),

$$
\gamma=\ln B_{0}+\delta \ln A+\delta \ln \frac{\alpha \beta}{1+\beta}+\delta \ln (1-\psi)+\delta \alpha \ln \frac{G}{k}
$$

Solving for $\psi$ of (5.12) and substituting the result into (5.13),

$$
\gamma=\ln B_{0}+\delta \ln A+\delta \ln \frac{\beta \alpha}{1+\beta}+\delta \ln \left[\frac{\left(\frac{G}{k}\right)^{\alpha}}{1+\frac{G}{k} \frac{\beta \alpha}{1+\beta}\left(\frac{B_{0}}{B_{1}}\right)^{\frac{1}{\delta}}}\right]
$$

Equation (5.14) represents the growth rate of the economy as a function of the steady state public-private capital stock ratio $\frac{G}{k}$. The last term of (5.14) captures the nonlinear relationship between economic growth and the public-private capital ratio, in the same spirit as Aschauer's (2000a) equation (5.13) (but different in the contents).

The growth-maximizing public-private capital stock ratio $\frac{G}{k}^{*}$ is derived by taking the first derivative of (5.14) with respect to $\frac{G}{k}$,

$$
\frac{G^{*}}{k}=\frac{\alpha}{(1-\alpha)} \frac{1+\beta}{\beta}\left(\frac{B_{1}}{B_{0}}\right)^{\frac{1}{\delta}},
$$

With regard to the flow of public capital, $s_{t}^{g}$, we substitute (5.12) into (5.13), and use (5.5), to get

$\gamma=\ln B_{0}^{1-\alpha} B_{1}^{\alpha}+\ln A^{\delta}+\ln \left(\frac{\alpha \beta}{1+\beta}\right)^{(1-\alpha) \delta}+\ln \left(\left(1-\frac{s^{g}}{y}\right)^{\delta(1-\alpha)}\left(\frac{s^{g}}{y}\right)^{\delta \alpha}\right)$

Equation (5.16) is the growth rate of the economy as a function of the steady state ratio of public capital $\frac{s^{g}}{y}$. By differentiating (5.16) with respect to $\frac{s_{t}^{g}}{y_{t}}$, we get, the following familiar result, typical in Barro-type models,

$$
\frac{s^{g *}}{y}=\alpha
$$

According to (5.17), the growth-maximizing level of public investment (as a fraction of output) $\frac{s^{\prime *}}{y}$ is equal to the output elasticity of public capital. 


\subsection{Empirics}

\section{Data}

In this section, we empirically investigate the relationship between the flow of public capital and growth for SSA countries. ${ }^{11}$ We use the panel data from SSA countries to determine the relationship between the flow of public capital and economic growth, and to estimate the elasticity of output with respect to public capital. We analyze the data extensively using both linear and nonlinear models. We apply dynamic panel data techniques in estimating the linear model. We estimate the nonlinear model using the model developed in the previous section. We use equation (5.16) (described in the box) to estimate the nonlinear relationship between public capital and growth, and to determine the elasticity of output to public capital while we appeal to (5.17) in estimating the growth-maximizing level of public capital and hence comparing it to the actually existing levels.

The data used in the chapter cover 29 SSA countries for the period 1960 to 2004 (in prices of the year 2000), for all of the variables except public and private investment for which data are available for the period 1965 to $2003 .^{12}$ Important variables include the level and growth rate of gross domestic product (GDP) percapita, public investment, private investment, investment price, population and life expectancy. The data come from different sources. The data for the GDP per-capita and investment price variables are obtained from the Penn World Table 6.2 (Heston et al. 2006) while data for the public and private investment variables are extracted from the World Bank African Database (World Bank 2005). Data for the rest of variables are obtained from the World Bank (2007).

Table 5.1 provides summary statistics for cross section units of the countries used in the study. The Table summarizes the averages of all the variables, used in the study, for each country over the study periods. The average public investment; of these countries over the period 1965-2003 is 8.28 percent of real GDP while the average growth rate over the period 1960-2004 is 0.63 percent. The minimum and maximum growth rates of the average growth rates of the 29 SSA countries, over the specified period, is -1.88 and 3.52 percentages. For public investment, the average values invested by thess countries over the period $1965-2003$ vary between 2.66 and 18.67 percent. ${ }^{13}$

\section{Public Expenditure and Growth: Linear Model}

We estimate both linear and nonlinear models in characterizing the relationship between public capital and growth. The model below assumes simply a linear

\footnotetext{
${ }^{11}$ We limit this study to the flow of public capital because data on public capital stock aro either limited or unroliable. This is, manly, dno to the fact that construction of public capital stock data depends on rather arbitrary nstwuptions aboul depreciation and initial capital stock.

${ }^{12}$ Countries are inchuded in the study bated on denta avtilability. As at rule of thumb, countrics are excluded if they have more than threo missing observations in their public cappital variable after the year 1985, and $\backslash$ or, of conrse, lave: no data at all for nny of the variables used in the study.

${ }^{13}$ Zimbabwe and Guinon-Biskau rogiktered liho minimum and maximum public investment: whereas Sierra Loono and Swazilnnd registiced hihe minimum and maximum growlih ratio, respoctively.
} 
Table 5.1: Summary statistics for SSA countries over the period 1960-2004

\begin{tabular}{lccccc}
\hline \multicolumn{1}{c}{ Variable } & Mean & Std. Dev. & Min & Max & N \\
\hline Growth Rate (\%) & 0.631 & 1.135 & -1.882 & 3.518 & 29 \\
GDP per Capita(10 ${ }^{9}$ ) & 1810.078 & 2493.447 & 518.3683 & 13421.38 & 29 \\
Public Investment (\%) & 8.281 & 3.48 & 2.655 & 18.667 & 29 \\
Private Investment (\%) & 10.931 & 5.898 & 2.241 & 31.162 & 29 \\
Investment Price & 115.942 & 76.24 & 43.303 & 366.287 & 29 \\
Population Growth (\%) & 2.55 & 0.447 & 1.757 & 3.572 & 29 \\
Life Expectancy (year) & 45.467 & 4.809 & 37.34 & 53.532 & 29
\end{tabular}

Notes: The data for public and private investment cover the period from 1965 to 2003 .

relationship between the flow of public capital and growth:

$$
\begin{aligned}
\text { Growth }_{i t}= & b_{0}+b_{1} G D P_{i t-1}+b_{2} \text { PublicInvest }_{i t} \\
& +b_{3} \text { PrivateInvest }_{i t}+b_{4} \text { InvestPrice }_{i t} \\
& +b_{5} \text { Pop }_{i t}+b_{6} \text { LifeExpect }_{i t} \\
& +v_{i}+e_{i t}
\end{aligned}
$$

Where Growth $_{i t}$, PublicInvest $i t, v_{i}$ and $e_{i t}$ denote a growth rate, a public investmentGDP percentage, unobserved country-specific effect and an error term, respectively. Whereas GDP ${ }_{i t-1}$, PrivateInvest $_{i t}$, InvestPrice $_{i t}$, Pop $_{i t}$ and LifeExpect $_{i t}$ represent control variables, i.e., a period lagged GDP per-capita, private investmentGDP percentage, investment price, ${ }^{14}$ population and life expectancy, respectively. ${ }^{15}$ $i$ refers to individual countries and $t$ refers to particular time periods. All the explanatory variables will be regressed in their logarithmic values.

For convenience, we rewrite equation (5.18) as

$$
\gamma_{i t}=b_{0}+b_{1} y_{i t-1}+\mathbf{b} \mathbf{X}_{i t}+v_{i}+e_{i t}
$$

where $\gamma_{i t}, y_{i t-1}$ and $\mathbf{X}_{i t}$ represent growth rate, a period lagged GDP per-capita and other explanatory variables, respectively. Equation $\left(5.18^{\prime}\right)$ is basically a dy-

\footnotetext{
${ }^{14}$ Investment price is used as a proxy indicator of market distortions (such as tariffs, corruption, etc.). It is frequently included in grow th regressions, in the literature, and it measures how investment cost varies among countries (e,g., Forbes 2000). It is calculated as the purchasing power parity for total investment divided by exchange rate times 100 .

${ }^{15}$ Initial GDP per-capita, investment price and life expectancy are some of the robusti variubles
in growth regression (see Bleaney and their inclusion among the eighteen robust variables.
} 
namic panel data model. We see that immediately if we rewrite the equation with grow th expressed as the difference in income level, $\gamma_{i t}=y_{i t}-y_{i t-1}$, and add initial income $y_{i t-1}$ to both sides, ${ }^{16}$

$$
y_{i \iota}=b_{\mathbf{0}}+c_{1} y_{i l-1}+\mathbf{b} \mathbf{X}_{i t}+v_{i}+e_{i \ell}
$$

where $c_{1}=b_{1}+1$.

Equation (5.18") shows a dynamic panel data model. The lagged dependent variable is explicitly modeled on the right hand side of the equation. Estimating $\left(5.18^{\prime}\right)$ or $\left(5.18^{\prime \prime}\right)$ as it is, using standard methods, may yield a biased and sometimes inconsistent result. The Ordinary Least Squares (OLS) estimators are biased and inconsistent due to the presence of correlation between the explanatory variables $y_{i t-1}$ and the composite error term $\left(v_{i}+e_{i t}\right)$, and this correlation does not vanish as the number of individuals or time periods increase (Bond 2002). The OLS estimator of the lagged variable is biased upward in large samples. On the other hand, the Within Groups $\backslash$ fixed effects (FE) estimator of the variable is biased downward. However, in the case of large time periods, the FE estimator is consistent and unbiased (Bond 2002). Latcr on, we estimate a nonlinear model for large time periods using FE.

\section{Dynamic Panel Data GMM Estimation}

Now, we estimate the models, in $\left(5.18^{\prime}\right)$ or $\left(5.18^{\prime \prime}\right)$, using the generalized method of moments (GMM) technique, which is developed by Holtz-Eakin et al. (1988) and furthor improved by Arellano and Bond (1991), Arellano and Bover (1995) and Blundell and Bond (1998). ${ }^{17}$

The general procedure in the dynumic panel GMM method is, as it is well known by now, first, to remove the individual effect, taking first differences, and search for instruments for the differenced lag depondent variable, and then use these instruments in GMM procedure to got efficiont estimators. Particularly, Arellano and Bond (1991) (following Holtz-Eakin et al. 1988) developed the Difference GMM a mothod that use past levels of lagged variables as instruments in GMM procedure, aftor first-difforencing. First differencing is required to eliminate the unobserved country specifice effect and hence to deal with the existing endogeneity between the lagged variable and the crror term, for example, between $y_{i t-1}$ and $\left(v_{i}+e_{i b}\right)$, respectively, in equation $\left(5.18^{\prime \prime}\right)$. Although this process creatics a new form of endogeneity, it could be dealt with using intornal instruments. For instance, first differencing $\left(5.18^{\prime \prime}\right)$ to remove $v_{i}$ gives

$$
\gamma_{i l}=b_{0}+c_{1} \Delta y_{i l \cdots 1}+\mathbf{b} \Delta \mathbf{X}_{i l}+\Delta c_{i \ell}
$$

\footnotetext{
${ }^{10}$ Receall that $y_{i c}$ is expressed in its logarilhmic: vahue. 'That, is, for inslinnce, $y_{i l}=\ln Y_{i b}$, whene $Y_{i t}$ is GDP per cappita of countiry $i$ ant lime $t$.

${ }^{17}$ Noto that dynanic: GMM has somo more actvantages over INA, particularly, in dealing with endogencity problems (oblher thinn that of ereated due to a presence of lagged dopendent variable). The Within Groups cstimation, for instance, muy control an endogencily problom that arises duc to the presenes of unobserved individual effect, but, it might not denl properly other forms of endogeneity (e.g. enclogoncily due to reverse causnlity between pmblic conpital and growth). The GMM approach intrinsically, however, dente with this form of endegencity (by using internal instrumentis).
} 
where $\Delta y_{i t-1}=y_{i t-1}-y_{i t-2}, \Delta \mathbf{X}_{i t}=\mathbf{X}_{i t}-\mathbf{X}_{i L-1}$ and $\Delta e_{i t}=e_{i t}-e_{i t-1}$. But, in (5.19), $\Delta y_{i t-1}$ is still correlated to the new error term $\Delta e_{i t}$, by construction. Arellano and Bond (1991) used internal instruments (built from past observations of the instrumented variables) to deal with this (and other endogeneity problom related to the rest of the covariates).

Under the assumption of sequential exogeneity and that the orror term $a_{i t}$ is not serially correlated, ${ }^{18}$ Arellano and Bond (1991) instruments $\Delta y_{i t-1}$ with $y_{i l-3 .}{ }^{19}$ The Difference GMM estimator thus uses the following moment conditions:

$$
E\left[y_{i t-k} \Delta e_{i t}\right]=0 \text { for } k \geqslant 2 ; t=3, \ldots, T
$$

However, the Difference GMM estimator would still have problems if the timo series are persistent. ${ }^{20}$ In this case, the lagged levels of the variables are weak instruments for the subsequent first differences that might result in downward biased coefficients with large asymptotic variances. ${ }^{21}$ To deal with the problems, Arellano and Bover (1995), and Blundell and Bond (1998) later, developed Systom GMM- estimating the equation of interest simultaneously in differences as woll as levels, in which the two equations have been distinctly instrumented. While the instruments for the difference equations are the same as above, the instrumonts for the level equations become the lagged difference of the corresponding variablos. The additional moment conditions available for the System GMM is thus:

$$
E\left[\Delta y_{i t-1}\left(v_{i}+e_{i t}\right)\right]=0 \text { for each } t>3
$$

Standard assumptions for consistency of the GMM estimators are related lo the validity of the instruments and that whether the error term are not serially correlated. The Sargan test of over-identifying restrictions is usually conductod to determine the validity of the instruments. And, the test for second ordor sc:rial correlation can also be easily conducted during the GMM estimation. Rocently there is also another important concern, emphasized by Roodman (2007), "instrument proliferation". In both the Difference and System GMM, numnerous internal instruments can easily be generated. Roodman (2007) warns "that too numerous instruments, by virtue of being numerous, can overfit endogenous variables." Consequently, coefficients of the estimators could be biased towards the non-instrumenting estimators. Thus, he strongly suggests reducing the number of instruments, particularly, in System GMM.

\footnotetext{
${ }^{18}$ Sequential exogeneity (weak endogencity) means that explanatory variablog (c.g., $y_{i i-1}$ ) are uncorrelated to future values of a time varying error term (e.g., $\left.e_{i t}, e_{i t+1}, \ldots\right)$ but; could bo correlated to the current (e.g., $e_{i t-1}$ ) and past values (e.g., $e_{i t-2} \ldots$ ) (Wooldrige 2002).

${ }^{19}$ Similar instruments can also be generated in regard to othor covarialies $\left(\mathbf{X}_{i t}\right)$ that aro thought to be endogenous.

${ }^{20}$ GDP per capita is a highly persistent series. See, for instance, the coeflicient estimate: of the lagged GDP per capita for OLS, in Table 5.6 (Appendix 5.B).

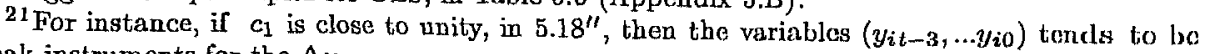
weak instruments for the $\Delta y_{i t-1}$.
} 


\section{Result Of GMM Estimation}

Table 5.2 presents estimation results of the model, in $\left(18^{\prime \prime}\right)$, using both System and Difference GMM. ${ }^{22}$ The data used cover the period 1960-2003, with five years average. In all of the regressions, public investmont is treated as endogenous and thus instrumented using internal instruments that are built from past observations of the variable, similar to the lagged GDP per-capita variable. In Table 5.2, the first and second column report the Difference GMM estimators with varying instrumental sets. ${ }^{23}$ Whereas, the third column provides estimation results for System GMM with reduced number of instruments. ${ }^{24}$

The GMM estimators generally support strong relationship between public capital and economic growth in SSA countries. But, as expected, the result from the Difference GMM estimation shows a symptom of weak instrumentations. ${ }^{25}$ The coefficient estimates for the lagged variable $Y_{i t-1}$, in the Difference GMM estimations, column one and two, -0.37 and -0.34 , respectively, are biased downward more than the coefficient estimate of the Within Groups estimator, $-0.3 .^{26}$ However, as discussed above, the FE and OLS estimators are expected to be biased downward (for small time period) and upward, respectively. And hence, we expect an unbiased consistent estimator to lie between these two.

The result for System GMM seems quite satisfactory. The coefficient estimate for the lagged GDP per-capita lies between the OLS and Within Groups estimators. All the regrossands are reported significant, and posses the right sign. The coefficient estimate for public capital is about 0.21 percent, and is significant at $1 \%$ level. The coefficient estimates for the rest of the control variables have also the right sign, and are significant, in line with the literature. The Sargan and the Difference Sargan test of over-identification in the System GMM estimation are also satisfied. ${ }^{27}$ Moreover, there is no second order serial correlation, a critical assumption required for consistency of the GMM estimators.

\footnotetext{
${ }^{22}$ OLS and Within (roups regressions aro also conducted using the same clatin and variables as benchmarks. The results are reportied in Table 5.5 ( $\left(\Lambda_{\text {ppendix }} 5.13\right)$.

${ }^{23}$ During tirst differencing, in the Differenee GMM, the coustant, term is eliminated. Period dummies are thus included, which aro not reportecl.

${ }^{24}$ Instruments arc collapsed as sugrestiod by Roodman $(2006 ; 2007)$.

${ }^{25}$ The roason for that; is that GDP' per capitia is a highly persistent series. For instiance, the coefficient estimate of the lagged GDP per capita in the un-instrumented OLS regression is -0.007 (Appendix 5.B, Thable 5.5, column 2).

${ }^{26}$ Seo column 1 of Table 5.5 (Appondix 5.B).

${ }^{27}$ The difforonce Surgan test of over-identification, in the Systom GMM, las a p-7ralue: of 0.390.
} 


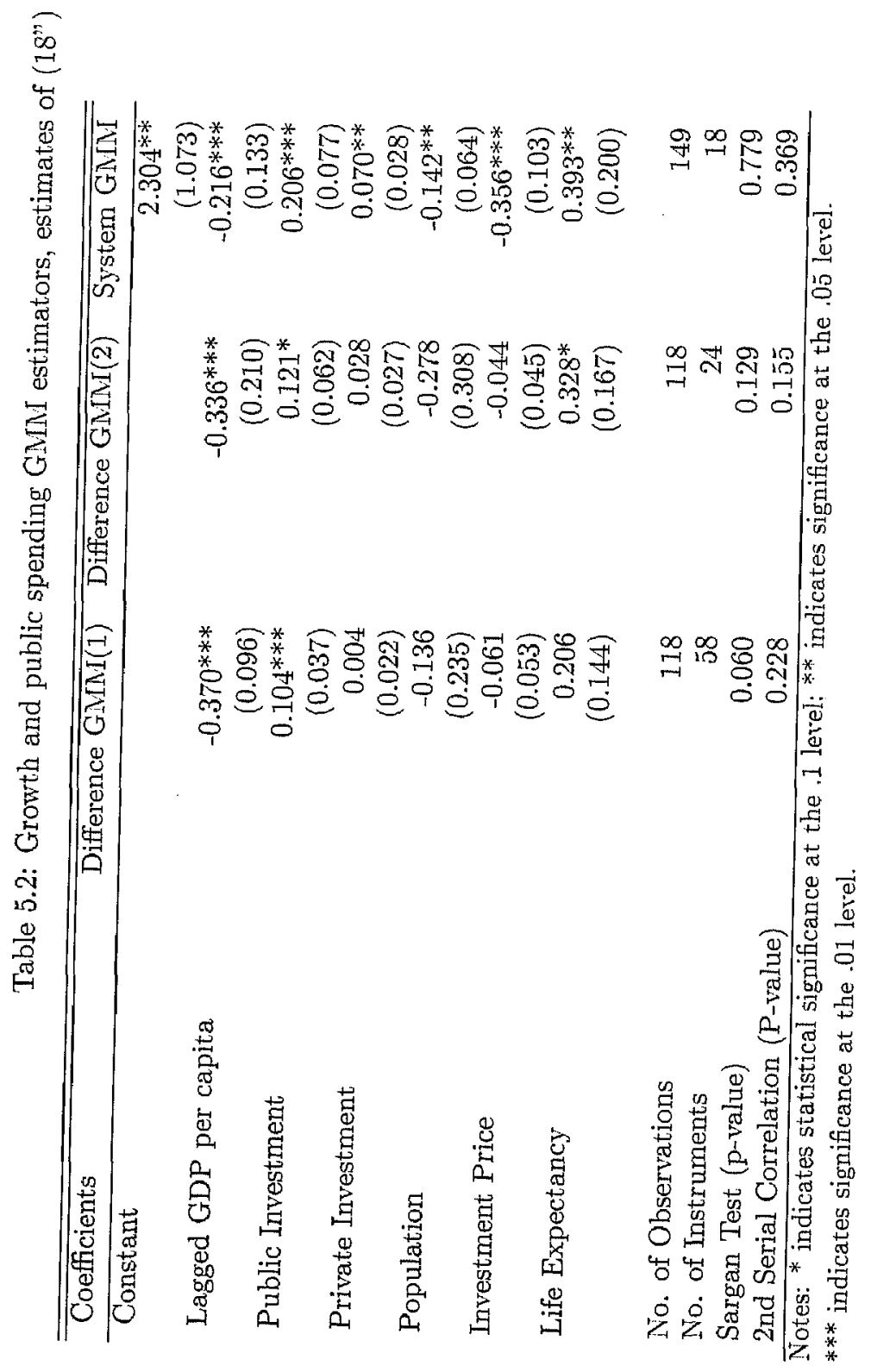


Sensitivity analysis of the results to further varying the number of instruments and a different specification is conducted. Table 5.3 reports regressions results where period dummies are included in all regressions, and, lagged GDP per capita, public investment, population and investment price are treated as endogenous. The results (particularly, in the System GMM) also show that there is a significant relationship between public capital and the growth rate of SSA countries. Coefficient estimate of public capital in the system GMM is about 0.12 percent, which is lower than the previous estimate but highly significant. The coefficient estimates for the most of the control variables are also significant, and have the right sign.

However, the System GMM estimator for the lagged dependent variable in Table 5.3 shows a symptom of "instrumental proliferation," in which the number of instruments is 41 . Consequently, (as noted by Roodman 2007), the lagged GDP per-capita has a very high coefficient estimate $(-0.003)$, which is biased towards the non-instrumenting OLS estimator. ${ }^{28}$ Therefore, the System GMM estimates in Table 5.2, are preferable, in which the number of instruments is 18 and hence the coefficient estimate for the lagged dependent variable is reasonably smaller $(-0.216)$.

\footnotetext{
${ }^{28}$ Rofer Table 5.5 in Appendix 5.B.
} 


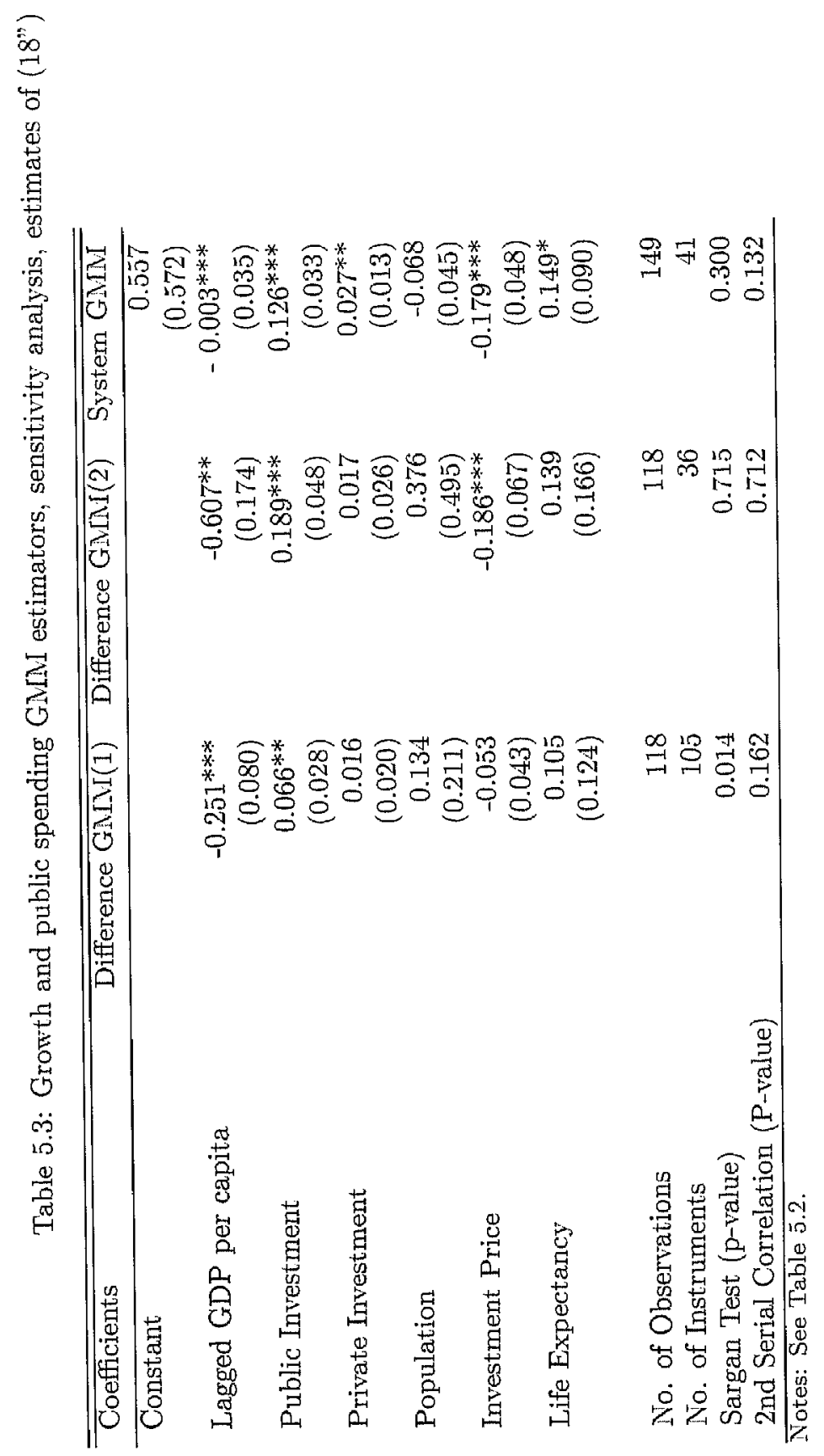




\section{Public Expenditure and Growth: Non-Linear Model}

We now test the nonlinear model derived in the theoretical section of the chapter. We appeal to different nonlinear estimation approaches in determining the nonlinear relationship between public capital and growth, and in estimating the public capital elasticity of output. We use nonlinear least square (NLS), weighted nonlinear least square (WNLS), and nonlinear seemingly unrelated regression (SUR) where countries' FE are also included. ${ }^{29}$ Kamps (2005) used NLS technique in estimating the elasticity of output of public capital, and the coefficient of a nonlinear public capital function for European countries, but without FE.

Thus, for the nonlinear estimation, recall equation (5.16), in the box, which shows a nonlinear relationship between public capital and economic growth:

$$
\gamma=\underbrace{\ln \left(B_{0}^{1-\alpha} B_{1}^{\alpha}\right)+\ln A^{\delta}+\ln \left(\frac{\alpha \beta}{1+\beta}\right)^{(1-\alpha) \delta}}_{\text {Constants }}+\ln \left(\left(1-\frac{s^{g}}{y}\right)^{(1-\alpha) \delta}\left(\frac{s^{g}}{y}\right)^{\alpha \delta}\right)
$$

The first three terms in (5.16) are simply constants whereas the last term is a nonlinear function of public capital. ${ }^{30}$ We may rewrite (5.16) (with control variables and error terms) in a panel form:

$$
\gamma_{i l}=a_{0}+a_{1} M_{i t}+a_{2} \mathbf{X}_{i t}+e_{i t}
$$

where $a_{0}$ and $e_{i t}$ denote the constant and error terms, respectively. And, $\gamma_{i l}, M_{i t}$ and $\mathbf{X}_{i l}$ represent growth rate, nonlinear function of public capital, and control variables, respectively. $M_{i t}$ is defined:

$$
M_{i l}=\ln \left(\left(1-\left(\frac{s^{g}}{y}\right)_{i t}\right)^{(1-\alpha)}\left(\frac{s^{g}}{y}\right)_{i t}^{\alpha}\right)
$$

We use equation (5.21) to estimate the nonlinear public capital coofficient $a_{1}$ and the output elasticity of public capital $\alpha$ using FE nonlinear regression methods. $^{31}$ We first insert $M_{i l}$ into (5.21) and then estimate the parameters $a_{0}, a_{1}, \alpha$ and $a_{2}$ (coefficients of control variables which are included in the regression). We include main control variables of growth regression (such as a lagged dependent variable, private capital, and population growth rate) in the nonlinear regressions.

\footnotetext{
${ }^{29}$ The SUR method takes into account, the contomporanoons corrolation in residuals of the country specific equationg. Whereas, the NWLS method usunlly involves twomstep estimation procodure. 'That is, NLS is applied to a weighlod data whore the woightis are ostimated in the first stage (of using NLS). T.hore are efficioncy gains from using NWLS compared to NLS.

${ }^{30}$ Rocall that $\gamma$ and $\frac{s^{a}}{y}$ ropresent; growtih rate and public invostiment-GDP ratio.

${ }^{3}$ FE cstimations are unbiased and consistont [or large time dynamie pand unlike OLS estimation (Bond 2002). The lagged dependent varinble, which is usually included as a control variable in growtil regressions, crontes inconsistency and biasedness (thati do not vanish witil increasing time period) due to its correlation with the orror term, in OLS regression.
} 
Table 5.4 presents the results for the estimations of (5.21) using nonlinear SUR, WNLS and NLS with FE, using the data for 28 SSA countries. ${ }^{32}$ The results are quite satisfactorily. The output elasticity of public capital $\alpha$ is significant at $1 \%$ level in all estimates, whereas the coefficient estimate for the nonlinear function of public capital $M$ is significant at $1 \%, 5 \%$ and $10 \%$ levels, in the nonlinear SUR, WNLS and NLS, respectively. Although the coefficient estimate for the lagged public investment variable has a negative sign, its total effect is positive in all of the regressions. The estimate for the public capital elasticity of output is about 0.16 , using any of the methods. The coefficient estimate for $M$ (the nonlinear public capital function) is about $0.3,0.22$ and 0.28 , in the nonlinear SUR, WNLS and NLS estimation techniques, respectively. The WNLS estimate is similar to that of the System GMM estimate of the coefficient of public capital in Table 5.2, which may make it more preferable. Moreover, the coefficient estimates for the lagged GDP per capita are in line with theory. ${ }^{33}$

\footnotetext{
${ }^{32}$ As a way of mitigating the influence of outliers, we exclude countries with unusual investment experience (specifically Gabon). In Gabon, public investment in the year 1976 (after the country became a full member of OPEC in the preceding year) is 37.4 percent - the highest of all obscrvations of all periods. In the linear models, we have averaged the data over five year periods that would smooth out any outlier's effects. In the nonlinear models, however, large time periods (for the FE estimation) are required so that averaging the data over time periods is not fousible.

${ }^{33}$ Bond (2002) argued that in small time period, the FE estimator of a lagged dependent variable becomes biased downward. This is demonstrated, for instance, in Table 5.5 (in Appendix 5.B) that the estimate for the lagged GDP per capita $(-0.3)$ is quite small, for nine time periods panel compares to the FE estimates (which ranges between -0.16 to -0.13) in Table 5.2 for larger time periods (thirty eight time periods panel).
} 


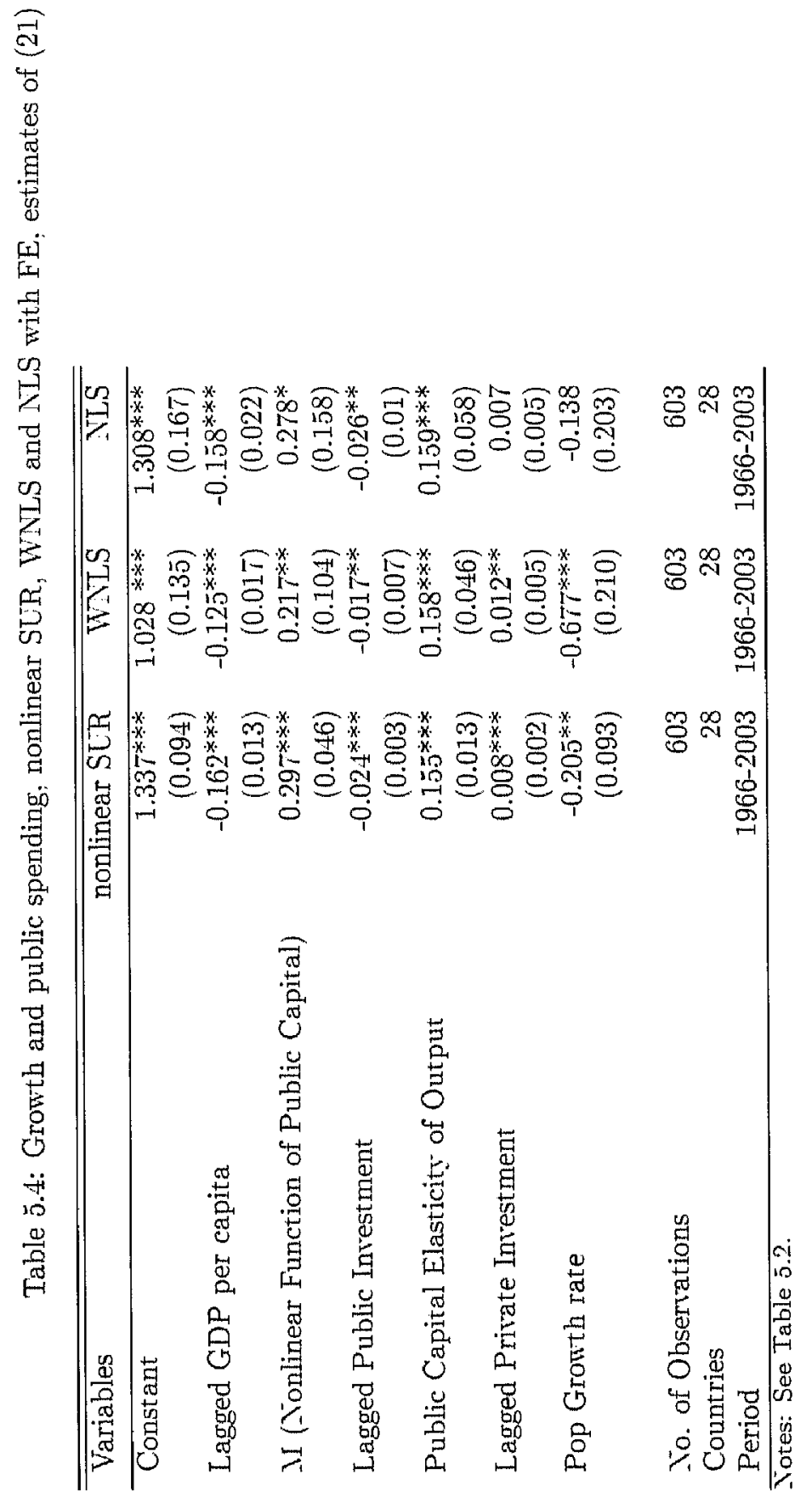




\section{Is Public Investment Growth-maximizing in SSA countries?}

From equation (5.17), the growth-maximizing government expenditure to GDP ratio is equal to the elasticity of output of public capital, $\frac{s^{\prime \prime}}{y}=\alpha$. In Table 5.4 , using nonlinear SUR, WNLS and NLS with FE, $\alpha$ is estimated to be about 0.16 . This estimate is lower in general compared to other estimates for the output elasticity of public capital. But, our finding is robust considering the various nonlinear estimation techniques we have employed to find more or less similar estimate for $\alpha$. Moreover, the techniques we have applied are more robust than earlier studies that used NLS in estimating the public capital elasticity of output because we have included individual countries' FE in our regressions.

In estimating the public capital elasticity of output, and in determining the coefficient of a nonlinear public capital function, earlier studies usually rely on calibration or NLS (without FE) techniques. ${ }^{34}$ For instance, Aschauer (2000a) estimated the public capital elasticity of output about 0.3 for US states using parametrization technique. ${ }^{35}$ Kamps (2005) estimated for European and OECD countries about 0.2, using NLS (but, without FE). Whereas, Miller and Tsoukis (2001) calibrated their model to estimate about 0.18 , for a wide range of low and middle income countries.

Public investment in most of the SSA countries which are studied in this chapter is much smaller than the growth maximizing level. From the descriptive statistics, in Table 1, the total average public investment is 8.28 percent of GDP, which is quite a bit less than the growth-maximizing public investment, about 16 percent. More than 93 percent of the observations in public investment are below the growth-maximizing percentage, between the year 1965-2003. ${ }^{36}$

Figure 5.1 and 5.2 show each sample countries' average public investment for the period 1965-2003, and the public investment made at year 2000, respectively. ${ }^{37}$ According to Figure 5.1, out of 29 SSA countries, only two countries Guinea-Bissau and Lesotho have an average public investment-GDP percentage slightly greater than 16 percent. Whereas, Figure 5.2 reports that Mauritania had public capital expenditure-GDP percentage which is greater than 16 percent at year 2000 .

\subsection{Conclusion}

In this chapter, we made a theoretical and an empirical study of the growth impact of public capital-, taking the case of SSA countries. We also made a detailed theoretical and empirical literature review on the topic. We developed a model that captures the nonlinear relationship between public capital and economic growth, which we used as the basis for the empirical analysis. We investigated the relationship between public capital and growth, empirically, using both a linear and

\footnotetext{
${ }^{34}$ In fact, with respect to estimation of lineur models, various methods have been implemented such as using simple production function (i.e., simply taking the log of a production function that include public capital, and estimating the elasticity of outputs), applying vector antoregression models, and using a cost function. See Romp and de Haan (2007) for a detailed discussion.

35 This makes Aschauer's estimate of public capital elasticity of output for the United States as high as approximately equal to that of private capital.

${ }^{36}$ Of course, growth maximization is not necessarily the same as welfare maximization. But values below the growth maximizing ones indicate the potential to increase growth rates.

${ }^{37}$ See Table 5.6 for list of countries used in the study.
} 
Figure 5.1: Average public investment (years 1965-2003)

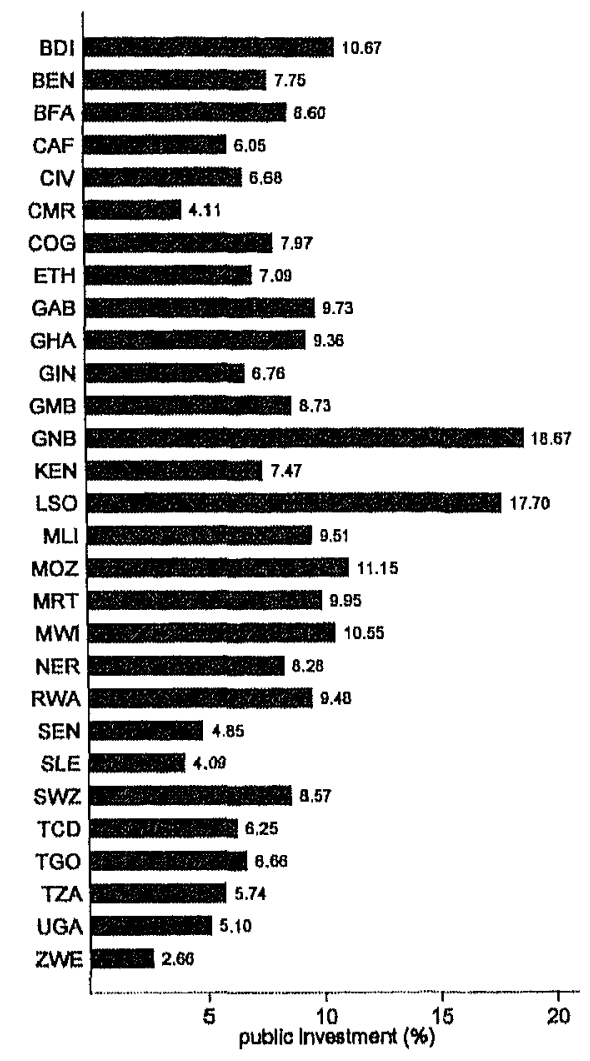

the nonlinear setup. Using the model, we estimated the public capital elasticity of output, determined the growth-maximizing level of public investment and compared it with the actual lovel of public invostment existed in SSA countries. We found that not only public investment highly matter to economic growth of SSA countries but also many of these countrics had public investment much below the level that maximizes growth, indicating a potential to increase growth. 
Figure 5.2: Public investment (year 2000)

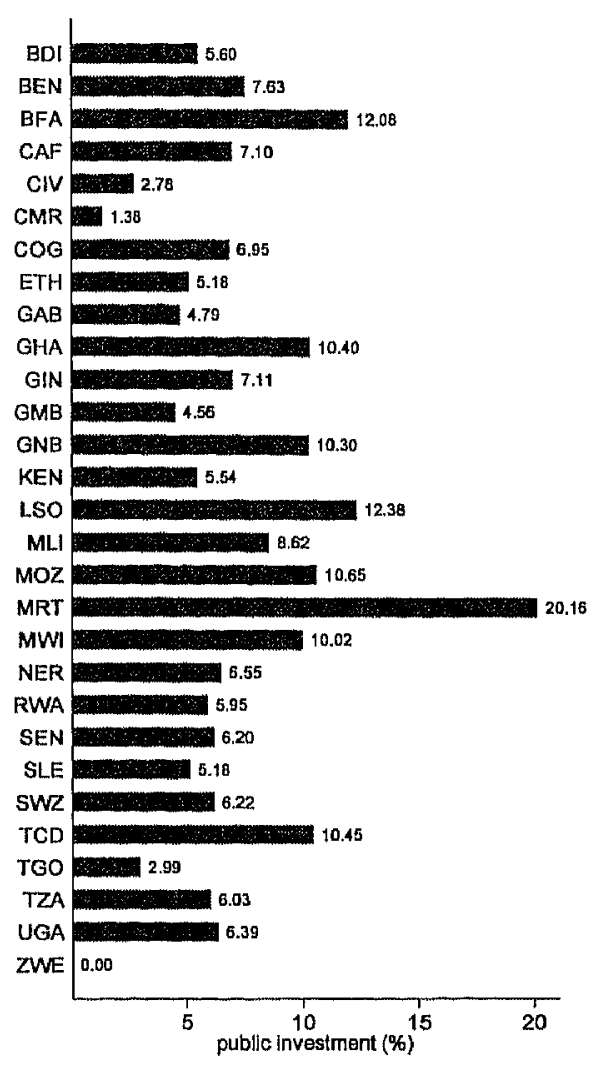




\section{A Growth Rate}

To get equation (5.12), first substitute equation (5.11) into equation (5.4), and use (5.9), to get the following difference equation for private capital accumulation,

$$
k_{l+1}=B_{0} k_{l}^{1-\delta}\left(\frac{(1-\psi)\left(\alpha A_{t} G_{t}^{\alpha} k_{l}^{1-\alpha}\right) \beta}{1+\beta}\right)^{\delta}
$$

Wo then get the difference equation for the public capital stock by substituting (5.5) into (5.6), and using (5.7),

$$
G_{l+1}=B_{1} G_{t}^{1-\delta}\left(\psi A_{t} G_{t}^{\alpha} k_{t}^{1-\alpha}\right)^{\delta}
$$

The dynamics of the economy are driven by the above two equations, (5.A.1) and (5.A.2). Dividing (5.A.2) by (5.A.1), and after some manipulation, we get

$$
\frac{G_{t+1}}{k_{t+1}}=\left(\frac{G_{\iota}}{k_{\iota}}\right)^{1-\delta} \frac{B_{1}}{B_{0}}\left(\frac{1+\beta}{\beta \alpha} \frac{\psi}{1-\psi}\right)^{\delta}
$$

The dynamics for (5.A.3) converges to a constant public-private capital stock ratio in the long-run, and hence becomes, as shown in equation (5.12),

$$
\frac{G}{k}=\left(\frac{B_{1}}{B_{0}}\right)^{\frac{1}{8}} \frac{1+\beta}{\beta \alpha} \frac{\psi}{1-\psi}
$$

Since the growth rate is

$$
\gamma=\ln k_{t+1}-\ln k_{t}
$$

by simply taking the logarithm of (5.A.1), we get equation (5.13), as given by 


$$
\gamma=\ln B_{0}+\delta \ln A+\delta \ln \alpha+\delta \ln \frac{\beta}{1+\beta}+\delta \ln (1-\psi)+\delta \alpha \ln \frac{G}{k}
$$

since in the steady state the public-private capital stock ratio is given by $\frac{G_{t}}{k_{t}}=\frac{G}{k}$.

\section{B Other Regressions and Tables}

Table 5.5: Growth and public spending, FE and OLS, 5 years average

\begin{tabular}{lrr}
\hline Coefficients & Fixed Effects & Ordinary Least Squares \\
\hline constant & $2.416^{* * *}$ & -0.489 \\
L.GDP per capita & $(0.791)$ & $(0.371)$ \\
& $-0.301^{* * *}$ & $-0.007^{* * *}$ \\
Private Investment & $(0.075)$ & $(0.019)$ \\
& 0.014 & $0.024^{* *}$ \\
Public Investment & $(0.015)$ & $(0.012)$ \\
& $0.077^{* * *}$ & $0.070^{* * *}$ \\
Population & $(0.028)$ & $(0.022)$ \\
& -0.027 & $0.022^{*}$ \\
Investment Price & $(0.051)$ & $(0.013)$ \\
& -0.053 & -0.024 \\
Life Expectancy & $(0.038)$ & $(0.021)$ \\
& 0.017 & 0.074 \\
F & $(0.123)$ & $(0.090)$ \\
$\bar{R}^{2}$ & & \\
No. of Observations & 18.23 & 821.08 \\
Period (5 years average) & $1960-2003$ & 0.972 \\
\end{tabular}


Table 5.6: Countries used in the study

\begin{tabular}{|l|l|}
\hline ISO Code & Country Name \\
\hline \hline BDI & Burundi \\
\hline BEN & Benin \\
\hline BFA & Burkina faso \\
\hline CAF & Central african republic \\
\hline CIV & Cote d'ivoire \\
\hline CMR & Cameroon \\
\hline COG & Congo, republic of \\
\hline ETH & Ethiopia \\
\hline GAP & Gabon \\
\hline GHA & Ghana \\
\hline GIN & Guinea \\
\hline GMB & Gambia, the \\
\hline GNB & Guinea-bissau \\
\hline KEN & Kenya \\
\hline LSO & Lesotho \\
\hline MLI & Mali \\
\hline MOZ & Mozambique \\
\hline MRT & Mauritania \\
\hline MWI & Malawi \\
\hline NER & Niger \\
\hline RWA & Rwanda \\
\hline SEN & Senegal \\
\hline SLE & Sierra leone \\
\hline SWZ & Swaziland \\
\hline TCD & Chad \\
\hline TGO & Togo \\
\hline TZA & Tanzania \\
\hline UGA & Uganda \\
\hline ZWE & Zimbabw \\
\hline & \\
\hline
\end{tabular}


CHAPTER 6

Poverty Trap and Public Capital

\subsection{Introduction}

In traditional economic growth models, efficient practices predict efficient outcomes. $^{1}$ In a perfectly competitive economy, agents make perfectly rational decisions that unanimously lead to unique, high-income equilibrium outputs. However, a snapshot of the real world provides a different picture: the fact is that both efficient and inefficient economies coexist. Theoretically, deviations from the neoclassical benchmark could generate inefficient outcomes along with efficient ones. A number of papers, for instance, show that multiple equilibria are likely to rise when fertility is endogenous, ${ }^{2}$ technologies are non-convex, ${ }^{3}$ income inequality prevails and/or the capital market is imperfect, ${ }^{4}$ etc. ${ }^{5}$

This chapter presents other possibilities that could cause multiple equilibria, along with a qualitative analysis (using phase-diagrams) of the role of growthmaximizing public investment in poverty trap which are rarely addressed in the literature. ${ }^{6}$ The study shows analytically how a poverty trap could arise due to side effects related to ongoing economic progress, and examines the role of growthmaximizing public investment in evading it.

It is well acknowledged while economic development has tremendous benefits (e.g., improved health and education quality), it also has downsides (e.g., a

\footnotetext{
${ }^{1}$ Classic oxamples are Solow (1956), Romer (1986), and Lucas (1988).

${ }^{2}$ Beckor ot al. (1990).

${ }^{3}$ Azariadis and Drazen (1990).

${ }^{4}$ Galor and Zoira (1993) and Galor and Tsiddon (1997).

${ }^{5}$ Sec also Galor (1996), Azariadis (1996), and Azariadis (2006) for more models with multiple equilibria with subsistience consumption, impatient government, incomplete market, monopolistic: competition in product or factior market, angmented human capital, externalities, and income distribution.

${ }^{6}$ Galor and Tsiddon (1997) have done qualitative analysis (using phase-diagrams) on technology's effect on poverty trap. Azariadis (2006, p. 32-34) presents an informal discussion of the role of public policy in cconomice characterized by multiple equilibria and poverty trap.
} 
temporary increase in income inequality, pollution, skilled migration, and lower social cohesion). ${ }^{7}$ Some of these phenomena may seriously damage further economic progress. For instance, a temporary increase in brain drain (skilled migration) during an economy's takeoff could potentially cause poverty trap, and the literature provides no reason why it should not. Sometimes referred as "migration humps, or temporary increases in emigration during a country's economic take-off, 18 this is both a notable and a theoretically and empirically supported phenomenon that is detrimental to economic growth.

We have thus developed a model that shows economic development not only as a source of positive learning-by-doing externality that enhances further productivity, but also as a source of negative externality that discourages it. In the model, therefore, production takes place in an environment where learning-bydoing externality prevails, in line with Arrow (1962), Frankel (1962), and Romer (1986), which complements individual production and hence promotes endogenous growth. However, along with this learning-by-doing externality, a negative development-related externality also exists, which deters individual and aggregate productivity. The development-related problem is a temporary phenomenon particularly assumed to arise at the initial stage of economic growth, and then decline. We focus on a particular instance of "migration hump" type brain drain as the development-related problem.

In the model, individuals accumulate human capital via private and public inputs while using it for goods production. Production of final goods takes place using Newman and Read's (1961) production function. This is a generalized CobbDouglas production function, but for a certain value of its parameter it contains the popular CD function. It is less restrained on technologies; specifically, it is a variable elasticity of substitution (VES) production function rather than a standard CD production function. We use certain parameters of the Newman-Read production function to denote the development-related problem, in particular the "migration hump" effect.

The dynamics of the economy described above, for a range of parameters, yields a multiplicity of growth paths with possibilities that the economy could converge to a low or high equilibrium depending on initial human capital wealth. In the model, economies that start out below a certain critical value of initial economic development (or initial human capital wealth) may converge to the lowincome equilibrium (poverty trap). However, they could monotonically converge to the high-income equilibrium if their initial human capital wealth is beyond the threshold value. The multiplicity of growth paths is mostly related to changes in technological states. The hump-shaped brain drain "interchanges" increasing for decreasing returns to social input (aggregate human capital), which gives the production function a convex and concave curvature at the bottom and upper part respectively. ${ }^{9}$

This chapter analyzes the role of growth-maximizing public investment in the

\footnotetext{
${ }^{7}$ Seo, o.g., Kuznots (1955) for a temporary increase in income inequality during an cconomy's tiake-off.

${ }^{8}$ Martin and Taylor (1996, p. 45).

${ }^{0} \mathrm{Sec}$ A decreasing returns to a social input conld result in multiple equilibria.
} 
poverty trap model. Although policy may not necessarily enable a country to evade poverty trap, its role in the economy described above is important. ${ }^{10}$ In the model, a policy shock changes the threshold value of the poverty trap. But whether the change enables the economy to evade the trap depends on other exogenous factors, such as the history and technology of the country at stake. In general, the effect of public policy in evading poverty trap is undecided in the model. (1) On the one hand, a policy shock could result in a growth miracle. Optimal (in terms of growth-maximizing) public investment may create a growth miracle by increasing the human capital stock from slightly below to slightly above the critical threshold value that determines the long-run growth path of the economy. It could even abolish the poverty trap and thus create an opportunity for the economy to move to a unique and globally stable high-income steady state equilibrium. ${ }^{11}$ (2) Alternatively, a policy shock could change the critical value, but not enough to evade the poverty trap. In other words, the change may not leave the country above the threshold value, and hence the economy will inevitably converge to a low-income steady state equilibrium.

The proposition that brain drain could cause poverty trap is based upon two main premises that are largely supported by empirical evidence. The first is that there is a nonlinear relationship between migration and economic development. That is, economic development is one of the fundamental, driving forces of outmigration that rises at the initial stage of economic growth and then declines (sce, e.g., Martin and Taylor 1996; Hatton and Williamson 2005; Chiswick et al. 2003). ${ }^{12}$ Martin and Taylor (1996) state that migration humps, or temporary increases in emigration during a country's economic growth, are not new phonomena. Rather, thoy argue, migration humps have existed from the 19th century (Europe's period of industrialization) to the modern days of East Asian countries' growth miracles. ${ }^{13}$

It is largely believed that skilled migration constitutes the lion's share of total migration from developing to developed countries, particularly in recent times. According to Adams (2003), the vasti majority of migrants from developing countries to the United States and the Organization for Economic Cooperation and Development (OECD) have a secondary or higher education. Hatton and Williamson $(2006$, p.328-329) calculated that the ratio of highly educated emigrants to total emigrants from poor nations to the OECD in 1990 averaged more than 14 to 1. Mishra (2007) found that many Caribbean countries have lost more than $70 \%$ of their skilled labor forces (12 years plus) due to emigration to the OECD. Docquier et al. (2007) state that, "Between 1990 and 2000, the stock of skilled immigrants in OECD countries increased by 64 percont. The rise was stronger for immigrants from developing countries (up 93 percont), especially from Africa (up 113 percent), Latin America and the Caribbean (up 97 percent)." Collier et al.

\footnotetext{
${ }^{10}$ A mariadis (2006, p. 32-34) argues informally that policy and history mattor much moro in an environmont, with poverty trap than they do in one without, such as that is found in a tradilional orgodic growth model.

11. Soc Galor and 'T'sicklon (1997) for a similar offect of techology on poverty trap.

${ }^{12} \mathrm{Sec}$ Ziesemer (2008) for a delated survey of the literabure on migration humps.

13rThe most common rensons montioned in the literature as to why migration humps exist aro "supply-push comigralion" (Martin and 'Thylor 1996) and an increaso in poople's capnbilities and aspirations during economic developmont (de Han 2007).
} 
(2004) documented that the last decade's "hemorrhage" of African human capital is accelerating. ${ }^{14}$ The authors argued that Africa's financial capital flight (which, up to the late 1980s, reversed the human capital flight) is the new challenge in Africa's post-independence history. ${ }^{15}$

The second premise is that brain drain could be detrimental to the economy of either the home or the destination country. It could negatively affect the quantity and quality of human capital of those remaining at home, which, in turn, could hurt the economic growth of the home country. Bhagwati and Hamada (1974), in one of the earliest contributions on this topic, argued that the drain of highly skilled individuals is a loss to those left behind, and has negative implications for the income and welfare of the destination country. The negative impact of brain drain on the home country has also been emphasized in recent endogenous growth literature (Miyagiwa 1991; Haque and Kim 1995; Galor and Tsiddon 1997; Wong and Yip 1999; Beine et al. 2001). Wong and Yip (1999) argue that brain drain damages both the nonemigrants and the source country's economic growth. Haque and Kim (1995) developed a two-country endogenous growth model and showed that brain drain negatively affects the growth rate of the effective human capital of the emigrants' country and hence reduces its economic growth.

Recently, some studies have turned the issue of brain drain into brain gain by searching for some compensatory effect such as remittances, return migrations, or enhanced human capital accumulation. The main rationale of the latter is that when education is privately and endogenously determined, the possibility of migrating to a higher-wage country increases the average rate of return in the home country, which in turn increases domestic individual investment in human capital accumulation (Mountford 1997; Stark et al. 1998; Beine et al. 2001). However, the fact that much of the educational investment in developing countries is undertaken by the state (Fosu 2007) could undermine this compensatory effect. Moreover, some argue that the high probability of emigration could lead individuals to "under-invest" in education. Lien and Wang (2005) developed a model showing that when individuals choose education and language before migration, they can invest less in their human capital, depending on the substitution effect. between language and education. "The result is a less educated, 'Americanized' population with better language skills and lower human capital" (Lien and Wang 2005 , p. 154).

This chapter is organized as follows: Section 6.2 describes the model, while Section 6.3 discusses the dynamics of aggregate variables, multiple equilibria and poverty trap. Section 6.4 analyzes the effect of optimal productive public investment in poverty trap. Section 6.5 concludes.

\footnotetext{
${ }^{14}$ See also Fosu et al. (2004) for a discussion on Africa's challengo with respect to the flight of its human and other capital flight .

${ }^{15} \Lambda$ frica also experienced high growth rate in the 1990s. Ndulu et al. (2007) noted: "Since 1995, more than one-third of the countrics in SSA are growing at average rates exceeding 5 percent annually. Several others have shown themselves to be capable of short spurts of high growth. The challonge for them is how to sustain such a pace for longer poriods."
} 


\subsection{The Model}

\section{Preferences and Technologies}

Suppose we have a continuum of homogeneous households, $i \in[0,1]$, with overlapping generations. Each household $i$ consists of an adult of generation $t$ and a child of generation $t+1$. The population size is thus constant and normalized to be one. Let, at the beginning, each houschold $i$ of the initial generation be endowed with an initial human capital $h_{0}$.

When young, individuals accumulate human capital using both private and public input in a standard Cobb-Douglas production technology. As adults, they use their accumulated human capital for final goods production. The government taxes income using a flat rate tax $\psi$ in order to finance the public input, denoted by $G_{t}$, which is used to complement the accumulation of human capital. ${ }^{16}$ During their active period, individuals allocate after-tax income between current consumption $c_{t}$ and saving $e_{t}$ to use for their children's education. The latter is incorporated in individuals' utility function as the "joy of giving." Therefore, altruistic individuals derive utility from consumption and giving, i.e., investing in the human capital of their offspring $h_{t+1}$.

The utility of an individual is thus defined as

$$
u_{t}\left(c_{t}, e_{t}\right) \equiv \ln c_{t}+\beta \ln e_{t}
$$

subject to

$$
c_{t}+e_{t}=(1-\psi) y_{t}
$$

whore $y_{t}$ represents the individual's income.

As previously mentioned, the human capital accumulation function of the offspring $h_{t+1}$ is a function of public investmont $G_{t}$ and parental investment $e_{t}$. The accumulation function takes the standard Cobb-Douglas form, with constant returns to scale in factors. Thus, for an individual born at time t, the human capital at $t+1$ is given by

$$
h_{\ell+1}=A\left(G_{\ell}\right)^{1-\eta}\left(e_{t}\right)^{\eta}+\chi
$$

where $\chi>0$ is a paramoter that assures $h_{t+1} \neq 0$ even if parental investment on education is $e_{t}=0$.

The government leviss a flat-rale tax $\psi$ on output $Y_{t}$, which is used to finance public investment. The government budget is balanced at all times as

$$
G_{t}=\psi Y_{t}
$$

where $G_{t}$ and $Y_{t}$ represent public investment; and aggregate income, respectively.

According to the above descriptions, an adult of period $t$ solves the following problem, which is derived by substituting (6.2) into (6.1),

\footnotetext{
${ }^{16}$ Note that in this chapher, lower- and appercase letters are used to denoto individual and aggregato/average voriables, respectively.
} 


$$
\underset{e_{t}}{\operatorname{Max}} \ln \left((1-\psi) y_{t}-e_{t}\right)+\beta \ln e_{t}
$$

taking as given $\psi$ and $G_{t}$.

The first-order condition gives

$$
e_{t}=a(1-\psi) y_{t}
$$

where $a=\frac{\beta}{1+\beta}$. Equation (6.6) shows an individual's saving as a fraction of her after-tax income.

\section{Goods Production}

There are infinite numbers of competitive small firms owned by households. We suppose that production at firm level occurs using both private and social inputs in a Newman and Read (1961) production setting. At time $t$, output $y_{t}$ is produced using individual and aggregate human capital inputs, denoted by $h_{t}$ and $H_{t}$ respectively. However, we model the latter to reflect positive learning-by-doing spillover, in line with Arrow (1962), Frankel (1962), and Romer (1986), along with a negative development-induced externality.

The Newman and Read (1961) production function is employed to capture these phenomena together. This is a generalized Cobb-Douglas production function that contains the popular Cobb-Douglas production function for a certain value of its parameter. It is less restrained in technologies in that it is a. VES production function with a variable-factors income share. Although its use is rolatively rare in the literature of economic growth, the Newman-Read production function offers a powerful analytical framework for economic development studies. In addition to its suitability for modeling a negative development-induced spillover (e.g., a temporary increase in skilled migration) along with a positive one (e.g., learning by doing), unlike the Cobb-Douglas and the constant elasticity of substitution (CES) production functions, it is more suitable for income distribution studies $^{17}$ and gives a better approximation of the reality of the short-run behavior of factor shares. ${ }^{18}$

Thus, the income of an agent of generation $t$, in the Newman-Read production function, is defined as

$$
y_{t}=\left(h_{t}\right)^{\alpha}\left(H_{t}\right)^{\beta} \exp \left(-\lambda\left(H_{t}\right) \ln H_{t} \ln h_{t}\right)
$$

\footnotetext{
${ }^{17}$ In Chapter 4, we have argued that the standard production functions such as CD and CES lack either flexibility in parameters or analytical tractability with regard to income alistribution studies. Howevor, tho Newman-Read generalized CD function is both flexible in tho values of the parameters und analy tically tractable with respect to distribution studies. In Chuptior 4, wo have applied the Newman-Read production function in analyzing the effect of public capital on income inequality dynamics.

${ }^{18}$ Empirical studies reveal that factor shares show large short-run fluctuations, but no long-run trend (e.g. Accmoglu 2003). The Newman-Read goneralized CD production function contains a framework that provides a satisfactory approximation to this reality, particularly in contrasti to the popular CD function. The latter imposes strict restrictions on rclative factor share and on the elasticity of substitution between factors. In particular, the factor shares are constant: and the factors' elasticity of substitution is equal to unity.
} 


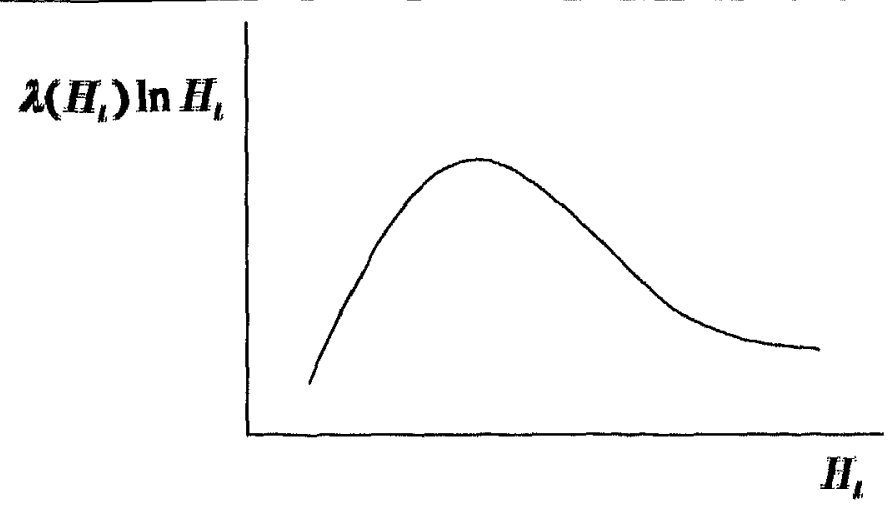

Figure 6.1: Negative externalities during an economy's takeoff

where $y_{t}$ and $h_{t}$ represent individual output and human capital, respectively; $H_{t}$ is aggregate human capital, which is defined as $H_{l} \equiv \int_{0}^{1} h_{l} \Gamma\left(h_{l}\right)$, where $\Gamma\left(h_{\ell}\right)$ is the distribution of wealth at time $t$. We assume:

$$
\begin{aligned}
H_{l} & \geqslant 0 ; h_{\iota} \geqslant 0 \\
\lambda\left(H_{t}\right) & >-1
\end{aligned}
$$

The exponential term $-\lambda\left(H_{t}\right) \ln H_{t} \leq 0$ in the Nowmen-Roal function may represent, in general, the negative oxternalitios that may arise in a country's conomy (such as skilled "migration hump") during the economy's takcoff. ${ }^{10} \lambda\left(H_{t}\right)$, which is a fixed parametor (or simply $\lambda$ ) in the original Nowman-12,ond function, is assumed here to be a function of aggregate human capital.

We use $\lambda\left(H_{l}\right)$ ln $H_{l}$ as a function of aggregate human capitial to dictate a skilled migration hump, or a nonlinear relationship botweon brain drain and economice development, as the latter is denoted by an increase in $H I_{t}$. Thorofore, wo shall assume $\lambda\left(H_{t}\right) \ln H_{t}$ to rise at the initial stage of economic dovelopment and then to decline as shown in Figure 6.1.20

We further assumo that the production function in (6.7) oxhibits diminishing (increasing) returns to scale with respect to individual (total) input(s):

\footnotetext{
${ }^{19}$ This negative extornality can be onsily understood as gundity and gunntily reductions in effective human capital due to brain drain. J'or instanece, if a home country produces human

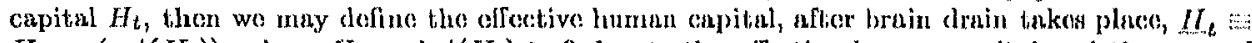
$H_{t} \exp \left(-\phi\left(H_{t}\right)\right)$, where $\underline{H}_{l}$ and $\phi\left(H_{l}\right) \geqslant 0$ denote the effective human capital and the trito of brain drain. If wo substilute this in a simple CD production function such as $y_{t}=\left(h_{t}\right)^{\alpha}\left(I_{f}\right)^{\beta}$, then we get a production function sitnilar to (6.7), $y_{t}=\exp \left(-\beta \phi\left(I H_{l}\right)\right)\left(h_{t}\right)^{\alpha}\left(I h_{l}\right)^{\beta}$.

${ }^{20}$ Note that migration hump is trealod here in an exogrnous manner. 'That is, the loump shupe atitributed to $\lambda\left(H_{l}\right) \ln H_{l}$ is an assumption based on an observalion that has large ompirienl support.
} 


$$
0<\alpha, \beta<1, \text { but } \alpha+\beta>1
$$

\section{Properties of Individual and Aggregate Production Function}

As noted above, the production function used here is of a Newman and Read (1961) form. For certain values of its parameters, the Nowman-Read production function satisfies the standard properties of production functions. As Solow (1957) noted, a particular functional form adopted for a production function is a matter of no great consequence as far as it possesses a positive partial derivative and the right curvature.

The first and the second derivative of the production function in (6.7) are positive and negative, respectively:

$$
\begin{aligned}
\frac{\partial y_{t}}{\partial h_{t}} & =\frac{y_{t}}{h_{t}}\left(\alpha-\lambda\left(H_{t}\right) \ln H_{t}\right)>0 \\
\frac{\partial y_{t}}{\partial h_{t} \partial h_{t}} & =\frac{y_{t}}{\left(h_{t}\right)^{2}}\left(\alpha-\lambda\left(H_{l}\right) \ln H_{t}-1\right)\left(\alpha-\lambda\left(H_{l}\right) \ln H_{t}\right)<0
\end{aligned}
$$

assuming $^{21}$

$$
\alpha>\lambda\left(H_{t}\right) \ln H_{t} ; \beta>\lambda\left(H_{l}\right) \ln H_{l}
$$

Therefore, at an individual level, and with respect to private factor humn capital, the Newman-Read production function obeys the neoclassical rule in that, it has a positive marginal productivity and a concave curvature.

In characterizing the properties of individual and aggregate production functions with respect to the social human capital $H_{b}$, we assume that the olasticity of the brain drain parameter $\lambda\left(H_{t}\right)$ to aggregate human capital $H_{l}$ is sufficicntily small, in a well-defined sense,

$$
-\infty<\rho\left(H_{t}\right) \equiv \frac{H_{t} \lambda^{\prime}\left(H_{t}\right)}{\lambda\left(H_{t}\right)}<\frac{\beta-\lambda\left(H_{t}\right) \ln H_{t}}{\lambda\left(H_{t}\right) \ln H_{t} \ln h_{t}}
$$

where $\rho\left(H_{t}\right)$ denotes the elasticity of $\lambda\left(H_{t}\right)$ to $H_{l}$.

We establish the following two Lemmas to characterize the propertios of individual and aggregate production functions with respect to the social human capilial
$H_{t}$.

Lemma 5 Assumption (A.6.5) provides sufficient condition for an individual production function to have a positive marginal productivity, $\frac{\partial y_{t}}{\partial I_{t}}>0$, with respect to
the social input $H_{t}$.

\footnotetext{
${ }^{21}$ Newman and Read (1961) show that their production function obeys neoclawsical rules (positive marginal productivity and concavity) if the parameter $\lambda>-1$. Sco also assumption
(A.6.2).
} 
Proof. The first derivative of (6.7) with respective to $H_{t}$ is given by

$$
\frac{\partial y_{t}}{\partial H_{t}}=\frac{y_{t}}{H_{t}}\left[\beta-H_{t} \lambda^{\prime}\left(H_{t}\right) \ln H_{t} \ln h_{t}-\lambda\left(H_{t}\right) \ln h_{t}\right]
$$

Then, sufficient condition for $\frac{\partial y_{\ell}}{\partial H_{l}}>0$ is

$$
\beta>H_{t} \lambda^{\prime}\left(H_{t}\right) \ln H_{t} \ln h_{t}+\lambda\left(H_{t}\right) \ln h_{t}
$$

Rearranging the above gives

$$
\rho\left(H_{t}\right) \equiv \frac{H_{t} \lambda^{\prime}\left(H_{t}\right)}{\lambda\left(H_{t}\right)}<\frac{\beta-\lambda\left(H_{t}\right) \ln H_{t}}{\lambda\left(H_{t}\right) \ln H_{t} \ln h_{l}}
$$

Aggregate income is simply derived by aggregating (6.7), ${ }^{22}$

$$
\begin{aligned}
Y_{t} & =\int_{0}^{1}\left(h_{t}\right)^{\alpha}\left(H_{t}\right)^{\beta} \exp \left(-\lambda\left(H_{t}\right) \ln h_{t} \ln H_{t}\right) \\
& =\left(H_{t}\right)^{\beta}\left(H_{l}\right)^{\alpha-\lambda\left(H_{l}\right) \ln H_{t}}
\end{aligned}
$$

Alternatively,

$$
Y_{l}=\left(H_{l}\right)^{\alpha+\beta-\lambda\left(H_{l}\right) \ln H_{l}}
$$

Therefore, equation (6.8) denotes aggregate production function in the economy. The following Lemma charactorizes its property with respect to the social hurnan capital $H_{t}$.

Lemma 6 Assumptions (A.6.4) and (A.6.5) provide sufficient conditions for the aggregate production function (8) to have a positive maryinal productivity with respect to its factor input $H_{L}$, or $\frac{\partial Y_{l}}{\partial H_{l}}>0$.

Proof. The first derivative of (6.8) with respect to $H_{L}$ is given by

$$
\frac{\partial Y_{t}}{\partial H_{t}}=\frac{Y_{t}}{H_{l}}\left(\alpha+\beta-2 \lambda\left(H_{t}\right) \ln H_{t}-H_{t} \lambda^{\prime}\left(H_{l}\right) \ln ^{2} H_{t}\right)
$$

Then, sufficient condition for $\frac{\partial Y_{t}}{\partial I_{t}}>0$ is

$$
\alpha+\beta>H_{l} \lambda^{\prime}\left(H_{l}\right) \ln ^{2} H_{l}+2 \lambda\left(H_{l}\right) \ln H_{l}
$$

But, from (A.6.4) and Lemma 5, wo have $\alpha>\lambda\left(H_{l}\right) \ln H_{l}$ and $\beta>H_{l} \lambda^{\prime}\left(H_{t}\right) \ln ^{2} H_{t}+$ $\lambda\left(H_{t}\right) \ln H_{t}$, respectively.

The second derivative of the individual and aggregate production function might be positive or negative. In fact, at this point, deviation from the neoclassical benchmark is required to gonerato multiple equilibria and hence poverty trap.

\footnotetext{
${ }^{22}$ Note that $\left(h_{l}\right)^{\alpha} \exp \left(-\lambda\left(H_{l}\right) \ln h_{l}, \ln H_{t}\right)=\left(h_{l}\right)^{\alpha-\lambda\left(r_{l}\right) \ln H_{l}}$. To sec this, let $x=$ $\left(h_{l}\right)^{\alpha} \exp \left(-\lambda\left(H_{l}\right) \ln h_{l} \ln H_{l}\right)$. Then, $\ln x=\ln \left(h_{l}\right)^{\alpha}-\lambda\left(H_{t}\right) \ln H_{t} \ln h_{l}=\left(\alpha-\lambda\left(H_{l}\right) \ln H_{t}\right) \ln h_{t}$. Thus, $x=\left(h_{t}\right)^{\alpha-\lambda\left(H_{t}\right) \ln H_{t}}$
} 


\subsection{Dynamics, Multiple Equilibria, and Poverty Traps}

\section{Dynamics of Individual and Aggregate Human Capital}

In this section we characterize the dynamics of the economy described in previous section. We derive aggregate human capital dynamics using the individual and aggregate production functions, and determine whether multiple equilibria and poverty trap exist. But before we start dealing with aggregate variables, we must first derive individuals' capital accumulation function that is related to their optimal behavior by substituting (6.4) and (6.6) into (6.3), and using (6.7) and $(6.8){ }^{23}$

$$
\begin{aligned}
h_{t+1}= & A \psi^{\eta}(a(1-\psi))^{1-\eta}\left(H_{t}\right)^{\left(\alpha+\beta-\lambda\left(H_{l}\right) \ln H_{l}\right) \eta+\beta(1-\eta)}\left(h_{l}\right)^{\alpha(1-\eta)} \\
& \exp \left(\left(-\lambda\left(H_{t}\right) \ln h_{t} \ln H_{L}\right)(1-\eta)\right)+\chi
\end{aligned}
$$

Thus, equation (6.9) shows an individual's human capital accumulation function, which is associated to her optimal behavior. We simply aggregato (6.9), in determining the economy's human capital dynamic equation, ${ }^{24}$

$$
H_{t+1}=\Omega\left(H_{t}\right)^{\alpha+\beta-\lambda\left(H_{l}\right) \ln H_{t}}+\chi
$$

where $\Omega$ is defined

$$
\Omega \equiv A(\psi)^{\eta}(a(1-\psi))^{1-\eta}
$$

Equation (6.10) thus determines the dynamics of the economy, which wo characterize in detail below.

\section{Multiple Equilibria and Poverty Trap}

The dynamics of (6.10) are characterized by the existence of multiple equilibrit. For a range of parameters, equation (6.10) yields multiple growth paths that lead to three steady states, of which two are stable and one is unstable. Of the stablo. steady states, one is characterized by low-income equilibrium (or poverty trap); the other by high-income equilibrium.

In characterizing (6.10) and showing the existence of multiple equilibria, wo follow Galor and Tsiddon (1997). We thus take the first derivative of $(6.10)$ to got

$$
\frac{\partial H_{t+1}}{\partial H_{t}}=\Omega\left(H_{t}\right)^{\alpha+\beta-\lambda\left(H_{t}\right) \ln H_{t}-1}\left(\alpha+\beta-2 \lambda\left(H_{t}\right) \ln H_{t}-H_{t} \lambda^{\prime}\left(H_{t}\right) \ln ^{2} H_{t}\right)
$$

Following the Lemmas, wo defino the term in

$$
\alpha+\beta-2 \lambda\left(H_{t}\right) \ln H_{t}-H_{t} \lambda^{\prime}\left(H_{t}\right) \ln ^{2} H_{t} \in(0, \infty)
$$

We make the following two additional assumptions which are related to a negative development-related externality:

\footnotetext{
${ }^{23}$ See Appendix 6.A for details on the derivation.

${ }^{24}$ See Appendix 6.3 for details on the derivation.
} 


$$
\begin{aligned}
& \lim _{H_{t} \rightarrow 0} \alpha+\beta-\lambda\left(H_{t}\right) \ln H_{t}>1 \\
& \lim _{H_{t} \rightarrow \infty} \alpha+\beta-\lambda\left(H_{t}\right) \ln H_{t}<1
\end{aligned}
$$

Then, together with earlier assumptions (A.6.1) (A.6.5) and henco (6.12), (A.6.6) and (A.6.7) assure that equation (6.10) becomes a well-behaved non-comvox function. (A.6.6) in particular creates increasing returns to scale at a lower lovel of human capital related to the existence of low-income equilibrium, whoroas (A.6.7) assures the existence of a high-income steady state equilibrium rathor than a divergence one: $\lim _{H_{t} \rightarrow \infty} H_{t+1}=H$. The following proposition summarizes the existence of multiple equilibria and hence poverty trap, in the economy described in equation (6.10).

Proposition 7 Given assumptions (A.6.1)-(A.6.7), (6.12), and $\chi>0$, the economy described in (6.10) is characterized by multiple steady-state equilibria satisfying the following conditions:

1. $\lim _{I_{\ell} \rightarrow 0} \frac{\partial H_{L+1}}{\partial H_{t}}=0$

2. $\lim _{H_{L} \rightarrow \infty} \frac{\partial H_{L+1}}{\partial H_{l}}=0$

3. $H_{t+1}>H_{t}$ for some values of $H_{t}$.

Proof. It follows from the continuity of (6.10), Figure 6.2, assumptions $(\Lambda .6 .1)$ (A.6.7) and the intermediate value theorem (see also Galor and Tsidelon 1997, section 2.5). Equation (6.10) is conlinuous at $H_{\ell}$ by dofinition. Thorefore, from the intermediate value theorem, the third condition is satisfied. The first and second conditions are satisfied from assumptions $(A .6 .6),(A .6 .7)$ and equation (6.12).

Together a sufficiently small $\chi$, the first condition tussures the oxistence of a lowincome equilibrium, as shown in Figure $6.2, H H_{1}$. The second condition, togethor with the third, assures the existence of a high-income equilibrium (nlso shown in Figure 6.2, $\mathrm{H}_{3}$ ).

Thus, Figure 6.2 shows multiple equilibria, with three steacly states for a givon level of $\Omega$. There is a low income stable steady state $H_{1}$, a threshold unstable stinady state $\mathrm{H}_{2}$ and a high-income stable steady state equilibrium $H_{3}$. The scoond stondy state equilibrium, $H_{2} \in\left(H_{1}, H_{3}\right)$, creates a critical point for tho low- and highincome steady state equilibria to be realized. The low steady state equilibrium $I_{1}$ is similar to what the literature refers to as a "poverty trap." For a given range of technological parameters, both the low and high steady states $H_{1}$ and $I_{3}$, respectively, are self-reinforcing. Given a technological level $\Omega$, an initial human capital $H_{0}$ smaller (greater) than the threshold level human capital $H_{2}$ converges to the low steady state $H_{1}$ (high-income steady state $H_{3}$ ) in tho long run. 


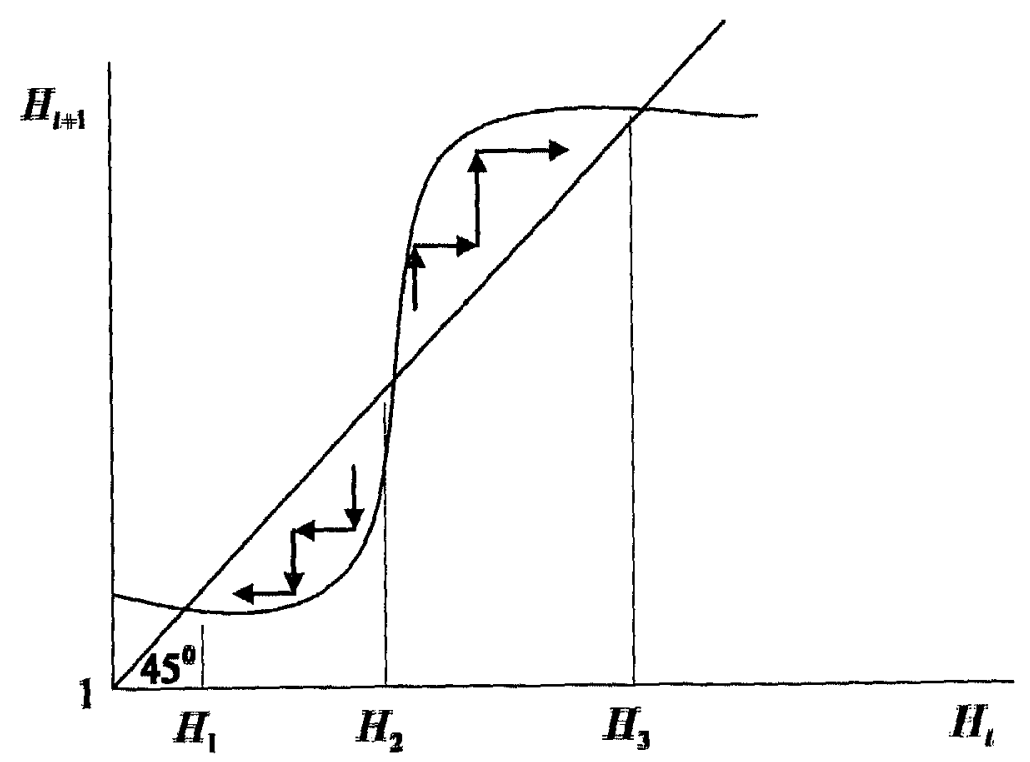

Figure 6.2: Multiple equilibria and poverty trap

\subsection{Public Investment and Threshold Externality}

\section{Does Public Policy Matter for Long Run Growth?}

Is there any role for public policy in this economy? Does growth-maximizing public investment in this economy lead a country to evade the poverty trap? Growthmaximizing public investment in this economy is the tax-rate level that maximizes the technological parameter $\Omega$ shown in equation (6.10), where $\Omega$ is defined in $\left(6.10^{\prime}\right) .{ }^{25}$ The tax rate that maximizes $\Omega$ is given by,

$$
\frac{\partial \Omega}{\partial \psi}=0 \Rightarrow \psi^{*}=\eta
$$

where $\psi^{*}$ denotes the growth-maximizing tax-rate. In this economy, a policy shock has an effect on the threshold point. Even a temporary policy shock may bring permanent consequences.

In general, two different possibilities are presented in relation to a chango in public policy towards growth-maximizing level of public investment. First, such policy change in an economy described in equation (6.10) may abolish the poverty trap and thus create an opportunity for the economy to move to a unique and

\footnotetext{
${ }^{25}$ Recall that $\Omega$ constitutes both exogenous technological and public investment paramoters.
} 


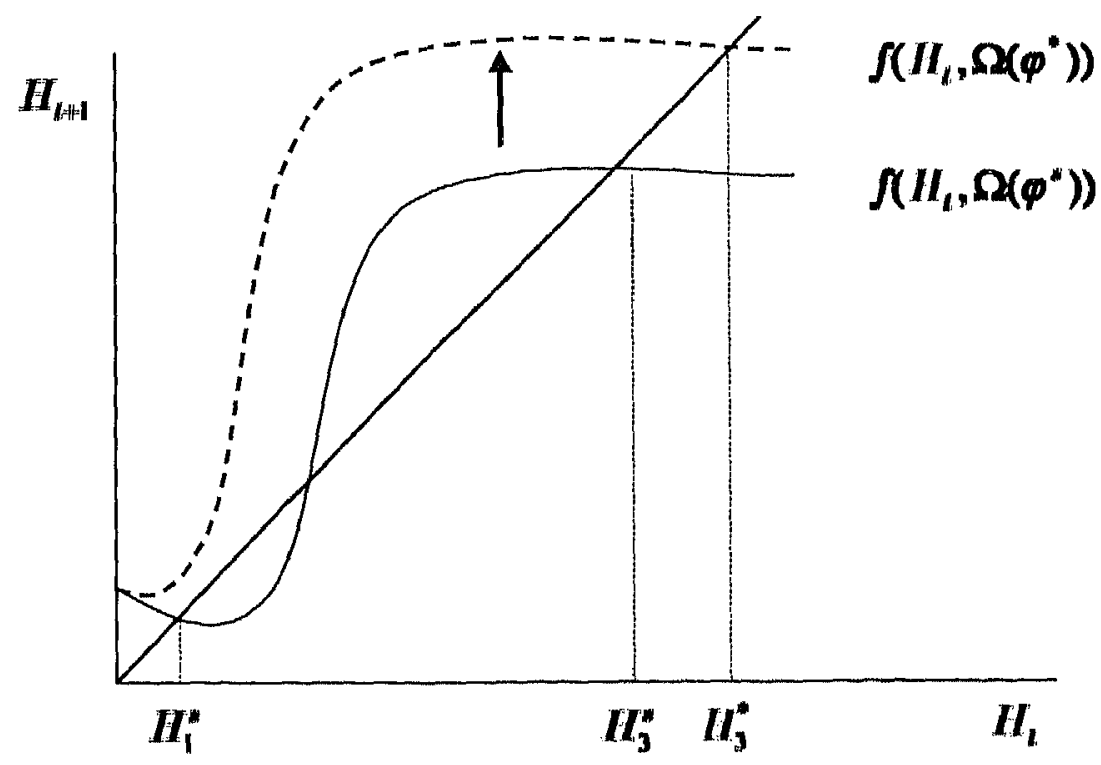

Figure 6.3: A shock that may abolish a poverty trap and honco rosult in a growth miracle

globally stable high-income steady state equilibrium as shown in Figure 6.3.20 The figure illustrates a possible offect of a policy shook via a chango in hax rati: from a suboptimal to growth-maximizing lovel of public investinent, donoted by $\psi^{4}$ and $\psi^{*}$ respectively, where the curves associated with tho suboptimal and growthmaximizing policies are represented by $f\left(H_{L}, \Omega^{s}\right)$ and $f\left(H_{l}, \Omega^{*}\right)$ rowpectivoly. The shock moves the curve defined in (6.10) upward in the dircetion of the arrow. As a result, the economy changes from a non-crgodic cconomy with multiplo stouly states to an ergodic one with a unique stoady state. Tho shock not only onsures that the economy evades a poverty trap but also croutes a new, hightor caulibrium point (compare $H_{3}^{s}$ and $H_{3}^{*}$ ).

Second, a policy shock (a chango in public policy towards growth-meximizing level of public investment) in an conomy described in (6.10) muy ahange tho threshold value, but whether this change loads the economy out of the poverty trap depends on other factors, such as initial income/capital of the oconomy at: stake. If the economy's initial capital is situated noar enough ho the throwhold value, the policy shock may create a growtih mirncle by incrousing tho capital stock from slightly below to slightly above tho threshold value. Howover, if tho initial income is sufficiently lower than the throshold value, tho policy chango may

\footnotetext{
${ }^{20}$ Galor and Tsiddon (1997) show that a teshnical progress conld have a dimilar aflocet.
} 


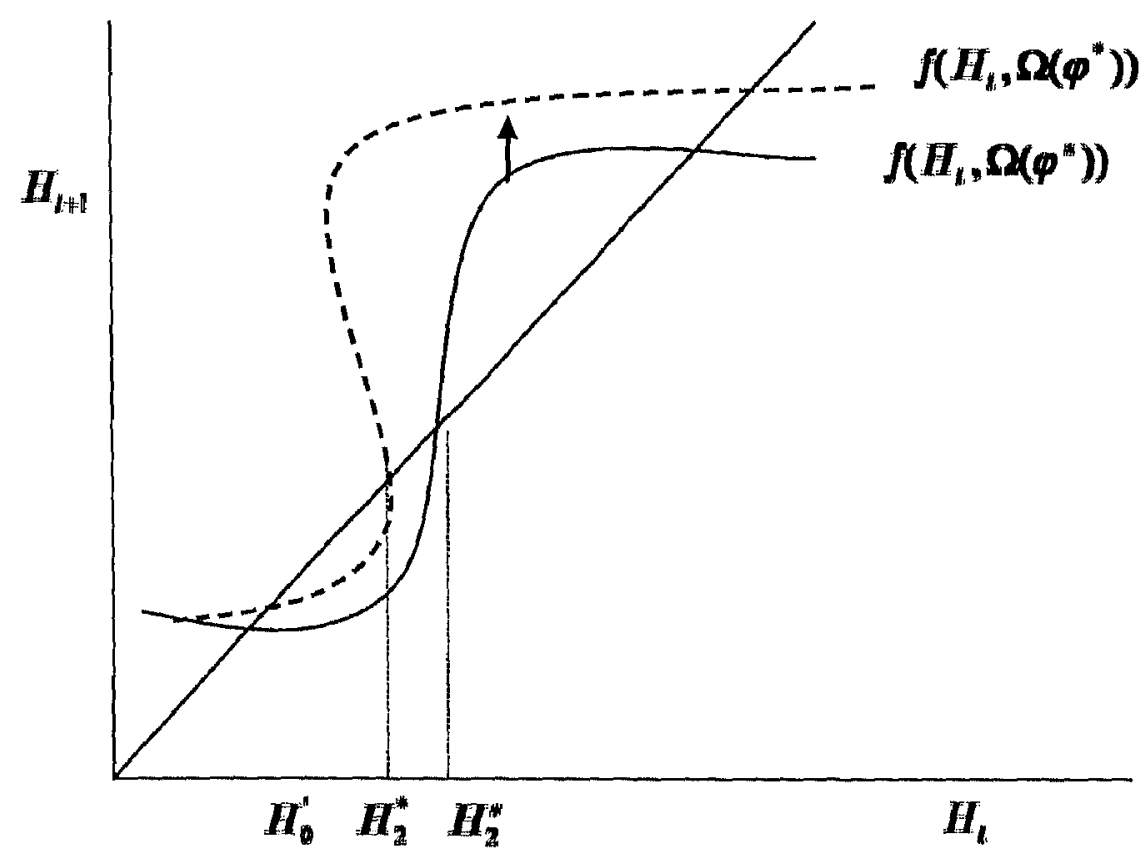

Figure 6.4: A policy shock that does not necessarily generate a growth miracle

not lead the country to evade poverty trap. Figure 6.4 shows that a policy shock moves the curve in equation (6.10) upward. However, this time the shock brings the desired growth miracle conditionally. That is, the miracle may happen only if the initial human capital stock $H_{0}$ is located in between the new and the old threshold levels, i.e., $H_{0} \in\left(H_{2}^{s}, H_{2}^{*}\right)$. However, if the initial human capital is sufficiently low (smaller than $H_{2}^{*}$ ), for instance if it is located at $H_{0}^{\prime}$, then the economy converges to a low-income steady state equilibrium despite the policy shock.

\subsection{Conclusion}

A number of factors, such as inequality, fertility, capital market imperfections, externalities and non-convexities of technologies, are mentioned in the literature as the causes of poverty traps in poor developing countries (e.g., see Becker et al. 1990; Azariadis and Drazen 1990; Galor 1996; Azariadis 1996; and Azariadis 2006 among many). The chapter presented a model that shows other possibilities that could cause multiple equilibria. The presence of negative externalities such as skilled "migration humps" or temporary increases in brain drain during an economy's takeoff can result in a poverty trap. In the model, a change in public policy towards growth-maximizing level of public investment was found to be crucial but 
indeterminate with respect to poverty trap. Depending on some initial conditions, however, such policy shock could create a threshold externality that could lead economies to evade poverty trap. 
Appendix 6

\section{A Individual Human Capital Dynamics}

To derive the individual's human capital accumulation equation, substitute (6.4) and (6.6) into (6.3), to get

$$
\begin{aligned}
h_{t+1} & =A\left(G_{t}\right)^{\eta}\left(e_{t}\right)^{1-\eta}+\chi \\
& =A\left(Y_{t} \psi\right)^{\eta}\left(a(1-\psi) y_{t}\right)^{1-\eta}+\chi
\end{aligned}
$$

Then, substitute (6.7) and (6.8) into the above to get

$$
h_{t+1}=A\left(\left(H_{t}\right)^{\alpha+\beta-\lambda\left(H_{t}\right) \ln H_{t}} \psi\right)^{\eta}\left(\begin{array}{c}
a(1-\psi)\left(h_{t}\right)^{\alpha}\left(H_{t}\right)^{\beta} \\
\exp \left(-\lambda\left(H_{t}\right) \ln h_{t} \ln H_{t}\right)
\end{array}\right)^{1-\eta}+\chi
$$

After rearranging, we get equation (6.9), of Section 6.3,

$$
\begin{aligned}
h_{t+1}= & A \psi^{\eta}(a(1-\psi))^{1-\eta}\left(H_{t}\right)^{\left(\alpha+\beta-\lambda\left(H_{t}\right) \ln H_{t}\right) \eta+\beta(1-\eta)}\left(h_{t}\right)^{\alpha(1-\eta)} \\
& \exp \left(\left(-\lambda\left(H_{t}\right)(1-\eta) \ln h_{t} \ln H_{t}\right)\right)+\chi
\end{aligned}
$$

\section{B Aggregate Human Capital Dynamics}

To get the economy's human capital accumulation function $H_{t+1}$, at $t+1$, we simply aggregate (6.9), i.e.,

$$
\begin{aligned}
H_{t+1}= & A \psi^{\eta}(a(1-\psi))^{1-\eta}\left(H_{t}\right)^{\left(\alpha+\beta-\lambda\left(H_{t}\right) \ln H_{t}\right) \eta+\beta(1-\eta)} \\
& E\left[\left(h_{t}\right)^{\alpha(1-\eta)} \exp \left(\left(-\lambda\left(H_{t}\right)(1-\eta) \ln h_{t} \ln H_{t}\right)\right)\right]+\chi
\end{aligned}
$$


Since

$$
E\left[\left(h_{t}\right)^{\alpha(1-\eta)} \exp \left(\lambda\left(H_{t}\right)(1-\eta) \ln h_{t} \ln H_{t}\right)\right]=\left(H_{t}\right)^{\left(\alpha-\lambda\left(H_{t}\right) \ln H_{t}\right)(1-\eta)}
$$

From combining (6.A.1) and (6.A.2), we get

$$
\begin{aligned}
H_{t+1}= & A(\psi)^{\eta}(a(1-\psi))^{1-\eta} \\
& \left(H_{\ell}\right)^{\left(\alpha+\beta-\lambda\left(H_{\iota}\right) \ln H_{l}\right) \eta+\beta(1-\eta)+\left(\alpha-\lambda\left(H_{\ell}\right) \ln H_{\iota}\right)(1-\eta)}+\chi \\
= & A(\psi)^{\eta}(a(1-\psi))^{1-\eta}\left(H_{l}\right)^{\alpha+\beta-\lambda\left(H_{\ell}\right) \ln H_{\iota}}+\chi
\end{aligned}
$$

We may rewrite the last equation to get equation (6.10), of Section 6.3,

$$
H_{t+1}=\Omega\left(H_{t}\right)^{\alpha+\beta-\lambda\left(H_{t}\right) \ln H_{t}}+\chi
$$

where

$$
\Omega \equiv A(\psi)^{\eta}(a(1-\psi))^{1-\eta}
$$




\section{CHAPTER 7}

This thesis has explored the possible role of public capital on economic development both analytically and empirically. It investigated important economic development problems relating to public capital, income inequality, economic growth, and poverty trap. The research questions included:

- What is the relationship between public capital and growth? How far does public capital matter to economic growth? How big should it be?

- What is the relationship between income inequality and economic growth? Is income inequality bad for economic growth?

- What is the relationship between public capital and income inequality? What determines the distributional effect of public capital? Could public capital increase economic growth in a disproportionate manner that benefits the poor?

- What is the role of public capital in poverty traps? Could public investment lead poor societies to evade a poverty trap?

While some of these questions have already been examined in depth by economists, others are rarely addressed. For instance, in the last decade a substantial volume of empirical and theoretical literature has been dedicated to examining the effects of fiscal policy on economic growth, motivated by the theoretical and empirical work of Barro (1990) and Aschauer (1989) respectively. Most of it acknowledged that productive public capital, especially infrastructure, plays important role in long-run economic growth by enhancing productivity and complementing the accumulation of private inputs.

Moreover, several papers have explored the effects of income inequality in growth using different approaches. For instance, from a political economy perspective, Alesina and Rodrik (1994) and Persson and Tabellini (1994), among others, argued that inequality harms growth because it demands a higher transfer 
of income redistribution from the rich to the poor that distorts saving, resulting in lower private capital investment and hence lower growth. Whereas, Galor and Zeira (1993) and Benabou (1996; 2000; 2002) showed that when the credit market is imperfect, inequality negatively affects economic growth. This is because, the argument goes, when credit markets are imperfect, relatively more high-return investment opportunities would be forgone by resource-poor households in inegalitarian than egalitarian societies. Thus, redistribution could help these opportunities not be missed.

On the other hand, few studies have examined the relationship between public capital and income inequality, particularly analytically. To our knowledge, only Ferreira (1995), García-Peñalosa and Turnovsky (2007), and Chatterjee (2008) have explicitly studied the relationship between public capital and income inequality analytically. Ferreira (1995) studied the relationship between public capital and inequality in a model with quite a complex setup while Garcfa-Peñalosa and Turnovsky (2007) and Chatterjee (2008) analytically studied the distributional irnpact of public capital focussing on its financing aspect. However, a growing number of empirical studies have recently addressed the impact of infrastructure on income inequality. For instance, Calderon and Servén (2004) and Lopez (2003) found that infrastructure reduces income inequality and at the same time enhances economic growth. The World Bank (2003) and Estache (2003) argue that infrastructure has a disproportionately positive impact on growth.

This thesis has complemented previous studies and brought new insights into view. It is composed of both theoretical and empirical contributions. In the theoretical part, it developed endogenous growth models that analyzed the role of public capital in income inequality, growth, and poverty trap. Whereas, the empirical section presented and tested a model that captured the nonlinear relationship between public capital and growth. Although the models were usually built in dynamic heterogenous-agent economy or non-ergodic/multiple-equilibria environment, they remained analytically tractable. The contributions of this thesis include its analysis of the distributional effect of public capital, its formulation of a joint theory that analyzes the relationship between public capital, income inequality, and growth simultaneously, in multiple sectors (the human capital and final goods production sectors), its analysis of the possible role of public policy in an economy with poverty trap, and empirical determination of the level of public: capital that maximizes long-run growth in developing countries.

For instance, in Chapter 3, we developed a joint theory of income inequality, public capital, and economic growth, in the context of capital markets imperfection. We thus extended the theories of imperfect credit markets in inequality and growth to inequality, public capital and growth.

The chapter developed a two-sector growth model in which initial wealth differs among individuals, access to credit is limited, and the government provides productive public goods used in both final goods production and human capital accumulation. In the model, based on the theories of capital markets imperfection, income inequality harms growth because imperfection in credit markets prevents the poor from undertaking the efficient amount of investment. However, the model showed that certain infrastructure provisions could come to the rescue through factor substitutions. Therefore, the model captured that, infrastructure 
affects growth not only through the direct channel (enhancing productivity and complementing the accumulation of private inputs) but also through an indirect channel (improving the distribution of income in the economy). It showed that public investment in both the human capital accumulation and the goods production sectors has a net positive effect on long-run growth through standard productivity effect, and, under the appropriate conditions, by indirectly affecting mitigating the negative influence of income inequality on economic growth.

In simple Cobb-Douglas production functions, Chapter 3 explicitly treated public capital as input where its importance varied among households. But in Chapter 4, we modeled public capital without imposing additional specifications that vary the benefit accrued from using the public input among different individual households. By applying the Newman-Read production function - a generalized Cobb-Douglas variable elasticity of substitution production function - to Hicks's notion of the "elasticity of substitution" as the determinant of factor shares, we showed that the effect of public capital in income distribution is closely tied to its elasticity of substitution to private capital. If the elasticity of substitution of a given type of public input is greater than unity, it could have a disproportionately positive impact on the income of the poor. Particularly if the credit market is imperfect, provision of public capital with high elasticity of substitution to private capital, could help the poor more through relaxing some of their resource constraints. This, in turn, results in improvement of income distribution throughout the economy.

In general, then, and in line with recent empirical findings - Calderon and Servén 2004, Calderón and Chong 2004, Lopez 2003, among many others - we conclude from these two chapters that under the appropriate conditions, public capital could promote pro-poor growth.

The litcrature in growth and public capital often analyzes the role of public investment in the economy within traditional growth models that generate a unique high-income equilibrium outcome. Chapter 6 took a different track from this literature by studying public investment in an environment with multiple equilibria and poverty trap.

On the other hand, the poverty trap literature studies a number of phenomena that cause poverty traps (e.g., fertility, income inequality, capital markets imperfection) in poor developing countries but rarely addresses the role of policy (in particular to public investment) in evading the poverty traps (e.g., Becker et al. 1990; Azariadis and Drazen 1990; Galor 1996; Azariadis 1996; and Azariadis 2006; and Galor and Tsiddon 1997 among many). Chapter 6 presented other possibilities that could cause a poverty trap along with an analysis of the role of growth-maximizing public investment in evading the poverty trap. It developed a model that showed negative externalities, which prevail during an initial stage of economic development (such as "migration humps") along with a positive learning-by-doing externality (that of similar to Romer's 1986), are the causes of the poverty trap. The study found that policy could be important but indeterminate with respect to poverty trap. Depending on some initial conditions, however, a policy change towards the growth-maximizing level of public investment could create a threshold externality that could lead economies to evade poverty traps. 
The empirical part of this thesis (Chapter 5) was based on a theoretical framework and studied the relationship between public capital and economic growth, taking the case of Sub-Saharan African countries. We developed a model that captured the nonlinear relationship between public capital and economic growth, and used this as the basis for the empirical analysis. We investigated the relationship between public capital and growth empirically, with both a linear and a nonlinear setup. Using the model, and applying more robust estimation techniques than those used in earlier studies, we determined the growth-maximizing level of public investment, and compared it with the actual level of public investment in SubSaharan African countries. We found not only that public investment matters highly to the economic growth of Sub-Saharan African countries, but also that many of these countries had public investment far below the level that maximizes growth.

In general, we found public capital to have profound effects in crucial issues surrounding the economic development of developing countries, such as economic growth, income inequality, and the poverty trap. 
Abramovitz, M. (1986): "Catching Up, Forging Ahead, and Falling Behind," Journal of Economic History, 46(2), 385-406.

Abramovitz, M., P. A. David, R. Landau, T. Taylor, and G. Wright (1996): "Convergence and Deferred Catch-up: Productivity Leadership and the Waning of American Exceptionalism," in The mosaic of economic growth, pp. 21-62. Stanford: Stanford University Press.

Acemoglu, D. (2003): "Labor- and Capital-Augmenting Technical Change," Journal of the European Economic Association, 1(1), 1-37.

AdAms, Richard H., J. (2003): "International Migration, Remittances, and the Brain Drain: A Study of 24 Labor-Exporting Countries," The World Bank, Policy Research Working Paper Series: 3069.

Agenor, P.-R. (2005): "Infrastructure, Public Education and Growth with Congestion Costs," University of Manchester, Centre for Growth and Business Cycle Research Discussion Paper Series: 047.

(2008): "Fiscal Policy and Endogenous Growth with Public Infrastructure," Oxford Economic Papers, 60(1), 57-87.

Agenor, P.-R.., AND B. MORENO-Dodson (2006): "Public infrastructure and growth : now channels and policy implications," The World Bank, Policy Research Working Paper Series: 4064.

Aguron, P. (2002): "Schumpeterian Growth Theory and the Dynamics of Income Inequality," .

Aghion, P., AND P. Bolson (1997): "A Theory of Trickle-Down Growth and Development," The Review of Economic Studies, 64(2), 151-172.

Aghion, P., E. Caroli, and C. Garcta-Penalosa (1999): "Inequality and Economic Growth: The Perspective of the New Growth Theories," Journal of Economic Literature, 37(4), 1615-1660. 
Aghion, P., AND P. Howitr (1998): Endogenous grouth theory. Cambridge and London: MIT Press.

Alesina, A., and R. Perotti (1996): "Income Distribution, Political Instability, and Investment," European Economic Review, 40(6), 1203-1228.

Alesina, A., and D. Rodrik (1994): "Distributive Politics and Economic Growth," Quarterly Journal of Economics, 109(2), 465-490.

Arellano, M., And S. Bond (1991): "Some Tests of Specification for Panel Data: Monte Carlo Evidence and an Application to Employment Equations," Review of Economic Studies, 58(2), 277-297.

A Rellano, M., AND O. Bover (1995): "Another Look at the Instrumental Variable Estimation of Error-Components Models," Journal of Econometrics, 68(1), 29-51.

A rrow, K. J. (1962): "The Economic Implications of Learning by Doing," Review of Economic Studies, 29(June), 155-173.

A Rrow, K. J., AND M. Kunz (1970): "Optimal Growth with Irreversible Investment in a Ramsey Model," Econometrica, 38(2), 331-344.

Aschauer, D. A. (1989): "Is Public Expenditure Productive?," Journal of Monetary Economics, 23(2), 177-200.

(1998): "How Big Should the Public Capital Stock Be? The Relationship between Public Capital and Economic Growth," The Jerome Levy Economics Institute of Bard College, Public Policy Brief: 043.

(2000a): "Do States Optimize? Public Capital and Economic Growth," Annals of Regional Science, 34(3), 343-363.

(2000b): "Public Capital and Economic Growth: Issues of Quantity, Finance, and Efficiency," Economic Development and Cultural Change, 48(2), 391-406.

Atrinson, A., and J. E. Stiglitz (1980): Lectures in Public Economics. London. London: McGraw-Hill.

Ayogu, M. D. (1999): "Before Prebendalism: A Positive Analysis of Core Infrastructure Investment in a Developing Fiscal Federalism," African Development Review/Revue Africaine de Developpement, 11(2), 169-198.

(2007): "Infrastructure and Economic Development in Africa: A Review," Journal of African Economies, 16, 75-126.

Azariadis, C. (1996): "The Economics of Poverty Traps: Part One: Complete Markets," Joumal of Economic Growth, 1(4), 449-496.

(2006): "The Theory of Poverty Traps: What Have We Learned?," in Poverty Traps, ed. by S. Bowles, S. N. Durlauf, and K. Hoff, pp. 17-40. New York: Russell Sage Foundation; Princeton and Oxford: Princeton University Press. 
Azariadis, C., AND A. Drazen (1990): "Threshold Externalities in Economic Development," Quarterly Journal of Economics, 105(2), 501-526.

BanerJee, A. V., And A. F. Newman (1993): "Occupational Choice and the Process of Development," The Journal of Political Economy, 101(2), 274-298.

Barro, R. J. (1989): "A Cross-Country Study of Growth, Saving, and Government," National Bureau of Economic Research, Inc, NBER Working Papers: 2855 .

- (1990): "Government Spending in a Simple Model of Endogeneous Growth," The Journal of Political Economy, 98(5), S103-S125.

(2000): "Inequality and Growth in a Panel of Countries," Journal of Economic Growth, 5(1), 5-32.

Barro, R. J., and X. SAla-I Martin (1992): "Convergence," Journal of Political Economy, 100(2), 223-251.

(2004): Economic Growth. The MIT Press, Cambridge, Massachusetts London, England, second edn.

BAUMOL, W. J. (1986): "Productivity Growth, Convergence, and Welfare: What the Long-run Data Show," American Economic Review, 76(5), 1072-1085.

Becker, G. S., K. M. Murphy, and R. Tamura (1990): "Human Capital, Fertility, and Economic Growth," Journal of Political Economy, 98(5), S12-37.

Beine, M., F. Docquier, and H. R.Apoport (2001): "Brain Drain and Economic Growth: Theory and Evidence," Journal of Development Economics, $64(1)$.

Benıbov, R. (1996): "Inequality and Growth," National Bureau of Economic Research, Inc, NBER Working Papers: 5658.

(2000): "Unequal Societies: Income Distribution and the Social Contract," The American Economic Review, 90(1), 96-129.

(2002): "Tax and Education Policy in a Heterogeneous-Agent Economy: What Levels of Redistribution Maximize Growth and Efficiency?" Econametrica, $70(2), 481-517$.

BenhabiB, J., nNI A. RUsticinni (1996): "Social Conflict and Growth," Journal of Economic Growth, 1(1), 125-142.

BhagWhti, J. N., AND K. HAMAdA (1974): "The Brain Drain, International Integration of Markets for Professionals and Unemployment: A Theoretical Analysis," Journal of Development Economics, 1(1), 19-42.

Bleaney, M., And A. NishiYama (2002): "Explaining Growth: A Contest between Models," Journal of Economic Growth, 7(1), 43-56. 
BlundelL, R., AND S. Bond (1998): "Initial Conditions and Moment Restrictions in Dynamic Panel Data Models," Journal of Econometrics, 87(1), 115-143.

Bond, S. (2002): "Dynamic Panel Data Models: A Guide to Micro Data Methods and Practice," The Institute For Social Studics Department Of Economics, Cemmap Working Paper: 09/02.

Boopen, S. (2006): "Transport Infrastructure and Economic Growth: Evidence from Africa Using Dynamic Panel Estimates," Empirical Economics Letters, $5(1), 37-52$.

Bose, N., J. A. Holman, and K. C. Neanidis (2007): "The Optimal Public Expenditure Financing Policy: Does the Level of Economic Development Matter?," Economic Inquiry, 45(3), 433-452.

Bourguignon, F. (1981): "Pareto Superiority of Unegalitarian Equilibria in Stiglitz' Model of Wealth Distribution with Convex Saving Function," Econometrica, 49(6), 1469-1475.

Brenneman, A., And M. Kenf (2002): "Infrastructure and Poverty Linkage: A Literature Review," Washington D.C.: World Bank.

Calderon, C. (2009): "Infrastructure and growth in Africa," The World Bank, Policy Research Working Paper Series: 4914.

Calderon, C., and A. Chong (2004): "Volume and Quality of Infrastructure and the Distribution of Income: An Empirical Investigation," Review of Income and Wealth, 50(1), 87-106.

Calderon, C., and L. Serven (2004): "The Effects of Infrastructure Development on Growth and Income Distribution," The World Bank, Policy Research Working Paper Series: 3400.

- (2008): "Infrastructure and economic development in Sub-Saharan Africa," The World Bank, Policy Research Working Paper Series: 4712.

CANning, D. (1999): "A Database of World Infrastructure Stocks, 1950 95," The World Bank, Policy Research Working Paper Series: 1929.

Casel.l一, F., And J. Feyrer (2007): "The Marginal Product of Capital," Quarterly Joumal of Economics, 122(2).

Cassou, S. P., and K. J. Lansing (1998): "Optimal Fiscal Policy, Public Capital, and the Productivity Slowdown," Journal of Economic Dynamics and Control, 22(6), 911-935.

ChatTFrJEe, S. (2008): "The Distributional Consequences of Government Spending," http://papers.ssrn.com/abstract $=1100163$.

Chiswick, B. R., T. J. Hatton, M. D. Bordo, A. M. Taylor, and J. G. Williamson (2003): "International Migration and the Integration of Labor Markets," in Globalization in historical perspective, pp. 65-117. NBER Conference Report series. Chicago and London: University of Chicago Press. 
Cohen, J. P., AND C. J. M. PAUl (2004): "Public Infrastructure Investment, Interstate Spatial Spillovers, and Manufacturing Costs," Review of Economics and Statistics, 86(2), 551-560.

Collier, P., A. Hoefrler, and C. Pattillo (2004): "Africa's Exodus: Capital Flight and the Brain Drain as Portfolio Decisions," Journal of African Economies, 13, iil5 54 .

De Gregorio, J. (1993): "Inflation, Taxation, and Long-Run Growth," Journal of Monetary Economics, 31(3), 271-298.

DE HAAS, H. (2007): "Turning the Tide? Why Development Will Not Stop Migration," Development and Change, 38(5), 819-841.

De la Croix, D., and P. Michel (2002): A Theory of Economic Growth: Dynamics and Policy in Overlapping Generations. Cambridge: Cambridge University Press.

DetNinger, K., AND L. SQUire (1997): "Economic Growth and Income Inequality: Reexamining the Links," Finance and Development, 34(1), 38-41.

Demetriades, P. O., AND T. P. M and Employment Effects of Public Infrastructure Capital: Evidence from 12 OECD Economics," Economic Journal, 110(465), 687-712.

Dessus, S., And R. Herrrera (2000): "Public Capital and Growth Revisited: A Panol Data Asscssment," Economic Denelopment and Cultural Change, 48(2), 407-418.

Docquiler, F., O. LoHest, And A. Marfouk (2007): "Brain Drain in Developing Countries," World Bank Economic Review, 21(2).

Dowrick, S., AN1) D.-T. NGUYen (1989): "OECD Comparative Economic Growth 1950-85: Catch-Up and Convergence," American Economic Review, $79(5), 1010-1030$.

DurLıuf, S. N. (1993): "Nonergodic Economic Growth," Review of Economic Studies, 60(2), 349-366.

(1996): "A Thcory of Persistent Income Inequality," Journal of Economic Growth, 1(1), 75-93.

Easterriy, W. (2006): "The Big Push Deja Vu: A Review of Jeffrey Sachs's The End of Poverty: Economic Possibilities for Our Time," Journal of Economic Literature, 44(1), 96-96.

Easterly, W., AND S. Rebelo (1993): "Fiscal Policy and Economic Growth: An Empirical Investigation," Journal of Monetary Economics, 32(3), 417-458.

Estache, A. (2003): "On Latin America's Infrastructure Privatization and its Distributional Effects," Washington D.C.: The World Bank. 
Estache, A., V. Foster, And Q. WOdON (2002): "Accounting for Poverty in infrastructure Reform: Learning from Latin America's Experience," Washington D.C.: The World Bank.

Estache, A., B. Speciale, and D. Verdas (2005): "How Much Doses Infrastructure Matter to Growth in Sub-Saharan Africa?," Washington D.C.: The World Bank.

Fedderke, J. W., P. Perkins, and J. M. Luiz (2006): "Infrastructural Investment in Long-Run Economic Growth: South Africa 1875-2001," World Development, 34(6), 1037-1059.

Ferreira, F. H. (1995): "Roads to Equality: Wealth Distribution Dynamics with Public-Private Capital Complementarity," The Suntory Centre, LSE STICERD Research Paper: TE/1995/286.

Forbes, K. J. (2000): "A Reassessment of the Relationship between Inequality and Growth," American Economic Review, 90(4), 869-887.

Fosu, A. K. (2007): "Fiscal Allocation for Education in Sub-Saharan Africa: Implications of the External Debt Service Constraint," World Development, $35(4), 702-713$.

Fosu, A. K., P. Krishinan, and L. Ndikumana (2004): "Africa and the World Economy: A Focus on Capital - An Overview," Journal of African Economies, 13(2), ii1-ii14.

Fosu, A. K., E. Lee, And M. VIVArelli (2004): "The Social Impact of Globalization: The Scope for National Policies," in Understanding globalization, employment and poverty reduction, pp. 327-348. Houndmills, U.K. and New York: Palgrave Macmillan.

Frankel, M. (1962): "The Production Function in Allocation and Growth: A Synthesis," The American Economic Review, 52(5), 996-1022.

Futagami, K., Y. Morita, ANd A. Shibata (1993): "Dynamic Analysis of an Endogenous Growth Model with Public Capital," Scandinavian Journal of Economics, 95(4), 607-625.

GaLoR, O. (1996): "Convergence? Inferences from Theoretical Models," Economic Journal, 106(437), 1056-1069.

GALOR, O., AND O. MOAV (2004): "From Physical to Human Capital Accumulation: Inequality and the Process of Development," Review of Economic Studies, 71(4), 1001-1026.

Galor, O., aNd D. Tsiddon (1997): "The Distribution of Human Capital and Economic Growth," Journal of Economic Growth, 2(1), 93-124.

GaLor, O., AND J. ZeIrA (1993): "Income Distribution and Macroeconomics," The Review of Economic Studies, 60(1), 35-52. 
Garcia-Penalosa, C., and S. J. Turnovsky (2007): "Growth, Income Inequality, and Fiscal Policy: What Are the Relevant Trade-Offs?," Journal of Money, Credit, and Banking, 39(2-3), 369-394.

(2008): "Taxation and Income Distribution Dynamics in a Neoclassical Growth Model," Memo, University of Washington.

Gerschenkron, A. (1962): Economic Backwardness in Historical Perspectives: a Book of Essays. Cambridge, MA ; London: Belknap Press of Harvard University Press.

GHosh, S., AND U. Roy (2004): "Fiscal Policy, Long-Run Growth, and Welfare in a Stock-Flow Model of Public Goods," Canadian Joumal of Economics, 37(3), $742-756$.

Glomm, G., and B. Ravikumar (1992): "Public versus Private Investment in Human Capital: Endogenous Growth and Income Inequality," The Journal of Political Economy, 100(4), 818-834.

(1994): "Public Investment in Infrastructure in a Simple Growth Model," Journal of Economic Dynamics and Control, 18(6), 1173-1187.

(1997): "Productive Government Expenditures and Long-Run Growth," Journal of Economic Dynamics and Control, 21(1), 183-204.

(1999): "Competitive Equilibrium and Public Investment Plans," Journal of Economic Dynamics and Control, 23(8), 1207-1224.

GRAMLICH, E. M. (1994): "Infrastructure Investment: A Review Essay," Journal of Economic Literature, 32(3), 1176-1196.

Greene, W. (2003): Econometric Analysis. Prentice Hall, 5th edn.

Gruen, F. H. (1986): "How Bad Is Australia's Economic Performance and Why?," Economic Record, 62(177), 180-193.

HAQUE, N. U., AND S.-J. KrM (1995): "Human Capital Flight': Impact of Migration on Income and Growth," International Monetary Fund Staff Papers, $42(3), 577-607$.

Hatton, T. J., ANI J. G. Willismson (2005): Global Migration and the World Economy: Two Centuries of Policy and Performance. Cambridge and London: MIT Press.

Heston, A., R. Summers, and B. Aten (2006): "Penn World Table Version 6.2," University of Pennsylvania, Center for International Comparisons of Production, Income and Prices.

Hicks, J. (1932): The Theory of Wages. London: Mcmillan.

Holtz-Eakin, D. (1994): "Public-Sector Capital and the Productivity Puzzle," Review of Economics and Statistics, 76(1), 12-21. 
Holtz-EAKIn, D., W. NEWey, and H. S. Rosen (1988): "Estimating Vector Autoregressions with Panel Data," Econometrica, 56(6), 1371-1395.

Hulten, C. R. (1996): "Infrastructure Capital and Economic Growth: How Well You Use It May Be More Important Than How Much You Have," National Bureau of Economic Research, Inc, NBER Working Papers: 5847.

Hung, N. M., AND P. MaKdissi (2004): "Escaping the Poverty Trap in a Developing Rural Economy," Canadian Journal of Economics, 37(1), 123-139.

JACOBY, H. C. (2000): "Access to Markets and the Benefits of Rural Roads," Economic Journal, 110(465), 713-737.

Jalan, J, and M. Ravallion (2003): "Does Piped Water Reduce Diarrhea for Children in Rural India?," Journal of Econometrics, 112(1), 153-173.

JoNES, C. I. (2002): Introduction to Economic Growth. New York; London: W.W. Norton and Company.

Jones, L. E., AND R. E. Manueldi (1990): "A Convex Model of Equilibrium Growth: Theory and Policy Implications," Journal of Political Economy, 98(5), 1008-1038.

KaLAITZIDAKIS, P., AND S. KaLYVITIS (2004): "On the Macroeconomic Implications of Maintenance in Public Capital," Journal of Public Economics, 88(3-4), $695-712$.

KaLdor, N. (1957): "A Model of Economic Growth," The Economic Journal, $67(268), 591-624$.

KAMPS, C. (2005): "Is There a Lack of Public Capital in the European Union?," EIB Papers, 10(1), 72-93.

Khandker, S. R., and G. B. Koolwal (2007): "Are Pro-Growth Policies ProPoor? Evidence from Bangladesh," Mimeo, The World Bank.

KInG, R. G., And S. Rebelo (1990): "Public Policy and Economic Growth: Developing Neoclassical Implications," Journal of Political Economy, 98(5), S126 50.

Kocherlakota, N. R., and K.-M. Yi (1996): "A Simple Time Series Test: of Endogenous vs. Exogenous Growth Models: An Application to the United States," Review of Economics and Statistics, 78(1), 126-134.

Kormendi, R. C., and P. G. Megutre (1985): "Macroconomic Determinants of Growth: Cross-Country Evidence," Journal of Monetary Economics, 16(2), $141-163$.

KuzNeTs, S. (1955): "Economic Growth and Income Inequality," The American Economic Review, 45(1), 1-28.

LAVY, V., AND ET AL. (1996): "Quality of Health Care, Survival and Health Outcomes in Ghana," Journal of Health Economics, 15(3), 333-357. 
LeIPZIGER, D., M. FAY, Q. WODON, AND T. YEPES (2003): "Achieving the Millennium Development Goals: The Role of Infrastructure," The World Bank, Policy Research Working Paper Series: 3163.

Lr, H., AND H.-F. Zou (1998): "Income Inequality Is Not Harmful for Growth: Theory and Evidence," Review of Development Economics, 2(3), 318-334.

LIEN, D., AND Y. WANG (2005): "Brain Drain or Brain Gain: A Revisit," Journal of Population Economics, 18(1), 153-163.

LOPEZ, H. (2003): "Macroeconomics and Inequality," Washington D.C.: World Bank.

LouRY, G. C. (1981): "Intergenerational Transfers and the Distribution of Earnings," Econometrica, 49(4), 843-867.

LuCAs, RoBERT E., J. (1988): "On the Mechanics of Economic Development," Journal of Monetary Economics, 22(1), 3-42.

(1990): "Supply-Side Economics: An Analytical Review," Oxford Economic Papers, N. S., 42(2), 293-316.

(2000): "Some Macroeconomics for the 21st Century," Journal of Economic Perspectives, 14(1), 159-168.

ManKIW, N. G., D. Romer, and D. N. WeIL (1992): "A Contribution to the Empirics of Economic Growth," Quarterly Journal of Economics, 107(2), 407-437.

Martin, P. L., And E. TaYlor (1996): "The Anatomy of a Migration Hump," in Development strategy, employment and migration: insights from models, ed. by E. Taylor. Organisation for Economic Cooperation and Development, Paris.

Millen, N. J., and C. Tsoukis (2001): "On the Optimality of Public Capital for Long-Run Economic Growth: Evidence from Panel Data," Applied Economics, $33(9), 1117-1129$.

MishrA, P. (2007): "Emigration and Brain Drain: Evidence from the Caribbean," B.E. Journal of Economic Analysis and Policy: Topics in Economic Analysis and Policy, 7(1), 1-42.

MrYagiwa, K. (1991): "Scale Economies in Education and the Brain Drain Problem," International Economic Review, 32(3), 743-759.

Mountrord, A. (1997): "Can a Brain Drain Be Good for Growth in the Source Economy?," Journal of Development Economics, 53(2), 287-303.

Munnelt, A. H. (1990): "How Does Public Infrastructure Affect Regional Economic Performance?," New England Economic Review, pp. 11-32.

Ndulu, B. J., L. Chakraborti, L. Lijane, V. Ramachandran, and J. WolGIN (2007): Challenges of African Growth: Opportunities, Constraints, and Strategic Directions. Washington D.C.: The World Bank. 
Newman, P. K., AND R. C. REad (1961): "Production Functions with Restricted Input Shares," International Economic Review, 2(1), 127-133.

OECD (2006): Promoting Pro-poor Growth: Infrastructure. Paris: OECD.

PANIZZA, U. (2002): "Income Inequality and Economic Growth: Evidence from American Data," Journal of Economic Grouth, 7(1), 25-41.

Parente, S. L., ANd E. C. Prescott (1997): "Monopoly rights: a barrier to riches," Federal Reserve Bank of Minneapolis, Staff Report: 236.

PEConino, P. (1997): "The Optimal Rate of Inflation When Capital Is Taxed," Journal of Macroeconomics, 19(4), 657-673.

Perotti, R. (1996): "Growth, Income Distribution, and Democracy: What the Data Say," Journal of Economic Growth, 1(2), 149-187.

Persson, T., and G. Tabellini (1994): "Is Inequality Harmful for Growth?," American Economic Review, 84(3), 600-621.

PIKETTy, T. (1997): "The Dynamics of the Wealth Distribution and the Interest Rate with Credit Rationing," The Review of Economic Studies, 64(2), 173-189.

(2001): "Income Inequality in France, 1901-1998," Memo, CEPREMAP.

PiketTy, T., AND E. SAEz (2003): "Income Inequality in the United States, 1913-1998," Quarterly Journal of Economics, 118(1), 1-39.

Pritchett, L. (1997): "Divergence, Big Time," Journal of Economic Perspectives, $11(3), 3-17$.

QUAH, D. T. (1996): "Empirics for Economic Growth and Convergence," European Economic Review, 40(6), 1353-1375.

Rebelo, S. (1991): "Long-Run Policy Analysis and Long-Run Growth," Journal of Political Economy, 99(3), 500-521.

REVANKaR, N. S. (1971): "A Class of Variable Elasticity of Substitution Production Functions," Econometrica, 39(1), 61-71.

RIOJA, F. K. (1999): "Productiveness and Welfare Implications of Public Infrastructure: A Dynamic Two-Sector General Equilibrium Analysis," Journal of Development Economics, 58(2), 387-404.

(2003a): "The Penalties of Inefficient Infrastructure," Review of Development Economics, 7(1), 127-137.

(2003b): "Filling Potholes: Macroeconomic Effects of Maintenance versus New Investments in Public Infrastructure," Journal of Public Economics, 87(910), 2281-2304.

(2005): "Roads versus Schooling: Growth Effects of Government Choices," B.E. Journals in Macroeconomics: Topics in Macroeconomics, 5(1), 1-22. 
ROMER, P. M. (1986): "Increasing Returns and Long-run Growth," Journal of Political Economy, 94(5), 1002-1037.

(1990): "Endogenous Technological Change," Journal of Political Economy, 98(5), S71-102.

Romp, W., AND J. DE HAAN (2005): "Public Capital and Economic Growth: A Critical Survey," EIB Popers, 10(1), 40-70.

(2007): "Public Capital and Economic Growth: A Critical Survey," Perspektiven der Wirtschaftspolitik, 8, 6-52.

Roodman, D. (2006): "An Introduction to "Difference" and "System" GMM in Stata," Center for Global Development, Working Paper: 103.

(2007): "A Note on the Theme of Too Many Instruments," Center for Global Development, Working Paper: 125.

SACHS, J. D. (2005): "The Development Challenge," Foreign Affairs, 84(2), 7890.

SAiNT-PaUl, G., AND T. Verdier (1993): "Education, Democracy and Growth," Journal of Development Economics, 42, 399-407.

Salda-i Martin, X., G. Doppelhofer, and R. I. Miller (2004): "Determinants of Long-Term Growth: A Bayesian Averaging of Classical Estimates (BACE) Approach," American Economic Review, 94(4), 813-835.

Solow, R. M. (1956): "A Contribution to the Theory of Economic Growth," The Quarterly Journal of Economics, 70(1), 65-94.

(1957): "Technical Change and the Aggregate Production Function," The Review of Economics and Statistics, 39(3), 312-320.

(1960): "Investment and Technological Progress," in Mathematical Methods in the Social Science, ed. by K. Arrow, S. Karelin, and P. Suppes, pp. 89-104. Stanford CA: Stanford University Press.

SoNGCO, J. A. (2002): "Do Rural Infrastructure Investments Benefit the Poor? Evaluating Linkages: A Global View, A Focus on Vietnam," The World Bank, Policy Research Working Paper Series: 2796.

Stark, O., C. Helmenstein, and A. Prskawetz (1998): "Human Capital Depletion, Human Capital Formation, and Migration. A Blessing in a 'Curse'?," Institute for Advanced Studies, Economics Series: 55.

STraub, S. (2008): "Infrastructure and growth in developing countries : recent advances and research challenges," The World Bank, Policy Research Working Paper Series: 4460.

Sturm, J.-E., G. H. Kuper, J. DE HaAn, S. Brakman, H. van Ees, AND S. K. K UIPERS (1998): "Modelling Government Investment and Economic Growth on a Macro Level: A Review," in Market behaviour and macroeconomic modelling, pp. 359-406. New York: St. Martin's Press. 
Tamura, R. (1996): "From Decay to Growth: A Demographic Transition to Economic Growth," Joumal of Economic Dynamics and Control, 20(6-7), 1237 1261.

Tenuel, R. G., AND Y. KUROD (2005): "Public Infrastructure and Productivity Growth in Philippine Agriculture, 1974-2000," Journal of Asian Economics, 16(3), 555-576, -

THORBECKE, E. (2007): "The Evolution of the Development Doctrin, 19502005," in Advancing Development: Core Themes in Global Economics, od. by G. Mavrotas, and A. Shorrocks. Foreword by Amartya Sen. Houndmills, U.K. and New York: Palgrave Macmillan.

Turnovsky, S. J. (1996): "Fiscal Policy, Adjustment Costs, and Endogenous Growth," Oxford Economic Papers, 48(3), 361-381.

(1997): "Fiscal Policy in a Growing Economy with Public: Capital," Macroeconomic Dynamics, 1(3), 615-639.

(2000): "Government Policy in a Stochastic Growth Model with Elastic: Labor Supply," Journal of Public Economic: Theory, 2(4), 389433.

(2004): "The Transitional Dynamics of Fiscal Policy: Long-Run Capital Accumulation and Growth," The Journal of Money, Credit and Banking, 36(5), 883-910.

Turnovsky, S. J., AND W. H. FisubR (1995): "Tho Composition of Governmont: Expenditure and Its Consequences for Macrocconomic: Performance," Journal of Economic Dynamics and Control, 19(4), 747786.

Verspagen, B. (1995): "Convergence in the global oconomy. A broad historical viewpoint," Structural Change and Economic Dynamics, 6(2), 143165.

WONG, K.-Y., AND C. K. YIP (1999): "Education, Economic Growth, and Brain Drain," Joumal of Economie Dynarnics and Control, 23(5-6), 699726.

Wooldridge, J. M. (2002): Econometric Analysis of Cross Section and Panel Data. Cambridge, Massachusetts: The MIT Pross.

WonsD, B. (1994): Infrastructure for Development. Washington D.C.: World Bank; Oxford and New York: Oxford University Pross.

(2003): Inequality in Latin America the Caribbean: Breaking anith History? Washington D.C.: World Bank.

(2004): World development report 2005: A better investment climate for everyone. Washington D.C.: World Bank; Oxford and New York: Oxford University Press. Bank.

(2005): African Development Indicators: 2005. Washington D.C.: World 

Bank.

(2007): World Development Indicators 200\%. Washington D.C.: World

Znesmmer, T. (1990): "Public Factors and Democracy in Poverty Analysis," Oxford Economic Papers, 42(1), 268-280.

(1995): "Endogenous Growth with Public Factors and Heterogeneous Human Capital Producers," FinanzArchiv, 52(1), 1-20.

(2008): "Growth with Endogenous Migration Hump and the Multiple, Dynamically Interacting Effects of Aid in Poor Developing Countries," United Nations University, UNU-MERIT Working Paper: 2008-057. 
Dit proefschrift onderzoekt de mogelijke rol van publiek kapitaal in economische ontwikkeling. Het bestaat uit zowel een theoretisch als een empirisch gedeelte Het theoretische gedeelte ontwikkelt een aantal endogene groeimodellen die de rol van publiek kapitaal met betrekking tot inkomensongelijkheid, economische groei en de armoedeval analyseren. Het empirische gedeelte bestaat uit een analyse van panelgegevens van een groot aantal landen in Sub Saharan Afrika, om het niet lineare verband tussen publiek kapitaal en economischeeconomishe groei te identificeren, en om het niveau van publiek kapitaal te bepalen waarbij de groei in deze landen maximaliseert.

Een belangrijke bijdrage van dit proefschrift is de analyse van het verband tussen publieke investeringen en inkomensongelijkheid. Het presenteert modellen en theorien die de relatie analyseren tussen publiek kapitaal en inkomens/welvaartdistributie, in de contexthet van de imperfectie van kapitaalmarkten. Andere bijdrages omvatten de analyse van de mogelijke rol van het overheidsheidbeleid in een economic met inkomensongelijkheid, en empirisch bepaling van het niveau van publiek kapitaal dat de economische groei in ontwikkelingslanden op de lange termijn maximaliseert.

Het proefschrift biedt een uitbreidinguit van theorien over imperfecte kapitaalmarkten, ongelijkheid, en groei, naar publiek kapitaal, ongelijkheid en groei. Volgens deze theorien is ongelijkheid slecht voor groei als imperfectie in kredietmarkten de armen verhindert om een efficient bedrag te investeren in ondernemen. De nieuwe theorien suggereren dat een bepaalde publieke investeringen een aantal beperkingenbeperking in middelen kan verminderen, door factor substititie en hiermee dus de distributie van inkomen en als gevolg de economishce groei kan verbeteren. (door een indirect kanaal). Het proefschrift laat zien dat de elasticiteit van substititie tussen privaat en publiek kapitaal de belangrijkste bepalende factor is voor het verdelingsefffect van privaat kapitaal. Als bijvoorbeeld de elasticiteit van subsitutie van een bepaald type publieke input groter is dan een, zal het een positief effect hebben op inkomensdistributie.

Het grootstegrootse gedeelte van de analytische literatuur over groei en publieke investeringen kijkt naar publiek kapitaal met gebruik van traditionele groeimodellen die een uniek hoog inkomens evenwicht als uitkomst geven. Dit proefschrift neemt een andere weg dan deze literatuur door het bestuderen van publieke investeringen in een omgeving met meervoudig evenwicht/armoedeval. De oorzaak van de armoedeval ligt in de negatieve externaliteiten die heersen in een beginsta- 
dium van economische ontwikkeling. De studio concludecrt dat exn verandering in publiek beleid ten opzichte van het groei-maximaliseringsniveau van publicke investeringen cruciaal is, maar onbepaald ten opzichto van de armoedeval. Afhankelijk van ecn aantal initiele voorwaarden kan een dergelijke belcidsverandering een drempelwaarde externaliteit creoren die kan leiden tot het vermijdenvoorkomen van armoedeval in economieen. 
About the Author

Yoseph Yilma Getachew was born in Addis Ababa, Ethiopia. Before he Joined UNU-MERIT at 2003, he had studied Agricultural Economics, in Haramaya University, in Ethiopia, and Gender and Development in Asian Institute of Technology, in Thailand. He had also worked as a junior researcher in Ethiopian Institute of Agricultural Research. He has worked in a variety of topics at UNU-MERIT, such as institutions, growth, inequality, public capital, and knowledge that has enriched his analytical and research skills in economic development studies. Yoseph is currently working as a research consultant in the World Knowledge Report project at UNU-MERIT. 